\title{
Neotropical Copestylum (Diptera, Syrphidae) breeding in bromeliads (Bromeliaceae) including 22 new species
}

\author{
G. E. ROTHERAY ${ }^{1 *}$, E. G. HANCOCK ${ }^{2}$ and M. A. MARCOS-GARCÍA ${ }^{3}$ \\ ${ }^{1}$ National Museums of Scotland, Chambers Street, Edinburgh EH1 1JF, UK \\ ${ }^{2}$ Zoology Museum, Graham Kerr Building, University of Glasgow, Glasgow G12 8QQ, UK \\ ${ }^{3}$ CIBIO, Centro Iberoamericano de la Biodiversidad, Universidad de Alicante, E-03080 Alicante, Spain
}

Received June 2005; accepted for publication August 2006

\begin{abstract}
Twenty-three species of Copestylum (Diptera, Syrphidae) were reared from Bolivia, Costa Rica, Ecuador, Mexico, and Trinidad from 1998 to 2004. Twenty-two were new species. We describe these new species, their breeding sites, and the third stage larva and/or the puparium of all 23 species. Adults had species-specific head shapes and colour patterns, but similarities between 14 of the species enabled two groups and three subgroups to be recognized. Nonetheless, the high level of morphological disparity suggests independent colonizations of bromeliads. Adult colour patterns appear to be predominantly cryptic in function and based on reflectiveness derived from matt to shiny integumental ground colours, combined with overlying areas of variously coloured hairs, dust, and pruinosity. In addition, disruptive spots, bands, and vittae occur on the face, thoracic pleurites, and second tergite. Larvae were saprophagous in either live or dead bromeliads with no overlap between categories. A major factor explaining variation in larval morphology could be access to food. Larvae in live bromeliads are characterized by varying levels of dorso-ventral flattening, and modifications to the mouthparts and prothorax. These features appear to facilitate feeding in the narrow spaces between overlapping bromeliad leaves. Larvae exploiting dead bromeliads are characterized by varying levels of armature to the thorax, and extensions to the anal segment. Armature either consists of arrangements of sclerotized spicules distributed at various places on the thorax or large hooks on the lateral margins. Armoured thoraces facilitate burrowing through decaying tissue, and extended anal segments may reduce exposure during respiration. (C) 2007 The Linnean Society of London, Zoological Journal of the Linnean Society, 2007, 150, 267-317.
\end{abstract}

ADDITIONAL KEYWORDS: crypsis - larva - phytotelmata - rearing - reflective colours.

\section{INTRODUCTION}

Copestylum Macquart, 1846 is one of four genera considered to comprise the Volucellini, distinguished from other Syrphidae (Diptera) by their straight or recessive apical crossvein and plumose arista, although some Graptomyza Wiedemann, 1820 species and Copestylum pseudotachina (Hull, 1930) have a bare arista (Thompson, 1981). The other volucelline genera are Volucella Geoffroy, 1762 and Ornidia Lepeletier and Serville, 1828 (Thompson, 1972). Adult Copestylum are distinguished from other volucellines by their bare anterior mesoanepisternum and bare posterior mesoanepimeron (Thompson, 1972).

*Corresponding author. E-mail: g.rotheray@nms.ac.uk
Copestylum is endemic to the New World, but the majority of species occur in the neotropics. With nearly 400 species it rivals Cheilosia Meigen, 1822 as the most speciose syrphid genus (Thompson, 1981).

For such a speciose genus, Copestylum is poorly known biologically. Until recently rearing data existed for only 27 species, either as published records or as unpublished data associated with specimens in museums. These show that larvae are saprophagous and develop in decaying plant materials. The most frequently reported medium is decaying stems and platyclades of cacti (Cactaceae) (Hubbard \& Schwarz, 1899; Bruch, 1919; Johnston, 1921; Sack, 1921; Williams, 1939; Bugbee \& Reigel, 1945; Ryckman \& Ames, 1953; Santana, 1961; Mann, 1969; Telford, 1973; Wallace \& Lavallee, 1973; Maldonado Capriles \& Berrios, 1977; Zimmerman, Erb \& McFadyen, 1979; Maier, 1982; 
Myles, 1986; Marcos-García \& Pérez-Bañón, 2001, 2002). Other breeding media include rotting banana stumps, Musa x cavendisii (Musaceae) (Sack, 1921), paw-paw, Carica papaya (Caricaceae) (Greene, 1923), exudate from timbo trees, Enterolobium timbouva (Leguminosae) (Sack, 1921), and Heliconia bracts (Strelitziaceae) (Seifert \& Seifert, 1976a, b).

Over the past six years we obtained rearing data for an additional 107 Copestylum species from a wide range of decaying plant materials. Many occurred in tropical forests, and it is clear that Copestylum biodiversity is poorly documented in these habitats and that many unrecognized species exist. For example, from fruits and flowers we reared three named and six new species, from tree sap and tree holes we reared four named and 12 new species, and from stems of under storey plants we reared ten new species and no named ones.

Our data show that in tropical forests species of Copestylum are generally specific to breeding site, and that under storey plants like tree ferns (Dicksoniaceae, Cyatheaceae), palms (Palmaceae), heliconias (Strelitziacaea), etc. have different species, sometimes whole groups of species, associated with the various parts: fruits, flowers, stems, or leaves. A group of plants exploited in this way are bromeliads (Bromeliaceae), and in this paper we deal with 23 Copestylum species reared from them, of which 22 are new. We describe these new species and give details of breeding sites and describe early stages of all 23 species.

The early stages of Syrphidae are diverse in morphology and ecology (Rotheray \& Gilbert, 1999), but those of Copestylum have been little studied. Over and above an inventory of species, the aim of our project, of which this paper is a part, is to give an account of early stage and adult morphology in Copestylum, so that characters can be recognized and used with other character sets, such as DNA sequences, to estimate Copestylum phylogeny. From this foundation and combined with data on breeding sites, habitats, and geographical distribution, etc., we can search for patterns that might explain diversification in Copestylum.

In Syrphidae, early stage characters have been informative phylogenetically (Rotheray \& Gilbert, 1999; Stahls et al., 2003). This is because syrphid larvae are interpreted to be conservative in evolution, i.e. innovations are modified by additions more than by losses, with characters either becoming hierarchically complex across taxa, such as the development of thoracic armature from spicules to one or two hooks, and then to varying arrangements of numerous hooks of various shapes and sizes, and associated changes to the muscles of the thorax in Xylotini (Syrphidae), or characters pass through speciation events little changed, like the mouthparts of the Xylotini (Rotheray \& Gilbert, 1999). Such a mode of evolution implies that if characters converge, they do so in ways that reveal their independent origins. For example, many syrphid larvae possess an extended anal segment that superficially appears similar, but the positions of landmark fleshy projections, termed lappets, sensilla, and folds on the integument indicates several independent developments, a result supported by relationships between adults. Hence in syrphid larvae, convergence resulting from shared functions do not appear to obscure phylogenetic relationships (Rotheray \& Gilbert, 1999; Stahls et al., 2003). We expect the same result from Copestylum.

Bromeliads are an almost exclusive New-World plant group of over 2700 mostly neotropical species (Benzing, 1980). The main preferences for growth are: terrestrial, growing on the ground; saxicolous, growing on rocks; and epiphytic, growing on other plants. Epiphytic and saxicolous bromeliads have phytotelmata within them, i.e. water-based, container habitats (Frank, 1983; Kitching, 2000). In many bromeliads the leaves grow in rosettes and overlap so that water, leaves, twigs, and other debris falling in accumulates, and so forms a phytotelmatum. The debris decays and nutrients from the resulting compost are absorbed into the plant through the leaves (Benzing, 1980). The 'water tanks' of bromeliads have a rich, associated biota that has been surveyed on many occasions (Frank, 2002). However, no Copestylum has apparently been reported. The only record of a Copestylum species in a bromeliad is a brief mention of an unidentified syrphid from bromeliads in Costa Rica (Picado, 1913). Picado (1913) illustrates the larva, and it is clearly a Copestylum, but gives no further details.

\section{METHODS}

\section{FINDING LARVAE}

We made 13 collecting trips from 1998 to 2004, of between 10 and 26 days each, to Bolivia (one trip, August), Costa Rica (four trips in the months February, June-August), Ecuador (two trips, June-September), Mexico (four trips, April, June-July), and Trinidad (two trips, July-August). Saxicolous bromeliads were sampled only in Bolivia and Mexico, and terrestrial species were sampled only in Costa Rica and Ecuador. Epiphytic bromeliads were sampled in all countries.

To find larvae in live epiphytic and saxicolous bromeliads, the leaves were taken off one by one and searched until the inner stalk or scape was reached. Larvae were usually located on the upper or lower surfaces of leaves below water level, deep down near the base of the plant. Bromeliads growing above head height were less frequently sampled, except where it was possible to reach them by climbing trees or rocks. Sometimes we threw weights tied to cord or used a 
long pole notched at one end, to place cord over a bromeliad-covered branch, and by pulling both ends of the cord, loosened the bromeliads until they fell to the ground, or we loosened bromeliads with poles. Highcanopy bromeliads often fall to the forest floor, however, either individually or in groups on fallen branches or toppled trees, although in such cases, it was rarely possible to tell how freshly fallen the bromeliads were.

Larvae were found in decaying bromeliads in only moist or wet conditions. Bromeliads decay from the central leaves out, and bromeliads lying on a moist forest floor with brown central and green outer leaves, as opposed to all green (too fresh) or all brown (usually too late), were most productive. Larvae were usually found between the leaves deep in the plant close to the scape. Larvae were also found in the decaying scape itself, either burrowing through the softened tissues, or frequently in the outside layers between it and the holdfast. It was not possible to identify more than a few of the many bromeliads we searched.

Terrestrial bromeliads, or puyas, are formidable plants with a large rosette of tough, spiky leaves, and were searched in a different way. Their flower stalks can be 2-m high, or more, and Copestylum larvae occurred at the base of plants with dead flower stalks. To find them, the dead flower stalk was gently pulled, and if it gave way easily this was a sign that the base was decayed. In such cases the stalk was pulled over, and the basal leaves were either cut or pulled to one side to expose areas of decay that were usually wet, often with standing water. Larvae were located between the soft, decayed remains of leaves attached to the base of the flower stalk.

\section{REARING LARVAE}

Larvae from epiphytic or saxicolous bromeliads were reared by placing them in either plastic bags or tubs with small quantities of tank water and debris, and a few cut bromeliad leaf bases. Alternatively, small bromeliads were emptied and cut to about 15-cm high and re-filled with water and debris. Larvae were placed in the cut bromeliad and the whole bromeliad placed in either a plastic bag or a tub. Larvae from decaying bromeliads were placed in tubs or plastic bags with either small quantities of decaying tissue or whole decaying bromeliads cut to a suitable size. Pin holes were made in bags to ensure the exchange of air, and bags or tubs were stored in cool, shaded conditions. Every few days containers were examined for puparia, which were usually found on dry parts of leaves or on the side of the container. A method we used later in the project involved placing bromeliads on a bed of almost dry tissue or vermiculite. Larvae used this material as a place to pupate.
To ensure association with the correct adult, puparia were removed and reared individually in separate containers. Puparia were only moved after the pupal spiracles had finished protruding. This process lasts up to 4 days following pupariation, and occurs through the dorsum of the first abdominal segment. Emerged adults were either fed dilute honey or were allowed to die in their tubes. Care was taken to ensure both loose pieces of puparium were retained because they carry characters of importance. These pieces may separate from the puparium at the time the adult emerges. The lower shield-shaped piece includes the dorsum of the prothorax and the anterior spiracles. The upper cresent-shaped piece includes the pupal spiracles. Where numbers permitted, some larvae were preserved by fixing them in boiling water for 2-3 min and then storing them in $70 \%$ alcohol.

\section{STUDY TECHNIQUES}

Larval head skeletons were removed from puparia by soaking the entire puparium in $\mathrm{KOH}$ for $15-20 \mathrm{~min}$, which was enough to enable them to be extracted with pins. Adult male genitalia were examined by relaxing pinned adults overnight in a sterile, humid atmosphere, which was enough to enable genital capsules to be removed with pins. Genital capsules were placed in $\mathrm{KOH}$ solution for up to an hour or more, and the genitalia dissected out with pins.

Drawings were made with a drawing tube attached to a binocular microscope. Measurements were made with either an eyepiece graticule or a micrometer.

Reared adults were identified by comparison with named specimens in collections, mainly those at the Smithsonian Institution, Washington DC, the Natural History Museum, London, and the Instituto Nacional de la Biodiversidad Santo Domingo de Heredia, Costa Rica, and also by reference to Dr F. C. Thompson (Smithsonian Institution, Washington DC, USA) who has expert knowledge of this genus.

\section{DESCRIPTIONS AND DIAGNOSES}

For new taxa, rather than provide wordy descriptions that would necessarily involve much repetition, we follow the methods developed by Erwin (1982) for dealing with the similarly species-rich, Neotropical genus, Agra (Coleoptera, Carabidae). For each named and new Copestylum species, characters and their states for early stages, males, and females are listed in two tables (Appendices 1, 2). Descriptions can be read from these tables by simply looking up characters and states scored as ' 1 '. Additionally, under each taxon in the text, we provide diagnoses that comprise accounts of, relative to the species considered here, unique characters and states, and also combinations of characters 
that enable taxa to be recognized and distinguished. The amount of innovative morphology varied between species, and this is reflected in the uneven lengths of diagnoses needed to account for it. Each species is given a number that corresponds to the columns in the online Supplementary Material (Tables S1, S2). The tables include data on a wider range of characters than those diagnosed. The tables provide the data required to make comparisons with other Copestylum species, and by including named as well as new species, begin the process of analysing morphology and building a set of characters for phylogenetic analysis.

Keys are provided to enable identification of adult, larval, and puparial stages relative to the species dealt with here. Use of the keys should enable Copestylum species reared from bromeliads to be readily identified. The diagnoses provide confirmatory data, and the tables are a source of information that should be useful for characterizing discoveries of new taxa. Furthermore, by scanning across rows in the tables, shared characters and morphological trends can be quickly assessed that would otherwise involve a lot of looking up. New or revised characters can be conveniently added to the tables as required.

Following species diagnoses, additional details of material examined, geographical distribution, institutions where holotypes may be studied, and breeding sites are given. The following initials indicate the institutions where material is deposited, and appear in the 'Material examined' section under each species: CIBIO, Centro Iberamericano de la Biodiversidad, University of Alicante, Alicante, Spain; HM, Hunterian Museum, University of Glasgow, Glasgow, UK; INBio, Instituto Nacional de Biodiversidad, Santo Domingo de Heredia, Costa Rica; NMS, National Museums of Scotland, Edinburgh, UK; PUCE, Pontificia Universidad Católica del Ecuador, Quito, Ecuador.

\section{RESULTS}

\section{FINDING LARVAE}

Epiphytic bromeliads occurred in a wide range of forest types on trees and shrubs from near the ground to high in the canopy. They were particularly abundant along ridges and hilltops in cloud forests. Saxicolous bromeliads occurred on exposed rock and cliff-faces in or near cloud forests, and terrestrial bromeliads occurred in paramo, above the treeline at about $4000 \mathrm{~m}$ or more.

In epiphytic and saxicolous bromeliads Copestylum larvae were common, occurring in up to $70 \%$ or more of the plants sampled at any one site. The number of larvae per plant varied from 0 to 50 . From the outside leaves to the scape, larvae were most frequent in the middle layers of overlapping leaves. Productive sites were those where bromeliads ranged from common to abundant, and where a range of plant sizes occurred together. Although no quantitative measurements were made, the larger the bromeliad, the greater was the probability of larvae being present, regardless of factors such as species of bromeliad, position or aspect of the plant. However, the largest bromeliads often occurred at subcanopy levels. Only one Copestylum species appeared to have a preference for a particular bromeliad species.

Copestylum larvae were also common in puyas with wet decay at their bases. Up to 12 larvae per plant were found in both Costa Rica and Ecuador. In Ecuador, however, frogs were not uncommon in water pools at the base of plants, and in such cases, larvae were never found, suggesting that they had been eaten. Copestylum puparia were rarely found in any bromeliad, suggesting that pupariation takes place outside the plant.

\section{REARING LARVAE}

Mortality of larvae in cultures varied, and was highest (>80\%) in those from puyas. Mortality was reduced to less than $10 \%$ by rearing larvae in whole bromeliads cut down to a convenient size, rather than by placing larvae in containers with extracted quantities of plant material. This applied to both live and decaying bromeliads. No parasitoids were encountered during this study. Overall approximately 140 adults were reared from bromeliads, with a rearing success rate of about $46 \%$.

\section{GROUP AND SPECIES SYSTEMATICS}

Groups and species are diagnosed in this section based on unique characters and states, and combinations of characters and states that enable taxa to be recognized and distinguished. These characters and others not included in the diagnoses are scored either present or absent for adults and third-stage and/or puparia (Appendices 1, 2).

\section{Copestylum species reared from live bromeliads}

\section{Tank group}

Diagnosis-adult: Face with either a straight or curved margin and dust below the antennae, and a clearly defined central tubercle (Figures 1-10); dust and usually pruinosity present on the genae; eye hairs reaching below mid-point of the eye and usually reaching the ventral margin; arista with dorsal plumes longer than ventral plumes; post and presutural bristles present; prescutellar bristles absent, but a transverse row of setae longer than the rest of the thoracic 

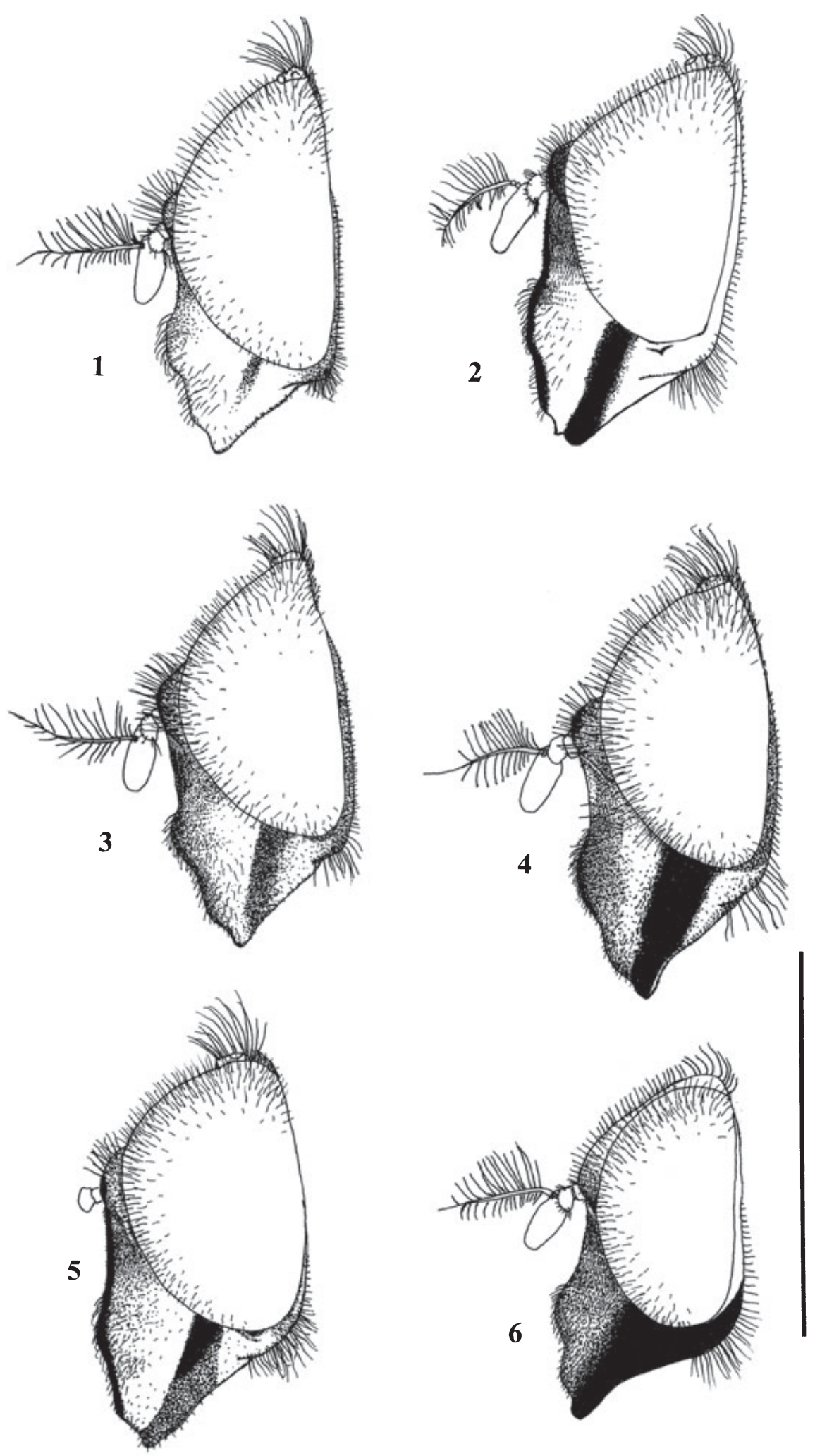

Figures 1-6. Adult Copestylum, lateral view of the head; scale line $=3.5 \mathrm{~mm}$. 1 . Copestylum galantei sp. nov., male holotype; 2. Copestylum gelenita sp. nov., male holotype; 3. Copestylum oscillans sp. nov., male holotype; 4 . Copestylum tacanense sp. nov., male holotype; 5 . Copestylum tapanti sp. nov., male holotype; 6 . Copestylum xalapensis sp. nov., female holotype. 


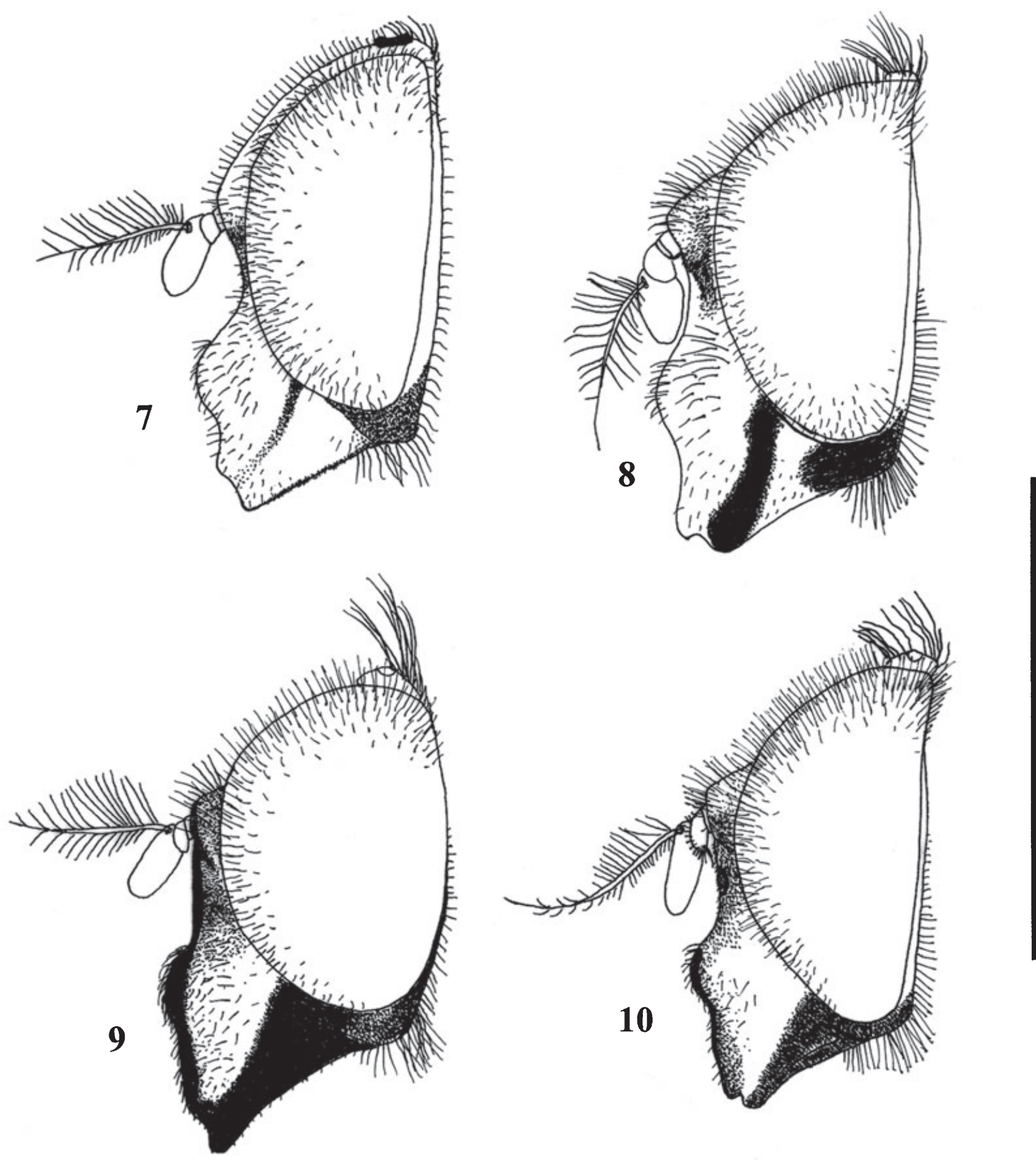

Figures 7-10. Adult Copestylum, lateral view of the head; scale line $=3.5 \mathrm{~mm}$. 7. Copestylum carlosii sp. nov., female holotype; 8. Copestylum volcanorum sp. nov., male holotype; 9. Copestylum barbara sp. nov., male holotype; 10. Copestylum elizabethae sp. nov., male holotype.

pile is present; posterior anepisternum dusted with one black bristle; scutellum without basal tubercles, apical depression or marginal ridge, but with between four and six pairs of marginal bristles; wings usually with extensive microtrichia; R1 scarcely broadened at apex; abdomen shiny but not metallic; male genitalia with epandrium lacking projection at point of articulation with the hypandrium; surstylus variable in shape from 
narrow and elongate to broad and rectangular-shaped basally with a tapering apex; superior lobe consisting of a pair of hook-like processes; body from mostly yellow to mostly black; body length, 12-13 $\mathrm{mm}$.

Diagnosis - larva and puparium: Oval in outline and dorso-ventally flattened; abdominal segments 1-7 with marginal band of fleshy lobes at level of sensilla 5 and 6 , these sensilla at dorso-apical positions on each lobe of abdominal segments 1-7, accompanied by either one or two long setae; lateral and apical margins of each lobe coated with setae of varying types; thorax either with or without marginal band; ovalshaped suckers on abdominal segments 1-6; inner anterior margin of suckers with rows of spicules, posterior margin with papillae; prothorax with anterior fold coated in brown-tipped, dentate-shaped spicules; mesothoracic prolegs divided by a deep longitudinal groove; this groove extending along each side of the body to the anal segment, and separating the marginal band from the raised medial area bearing the suckers; lappets on the anal segment either incorporated into the marginal band or not; posterior breathing tube orange to black; variable in length and cross-sectional shape; matt below transverse ridge, shiny and punctate above (the transverse ridge is a distinctive feature in many syrphid lineages - it appears usually as a raised keel or carina across the posterior breathing tube, but is sometimes a furrow or groove, or is only apparent by a change in surface ornamentation: above it the breathing tube is often punctured and shiny, below it is usually matt without punctures; Figs 99-102); spiracular plate bearing three pairs of straight, curved, or circular openings; pupal spiracles either yellow or black with openings either clustered at the apex or openings almost reaching base; head skeleton (Fig. 96): dorsal cornu short, narrow and almost parallel with ventral cornu, i.e. less than ten times as long as ventral cornu, and less than half as wide as ventral cornu; dorsal bridge and ventral pharyngeal ridges present; sclerotized tentorial bars narrowing apically beyond ventral bridge; mandibles and mandibular apodeme as narrow as tentorial bars or narrower.

Taxonomic notes: Future phylogenetic investigation may add support to this group concept, which for convenience is referred to by the name 'tank'. This name was suggested by students of the 1998 Insect Group, Glasgow University Expedition Society, because of the resemblance of the larval stages in shape and movement to military tanks. Tank species were found in tropical forests in all five countries visited, and their larvae develop in live epiphytic and saxicolous bromeliads.

The tank group is distinctive on a range of adult and larval characters, in particular the two-hooked supe- rior lobe in the male genitalia and locomotory organs consisting of suckers in the larvae. The group is most similar in gross adult morphology to Copestylum crepuscularium Hull, 1942 and Copestylum vampyrum Hull, 1942. Within the ten species of the tank group we recognize three subgroups based mainly on characters of the larval stages, in particular the form of the marginal band and the anal segment.

\section{Subgroup oscillans}

Diagnosis - larva and puparium: Marginal band incomplete, lobes not developed on thorax (Fig. 75); marginal band of first abdominal segment with two pairs of lobes; marginal band of anal segment with only one pair of lobes comprising the third pair of lappets; first two pairs of lappets on short projections on dorso-lateral margins of the anal segment; lobe margins with fine, cylindrical setae not dividing at apex, and neither flattened nor pressed together (Fig. 79); ventral surface of lobes, anal segment and rim of suckers with setae of various types; dorsal surface with vestiture of setae or papillae; anterior spiracles absent; browntipped spicules present in the lateral furrows of the mesothorax; mesothoracic prolegs with brown-tipped crochets across apex; posterior breathing tube base orange, short, such that transverse ridge is about halfway to a third along tube, wider than deep in crosssection, broader at base and apex, punctate either yellow or black above the transverse ridge; spiracular plates not close together and have a figure of eight in outline shape; spiracular plates at right angles to length of tube, not inclined.

Diagnosis - adult: Male eyes flattened dorsally, with a group of facets clearly larger than elsewhere on the eyes; wings without well-defined brown maculae; abdominal tergites usually more yellow than black.

Taxonomic notes: The name 'oscillans' for this subgroup comes from the first species we reared that belongs to it. It has six species distinguished by the marginal band being confined to the abdomen and not including the thorax. Other distinguishing characters include the marginal band of the anal segment comprising one pair of lobes, lobes of the entire marginal band lined with undivided setae, and a wider than deep posterior breathing tube. Between the larvae of this subgroup, the main directions of variation are in the type of vestiture, setae of the lobes, and the colour and distribution of openings of the respiratory organs. Among adult stages of tank group species, those of the oscillans subgroup are recognizable by a group of particularly enlarged eye facets on the flattened top of the male head. Oscillans subgroup species were found in tropical forests in Costa Rica and Mexico, and their larvae develop in epiphytic and saxicolous bromeliads. 


\section{COPESTYLUM GALANTEI SP. NOV. MARCOS-GARCÍA \& ROTHERAY}

Diagnosis - male holotype: face yellow with yellow hairs, lateral vittae lightly marked and not reaching the mouth (Fig. 1); mesonotum mainly yellow with yellow hairs anteriorly and black hairs posteriorly; scutellum yellow with black hairs; pleura yellow with yellow setae; wing membrane hyaline, darker in the costal margin and apically; legs yellow except darkened hind tibiae and tarsi; legs black haired except for yellow haired femoral bases; abdominal tergites 2-4 yellow except for posterior margins, which have black bands either narrowing or interrupted medially; sternites 1 and 2 yellow with yellow hairs; sternites 3 and 4 fuscous with black and yellow hairs; genitalia surstylus broad and triangular-shaped; hypandrium with triangular lateral projection; aedeagus smooth apically (Figs 23, 24, 25); female - similar to holotype male; width of vertex about $17 \%$ width of head. Length: body, 8.75-10.00 mm; wing, 9.16-9.50 mm $(N=6)$.

Diagnosis - larva and puparium: Suckers on abdominal segments 1-6; marginal band of fleshy lobes coated in long, fine, unbranched setae, present on abdomen only, not including the thorax; ventral surface of lobes on abdominal segments 1-6 coated with fine, matted setae; vestiture on the dorsal surface consisting of soft, fine setae, usually lying flat; posterior breathing tube orange and short, such that the transverse ridge is about halfway along tube; pupal spiracles black with openings clustered at widened apex.

Material examined-holotype: Male with puparium Costa Rica, Alajuela, San Carlos, Fortuna, 30 October 1999, ex water tank of bromeliad (Bromeliaceae), collected by J. D. Gutiërrez (INBO0003056063) (INBio).

Material examined - paratypes: Four males and one female as follows - two males, one female with puparia, same data as holotype (INBO0003056060, INBO0003056061, INBO0003056062) (INBio); one male with puparium, Costa Rica, Las Heliconias, 29 October 2000, ex water tank of bromeliad, J. D. Gutiërrez (CIBIO); one male with puparium, Costa Rica, Guanacaste, Santa Rosa, Est. San Gerardo, 25.vi. 2000, ex water tanks of bromeliad, J. D. Gutiërrez (NMS).

Material examined - additional material: one larva, Costa Rica, APC.0012.2, ex water tank of bromeliad (INBio); two larvae, Costa Rica, Guanacaste, Volcán Rincón de la Vieja, 19 August 2001, ex water tank of bromeliad EGH and GER (NMS); two larvae, Costa Rica, DBC-088, ex water tank of bromeliad (INBio).

Etymology: The name 'galantei' is descriptive of the name of my husband, with whom I have shared many productive hours in the field (MAM).
Taxonomic notes: Although generally a yellow species, variation occurs with dark markings on the face and sides of the thorax in some specimens, and yellow bands of hairs sometimes present on the anterior margins of abdominal tergites 3 and 4 . The adult of C. galantei is most similar to Copestylum oscillans and Copestylum tapanti in general body patterning and colouration, and in having relatively broad triangularshaped surstyli in the male genitalia. It can be most readily distinguished from these two species by the yellow hairs at the base of the femorae. Within the larval stages of the oscillans subgroup that have an orange posterior breathing tube, the early stages of C. galantei are readily distinguished by the fine, soft setae of the vestiture on the apico-ventral surfaces of the lobes of the marginal band.

Biology: Adults were reared from larvae in water tanks of epiphytic bromeliads (Bromeliaceae), and are known only from Costa Rica.

\section{CoPESTYLUM GELENITAE SP. NOV.}

\section{MARCOS-GARCÍA \& ROTHERAY}

Diagnosis - male holotype: Face yellow with strong, uninterrupted, black, mid-dorsal vitta from mouth to base of the antennae, black hairs mostly confined to vitta, yellow on rest of face; lateral vittae also strong, reaching mouth (Fig. 2); mesonotum mainly yellow with yellow hairs anteriorly and black hairs posteriorly; scutellum yellow with black hairs; pleura yellow and black with yellow hairs except black meron, katepisternum and anterior part of posterior anepisternum; wing membrane microtrichose except $1 \mathrm{~A}$ and second basal cells partially infuscated; legs with front and mid femorae yellow and fuscous at base, tibiae black, tarsi yellow, all black haired except for base of front and mid femorae; hind legs black except apex of femora and black haired; abdominal sternites and tergites 2-4 yellow, except for posterior margins that have complete black bands, neither narrowing nor interrupted medially; sternites 2-4 with yellow hairs basally and black hairs posteriorly; genitalia - surstylus narrow and elongate; hypandrium with triangular lateral projection; aedeagus smooth apically (Figs 26, 27, 28); female - similar to holotype male; width of vertex $17.3 \%$ width of head. Length: body, 10.75-12.00 mm; wing, $10.16-10.50 \mathrm{~mm}(N=3)$.

Diagnosis - larva and puparium: suckers on abdominal segments 1-6; marginal band of fleshy lobes coated in long, fine, unbranched setae, present on abdomen only, not including the thorax; ventral surface of lobes on abdominal segments 1-6 coated in short, thick, stiff setae; vestiture on the dorsal surface comprising dome-shaped to cylindrical papillae; third 

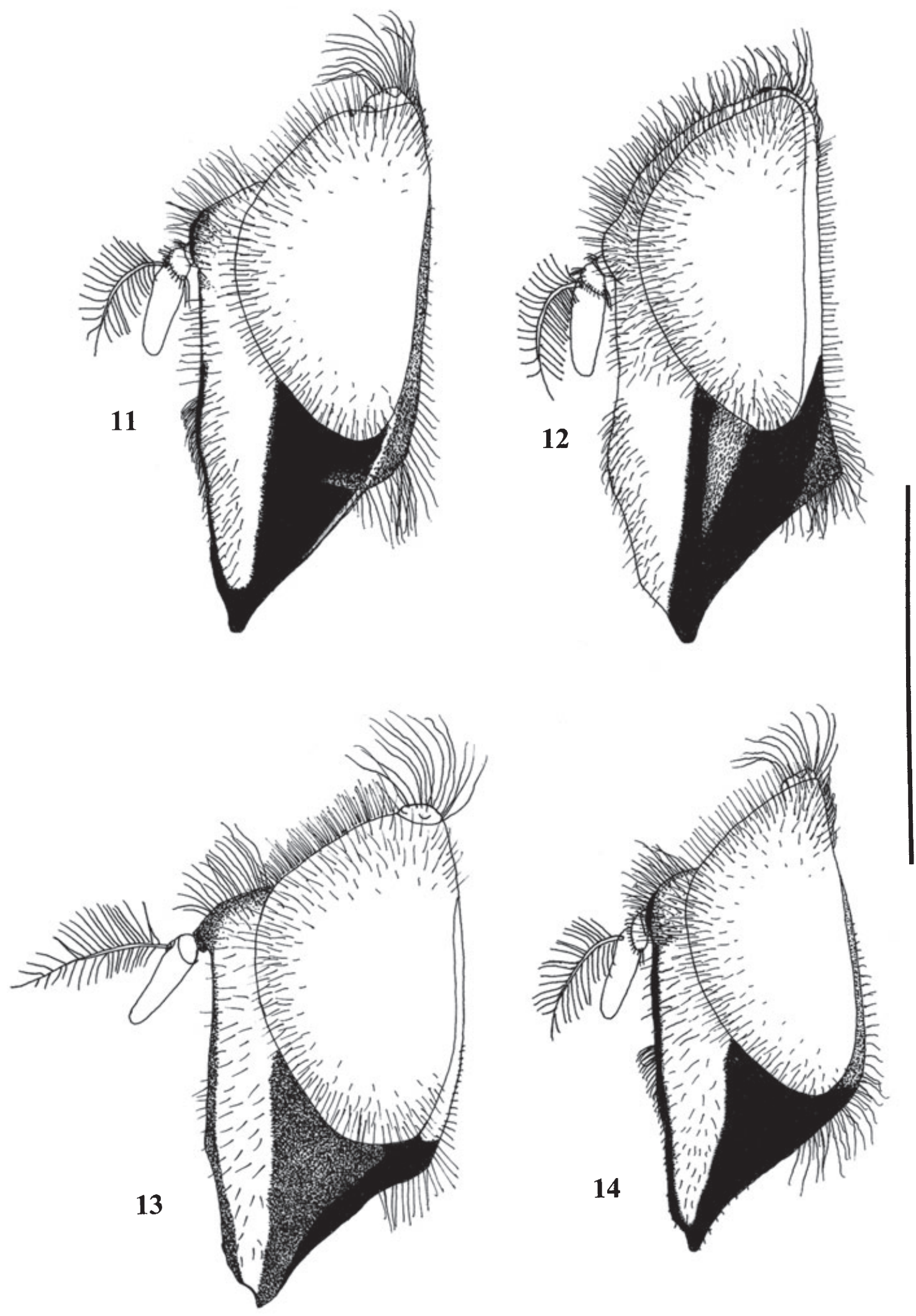

Figures 11-14. Adult Copestylum, lateral view of the head; scale line $=3.5 \mathrm{~mm} .11$. Copestylum boqueronense sp. nov., male holotype; 12. Copestylum mamorum sp. nov., female holotype; 13. Copestylum triunfense sp. nov., male holotype; 14. Copestylum unamas sp. nov., male holotype. 
pair of lappets part of the marginal band and setalose setulate ventrally almost to apex; posterior breathing tube orange with black tip and transverse ridge about two thirds along the tube; pupal spiracles yellow with openings about halfway down, not clustered at widened apex.

Material examined - holotype: Male with puparium, Mexico, Chiapas, Boquerón, 19 April 2002, ex live epiphytic bromeliad (Bromeliaceae), collected by GER, MAM and C. Pérez-Bañón (NMS).

Material examined - paratypes: one male with puparia, same data as holotype (CIBIO); one female with puparium, Mexico, Chiapas, Boquerón (2300 m), 19 July 2003, ex live epiphytic bromeliad (Bromeliaceae), collected EGH (HM).

Material examined - additional material: two larvae, Mexico, Chiapas, Boquerón, 19 April 2002, ex live epiphytic bromeliad (Bromeliaceae), collected by GER, MAM \& C. Pérez-Bañón (NMS).

Etymology: The name 'gelenita' is a family nickname for my daughter, Elena (MAM).

Taxonomic notes: A yellow species but darker in comparison with $C$. galentei and $C$. oscillans as a result of wider black posterior margins to the abdominal tergites, and black markings on the sides of the thorax and on the legs. In these features C. gelenitae is most similar to Copestylum tacanense, with which it also shares narrow elongate surstyli, but it can be separated from that species by its yellow scutum and lateral projections to the hypandrium. The early stages of C. gelenitae are readily distinguished by the vestiture of dome-shaped to cylindrical papillae, not setae, and the longer, posterior breathing tube that is yellow with a black tip. Another species with a similar larva apparently occurs in Chiapas, Mexico, but we failed to rear an adult. It is distinguished from $C$. gelenitae by having setulate vestiture.

Biology: Adults were reared from larvae in water tanks of epiphytic bromeliads (Bromeliaceae), and are known only from Chiapas State, Mexico.

\section{COPESTYLUM OSCILLANS SP. NOV.} HANCOCK \& ROTHERAY

Diagnosis - male holotype: Face yellow, with vague medial and lateral dark vittae, yellow haired except for a few black hairs near the tubercle (Fig. 3); mesonotum mainly yellow with four black vittae forming a pair of black marks posteriorly; scutellum yellow with a pair of black apical markings; pleura yellow with black marked katepisternum, meron, and anterior part of the anepisternum; wing membrane hyaline, darker at the apical margin, $\mathrm{R} 1$ either open or closed apically in the costal vein; legs yellow except for darkened tibial apices; femorae black haired anteriorly, yellow haired posteriorly, tibiae and tarsi black haired; abdominal tergites $2-4$ yellow, except for posterior margins that have black bands either narrowing or interrupted medially; sternites 1 and 2 yellow with yellow hairs; sternites 3 and 4 fuscous with black and yellow hairs; genitalia - surstylus broad and triangular-shaped with a straight outer margin and a curved inner margin; hypandrium lacking lateral projection; aedeagus with serrated apical margin (Figs 29, 30, 31); female - similar to holotype male; width of vertex about $15 \%$ of width of head. Length: body, 9.16$9.75 \mathrm{~mm}$; wing, 8.75-9.16 $\mathrm{mm}(N=4)$.

Diagnosis - larva and puparium: Suckers on abdominal segments 1-6; marginal band of fleshy lobes coated in long, fine, unbranched setae, present on abdomen only, not including the thorax (Fig. 75); ventral surface of lobes on abdominal segments 1-6 coated in short, thick, stiff setae; vestiture of soft, fine setae lying flat; third pair of lappets included in the marginal band, and setulate ventrally almost to apex; posterior breathing tube orange, transverse ridge at mid-point, three pairs of spiracular openings, more or less parallel; pupal spiracles brown/black with openings clustered at widened apex.

Material examined - holotype: Male with puparium, Costa Rica, Alajuela, Upala, Dos Rios, 13 September 1999, ex water tank of Vriesea sanguinolenta (Bromeliaceae), D. Briceño (INB0003056059) (INBio).

Material examined - paratypes: Two males and two females as follows - one male and one female with puparia, same data as holotype (INB0003056054, INB0003056055) (INBio); one male and one female with puparia, Costa Rica, Alajuela, San Carlos, Fortuna, Est. Peninsula, 30 October 1999 (ex water tank of bromeliads), J. D. Gutiërrez (NMS).

Material examined - additional material: one larva, Costa Rica, Cartago NP, Tapanti, February 1999, GER (NMS); one larva MAV-23 (INBio).

Etymology: The name 'oscillans' is descriptive of the characteristic back and forth movement of the posterior breathing tube during locomotion of the larva.

Taxonomic notes: The adult of $C$. oscillans can be distinguished by the presence of unique, paired, black markings on the otherwise yellow mesonotum and scutellum. Among the tank group species, C. oscillans is also unique in having a serrated apical margin to the aedeagus. Within the larval stages of the oscillans subgroup that have incomplete marginal bands and an orange posterior breathing tube, the early stages of this species are readily distinguished by the short, thick setae on the underside of the marginal lobes of 
the abdomen, setulate posterior lappets and more or less parallel spiracular openings of the posterior breathing tube. The early stages are most similar to those of $C$. tapanti, but $C$. oscillans is separated from that species by the parallel spiracular openings and brown/black, not yellow, pupal spiracles.

Biology: Adults were reared from larvae in water tanks of bromeliads including V. sanguinolenta, and are known only from Costa Rica.

\section{COPESTYLUM TACANENSE SP. NOV. ROTHERAY \& HANCOCK}

Diagnosis - male holotype: Face yellow, with diffuse, black, mid-dorsal vitta, but distinct, black, lateral vittae (Fig. 4); mostly black haired with yellow hairs about mouthedge; eye hairs black; mesonotum black with yellow lateral vittae; hairs on mesonotum yellow in the anterior part, black posteriorly; scutellum yellow with yellow hairs at base, and black elsewhere; pleura mainly black, only yellow marks on the posterior anepimeron and the katepisternum; wing dark along the costal margin; legs with coaxe and trochanters fuscous, femorae black at base, tibiae black at apex, and tarsi fuscous, otherwise legs yellow; black haired except for some yellow hairs on posterior margin of mid and hind femorae; abdominal tergites 2-4 with pairs of yellow square-shaped spots occupying more than $75 \%$ depth of each tergite, tergites otherwise black; black haired except for spots on tergite 2; sternites mainly yellow with black hairs and dark posterior margins; genitalia - surstylus narrow and elongate; hypandrium lacking lateral projections; aedeagus without serrated apical margin (Figs 32, 33, 34); female - similar to holotype male except eye hairs mostly yellow and mesonotum with a pair of middorsal yellow vittae; width of the vertex about $13 \%$ of width of head. Length: body, 8.56-10.15 mm; wing, 7.75-8.16 $\mathrm{mm}(N=4)$.

Diagnosis - larva and puparium: Suckers on abdominal segments 1-6; marginal band of fleshy lobes coated in long, fine, unbranched setae, present on abdomen only, not including the thorax; vestiture comprising thick upright setae; third pair of lappets part of the marginal band, setulate only at base; posterior breathing tube orange with three pairs of more or less straight and parallel spiracular openings; pupal spiracles black with openings about halfway down, not clustered at widened apex.

Material examined - holotype: Male with puparium, Mexico, Chiapas, El Triunfo, Reserva de la Biosfera, 28 July 2003, ex live small epiphytic bromeliad (Bromeliaceae), collected by GER and MAM (NMS).
Material examined - paratypes: One female with puparia, same data as holotype (NMS); one female with puparium, Mexico, Chiapas, Talquián, Tacaná, 23 July 2003, ex live small epiphytic bromeliad (Bromeliaceae), collected by GER (CIBIO); one female with puparium, Mexico, Chiapas, Talquián, Tacaná, 23 July 2003, ex live epiphytic bromeliad (Bromeliaceae), collected by GER (NMS); one larva, same data as holotype except collected on 27 July 2003, GER (NMS).

Etymology: The name 'tacanaense' is descriptive of the name of the volcano Tacaná where this species was first reared.

Taxonomic notes: In general, appearance and structure of the male genitalia the adult of $C$. tacanaense is similar to $C$. gelenitae. They are the only oscillans subgroup species with complete black vittae that extend across the gena from the lower eye margin to the mouthedge. They also have pairs of large, yellow spots on the abdomen with complete black margins to tergites 2-4. However, C. tacanaense differs from C. gelenitae in having a dark, not a yellow, mesonotum, and in lacking lateral projections to the hypandrium. It is unique among tank group species in having a male with black eye hairs. In all other species the eye hairs are either yellow or orange. The early stages of $C$. tacanaense are readily distinguished by the thick, upright, dorsal vestiture, and the underside of the third pair of lappets setulate only at the base.

Biology: Adults were reared from larvae in water tanks of small-sized bromeliads (Bromeliaceae) growing on exposed rocks, cliff-faces, and under storey trees, and are known only from Chiapas State, Mexico.

\section{COPESTYLUM TAPANTI SP. NOV. ROTHERAY \& HANCOCK}

Diagnosis - male holotype: Face yellow with narrow, black, medial vitta reaching the base of the antennae; lateral vittae interrupted before the mouth (Fig. 5); face yellow haired; mesonotum entirely yellow; hairs on mesonotum yellow in the anterior part, black posteriorly; scutellum yellow with black hairs; pleura mainly black, only yellow on the posterior anepisternum, the anepimeron and the katepimeron; wing infuscated, darker in the costal margin; legs yellow, except base of femorae fuscous and tibiae black apically; posterior margin of femorae with yellow hairs, otherwise legs black haired; abdominal tergites 2-4 yellow except for posterior margins, which have black bands either narrowing or interrupted medially; sternites 1 and 2 yellow with yellow and black hairs; sternites 3 and 4 yellow with black posterior margin and with yellow and black hairs; genitalia - surstylus broad and triangularshaped with rounded lateral margins; hypandrium with lateral projections; aedeagus without serrated 


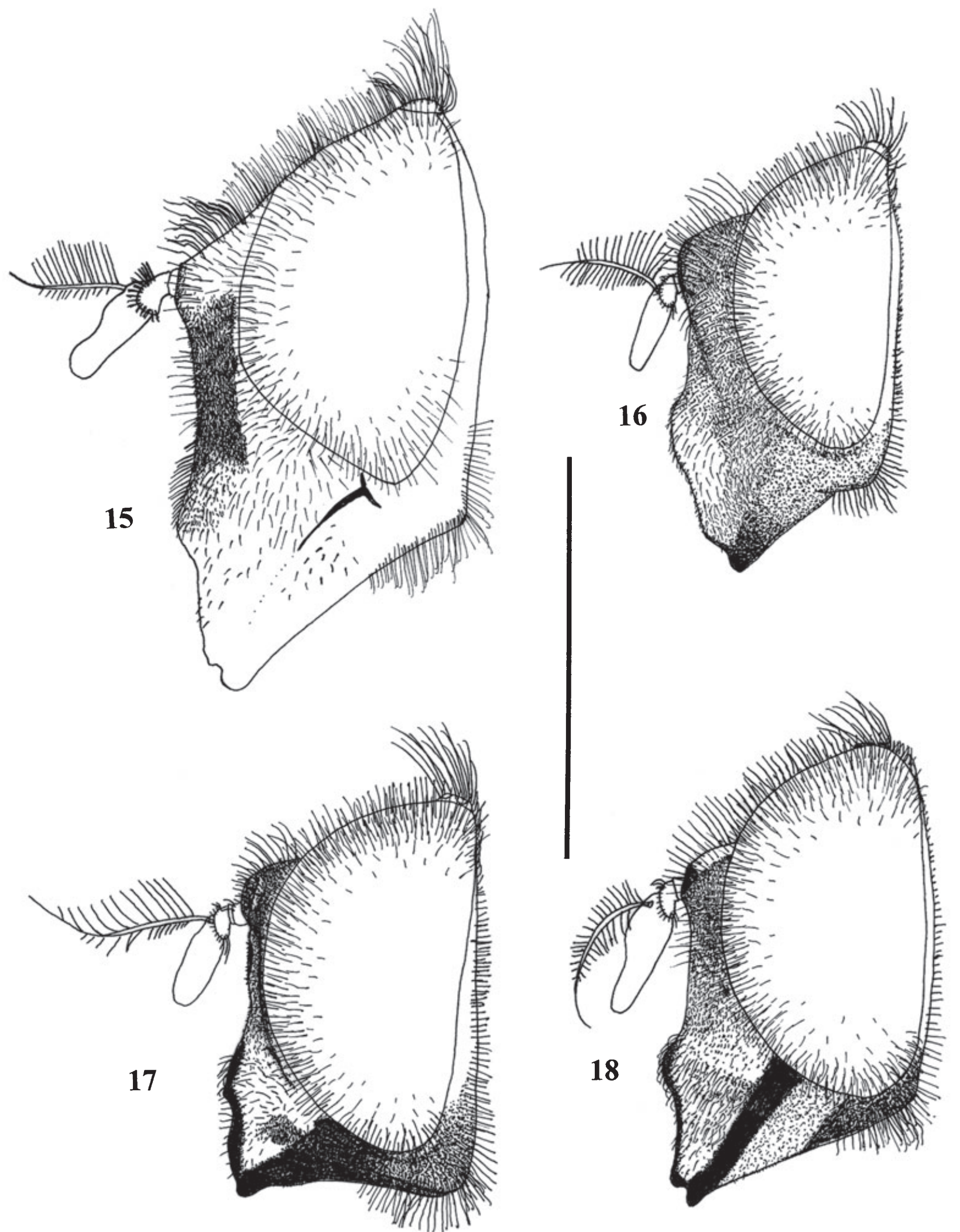

Figures 15-18. Adult Copestylum, lateral view of the head; scale line $=3.5 \mathrm{~mm}$. 15. Copestylum joei sp. nov., male holotype; 16. Copestylum louisae sp. nov., male holotype; 17. Copestylum otongaensis sp. nov., male holotype; 18. Copestylum puyarum sp. nov., female holotype. 
apical margin (Figs 35, 36, 37); female - unknown. Length: body, $9.15 \mathrm{~mm}$; wing, $8.16 \mathrm{~mm}(N=1)$.

Diagnosis-puparium: Suckers on abdominal segments 1-6; marginal band of fleshy lobes coated in long, fine, unbranched setae, present on abdomen only, not including the thorax; vestiture comprising thick upright setae; ventral surface of lobes on abdominal segments 1-6 coated in short, thick, stiff setae; third pair of lappets part of the marginal band setulate almost to apex; posterior breathing tube with three pairs of spiracular openings not parallel, middle pair almost at right angles to the other pairs; pupal spiracles yellow with openings about halfway down, not clustered at widened apex.

Material examined-holotype: Male with puparium missing antennae and front tarsi, Costa Rica, Cartago N.P., Alto de Robles, 6 July 2000, ex water tank of bromeliad, GER (INBio). Female unknown.

Etymology: The name 'tapanti' comes from a locality near Alto de Robles in Costa Rica, which is part of the Cartago Parque Nacional.

Taxonomic notes: This species is most similar to C. galentei in overall yellow body colour, and in having male genitalia with broad surstyli and hypandria with lateral projections. C. tapanti differs from C. galentei in having a medial vitta on the face and in having black hind femorae. Within oscillans subgroup species with incomplete marginal bands and an orange posterior breathing tube, the early stages of $C$. tapanti are distinguished by short, thick setae on the underside of the lobes, underside of the third pair of lappets setulate almost to apex, and middle pair of spiracular openings on the posterior breathing tube orientated at right angles to the other two pairs. In early stage characters $C$. tapanti is most similar to $C$. oscillans, but is separated from that species by the latter character an by having yellow, not brown/black, pupal spiracles.

Biology: The adult was reared from a larva in a water tank of an epiphytic bromeliad (Bromeliaceae), and is known only from Costa Rica.

\section{COPESTYLUM XALAPENSIS SP. NOV. ROTHERAY \& MARCOS-GARCÍA}

Diagnosis - female holotype: Face dark yellow without medial vitta, mostly yellow haired; lower margin of face from mouthedge to the occiput black (Fig. 6); frons darker than face with yellow hairs, and shiny, lacking pilosity; width of the vertex about $18 \%$ of width of head; mesonotum black with yellow hairs anteriorly, and black posteriorly; yellow lateral vittae present; scutellum yellow, mostly black haired; pleura entirely black; wing darker in the costal and apical margin; legs black including coxae and trochanters, except for yellow apices of femorae and bases of tibiae; mostly black haired except for posterior margin of femorae; abdomen - tergite 1 fuscous, tergite 2 with a white anterior band and narrow (third of the length of tergite) black band, tergites 3 and 4 black, each with a pair of yellow side-spots; tergites black haired except for hairs on white band of tergite 2 ; sternite 1 white with white hairs, and with a black apical band; sternite 3 and 4 black with a narrow yellow apical band, and black haired; male - unknown. Length: body, $9.15 \mathrm{~mm}$; wing, $7.15 \mathrm{~mm}(N=1)$.

Diagnosis-puparium: Suckers on abdominal segments 1-6; marginal band of fleshy lobes coated in long, fine, unbranched setae, present on abdomen only, not including the thorax; vestiture comprising soft, fine setae lying flat; ventral surface of lobes on abdominal segments 1-6 coated in short, thick, stiff setae; third pair of lappets included into the marginal band, and setulate only at base; posterior breathing tube with three pairs of spiracular openings, more or less parallel; pupal spiracles black with yellow apex, and openings clustered at widened apex.

Material examined - holotype: Female with puparium, Mexico, Veracruz State, Xalapa, Crta. Coatepec, 4 July 1999, ex water tank of bromeliad, GER, EGH and MAM (CIBIO).

Etymology: The name 'xalapensis' is in reference to the town closest to the type locality, Xalapa, in Mexico. This species is only known from Mexico.

Taxonomic notes: This is the darkest of the oscillans subgroup species, with an abdominal colour pattern similar to elizabethae subgroup species in having tergite 2 with a pale anterior band, and most of the remaining tergites black with pairs of inconspicuous yellow side spots. The colour pattern of the abdomen readily distinguishes C.xalapensis from other oscillans subgroup adults. It is easily separated from elizabethae subgroup species by the lack of a medial vitta on the face. Within the oscillans subgroup, the early stages of C. xalapensis are distinguished by the short, thick setae on the underside of the lobes, underside of the third pair of lappets setulate only at the base, and the more or less parallel spiracular openings of the posterior breathing tube. Early stages are most similar to C. tapanti, but are separated from that species by the black pupal spiracles. In C. tapanti the pupal spiracles are yellow.

Biology: The adult was reared from a larva in a bromeliad water tank (Bromeliaceae), and is known only from Mexico.

\section{Subgroup carlosii}

Diagnosis - larva and puparium: Marginal band complete including both abdomen and thorax; lobes of 
mesothorax and metathorax each comprising one pair of lobes; first abdominal segment with two pairs of lobes; lateral and apical margins of each lobe coated with dorso-ventrally flattened setae pressed close together basally and forked apically (Fig. 80); ventral surface of lobes matted with long, thin setae; sensilla $7 / 8$ on a long thin projection; anterior spiracles present, dark brown with either two or three spiracular openings at apex; vestiture consisting of dark papillae bearing aggregated groups of setae; dark papillae lacking setae present on the ventral surface of the anal segment; mesothoracic prolegs with a group of about eight crochets on inner lobe; rim of suckers smooth and shining without setae; anterior rim of each sucker with two lateral groups of between three and five crochets (Fig. 78); anal segment with first lappet pair not on a fleshy projection, reduced to sensillum and associated setae, posterior two pairs of lappets, about equally long and above, not part of, the marginal band that consists of two pairs of lobes (Fig. 76); posterior breathing tube dark brown to black; long, such that transverse ridge at apex of tube; cylindrical in cross-section and parallel sided; lightly punctate above the transverse ridge; spiracular plates close together and oval in outline shape; spiracular plates not inclined, with three pairs of curved openings; pupal spiracles, short, about same length as distance apart, either yellow or black with openings either below middle or at apex on raised bands, short hairs either absent or present.

Diagnosis-adult: Face with profile concave above prominent tubercle; male eyes without enlarged facets; mesonotum with complex pattern of black and white groups of hairs (view from behind), medial strip of white hairs on each side of which, from the anterior margin to a central point, a pair of black-haired strips, at the base of the postpronotum a patch of white hairs, and behind, a strip of black hairs reaching the transverse suture, rest of the mesonotum white-haired except for a pair of black-haired strips from just behind the transverse suture to the base of the scutellum, and black hairs on the postalar callus; wings with sharply defined brown maculae; superior lobe of male genitalia with subapical pair of hooks blunt and rounded, and this pair of hooks not as defined as in other tank subgroups.

Taxonomic notes: This subgroup of two species is easily distinguished by the marginal band that includes the thorax, but not the posterior two pairs of lappets. Additional distinguishing characters include the presence of crochets on the suckers (Fig. 78), marginal band consisting of only one pair of lobes each on the mesothorax and metathorax, abdominal sensilla $7 / 8$, which are on a long projection, and the presence of anterior spiracles. The adults are readily separated from other tank subgroups by the concave face between the tubercle and antennae (Figs 7 and 8). The subgroup is only known from Bolivia, and larvae were found in both epiphytic and saxicolous bromeliads.

\section{COPESTYLUM CARLOSII SP. NOV. ROTHERAY \& HANCOCK}

Diagnosis - female holotype: Face yellow with mostly black hairs; lateral vittae indistinct and without medial vitta (Fig. 7); face shiny, dust and pruinosity confined to a narrow strip by the eye margins, across the face under the base of the antennae and on the gena; tubercle rounded and prominent (Fig. 7); colour of the frons similar to the face and black haired; width of vertex about $17 \%$ of width of head; mesonotum black with yellow lateral vittae; scutellum same colour as mesonotum and black haired. Pleura yellow with black hairs; anepisternum with yellow hairs anteriorly and black hairs posteriorly; wings extensively microtrichose and medial crossveins infused black; legs mainly yellow and black haired; abdomen entirely black except for two triangular whitish spots at base of tergite 2; sternites black and black haired except for white and white-haired sternite 2 ; male unknown. Length: body, $9.00 \mathrm{~mm}$; wing, $8.50 \mathrm{~mm}(N=1)$.

Diagnosis - larva and puparium: Suckers present on abdominal segments 1-6; marginal band complete, including both thorax and abdomen; first abdominal segment with two pairs of lobes; anal segment with two pairs of long, narrow lappets above the marginal band (Fig. 76); ventral surface of lobes coated with setae; anterior spiracles present; vestiture of dark papillae bearing groups of setae; ventral surface of anal segment with dark papillae bare of setae; posterior breathing tube dark brown to black, short, such that length of tube below transverse ridge is about 1.5 times the length of tube above the ridge, with three pairs of spiracular openings that are curved in shape; pupal spiracles yellow with openings clustered at widened apex.

Material examined-holotype: Female with puparium, Bolivia, Reserva Santa Cruz, Los Volcanes, 18 August 2004, ex live epiphytic bromeliad (Bromeliaceae) collected by EGH (HM).

Material examined - additional material: six larvae, ex live epiphytic, bromeliads (Bromeliaceae), same data as female holotype (NMS).

Etymology: The name 'carlosii' is descriptive of the very helpful manager at Los Volcanes, Bolivia.

Taxonomic notes: In the adult stage, $C$. carlosii is separated from Copestylum volcanorum, the other species in the subgroup, by the dark, not yellow, scutellum 

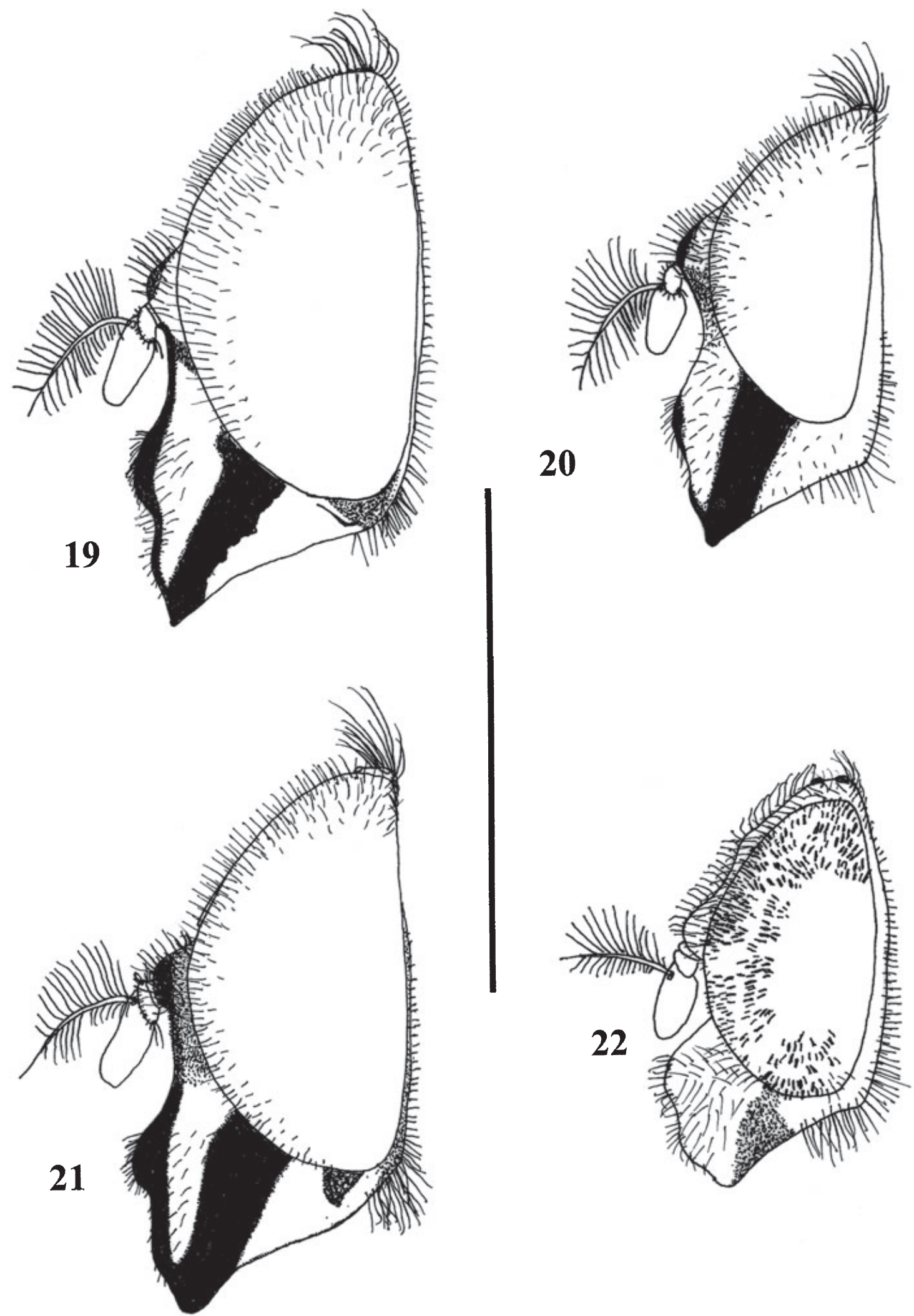

Figures 19-22. Adult Copestylum, lateral view of the head; scale line $=3.5 \mathrm{~mm}$. 19. Copestylum albertoi sp. nov., male holotype; 20. Copestylum conabioi sp. nov., male holotype; 21. Copestylum tapia sp. nov., male holotype; 22. Copestylum yowoi sp. nov., female holotype. 
and the yellow, not black, legs. Within the carlosii subgroup, with larvae distinguished by having marginal bands incorporating the thorax, and lappets that are not incorporated into the marginal band, the early stages of $C$. carlosii are readily distinguished from C. volcanorum by the shorter posterior breathing tube, which below the ridge is about 1.5 times the length of the tube above the ridge, and the yelloworange pupal spiracles with openings clustered at the apex.

Biology: Adults were reared from larvae in water tanks of bromeliads (Bromeliaceae) growing on and among vegetation along ridges, and are known only from Bolivia.

\section{COPESTYLUM VOLCANORUM SP. NOV.} HANCOCK \& ROTHERAY

Diagnosis - male holotype: Face as C. carlosii, but lateral vittae distinct from eye to mouth (Fig. 8); mesonotum as $C$. carlosii; scutellum yellow and black haired; pleura mainly black, only yellowish on the dorsal part of the anepisternum, posterior anepimeron, and katatergum and katepimeron; wings extensively microtrichose, and medial crossveins infused black; legs mainly black, except pale at apices of femorae and ventral surface of tibiae and tarsi; legs black haired; abdominal tergites $1-4$ black with pale yellow side spots; tergite 1 pale haired, tergite 2 with white hairs on side spots and posterior margin with a band of black hairs, tergites 3 and 4 black haired; sternites 1 and 4 black, sternites 2 and 3 yellow; sternites whitehaired; genitalia - surstylus broad and rectangularshaped with distal margins tapered; lower superior lobe of hypandrium more like a rounded projection than hook-like; hypandrium without lateral projections and aedeagus with smooth apical margin (Figs 38, 39, 40); female - similar to holotype male except for colour pattern of abdomen, which is black with a pair of large, square-shaped, white spots on tergite 2, and abdomen white-haired; sternites black except the sternite 2 and the anterior margin of sternite 3, which are yellowish; width of the vertex about $13.3 \%$ width of head. Length: body, 10.00$10.80 \mathrm{~mm}$; wing, 8.70-9.10 $\mathrm{mm}(N=2)$.

Diagnosis - larva and puparium: Suckers present on abdominal segments 1-6; marginal band complete, including both thorax and abdomen; anal segment with two pairs of long, narrow lappets above the marginal band; ventral surface of lobes coated with setae; anterior spiracles present; vestiture of dark papillae bearing groups of setae; ventral surface of anal segment with dark papillae bare of setae; posterior breathing tube dark brown to black, elongate such that length of tube below transverse ridge is more than twice the length of tube above the ridge, three pairs of spiracular openings that are curved in shape; pupal spiracles black with openings almost to base.

Material examined - holotype: Male with puparium, Bolivia, Reserva Santa Cruz, Los Volcanes, 18 August 2004, ex live bromeliad (Bromeliaceae) on cliff face, collected by EGH \& GER (NMS).

Material examined - paratype: One female with puparia, Bolivia, Reserva Santa Cruz, Los Volcanes, 8-12 August 2004, ex live bromeliad (Bromeliaceae) on rock face collected by EGH \& GER (NMS).

Etymology: The name 'volcanorum' is used in reference to the type locality, Los Volcanos in Bolivia.

Taxonomic notes: The dark scutellum and the black legs distinguish the adult of C. volcanorum from C. carlosii.

Within the carlosii subgroup, with larvae distinguished by having marginal bands incorporating the thorax, and lappets that are not incorporated into the marginal band, the early stages of $C$. volcanorum are readily distinguished from $C$. carlosii by the longer posterior breathing tube, which below the ridge is more than twice the length of the tube above the ridge, and the black pupal spiracles with openings almost at the base.

Biology: Adults were reared from larvae in water tanks of the cliff-face bromeliad, Tillandsia major (Bromeliaceae), and are known only from Bolivia.

\section{Subgroup elizabethae}

Diagnosis - larva and puparium: Marginal band complete round both abdomen and thorax; marginal band of mesothorax and metathorax each comprising two pairs of lobes; marginal band of first abdominal segment with three pairs of lobes (Fig. 77); lateral and apical margins of each lobe coated with dorsoventrally flattened setae pressed close together and each branching apically beween three and five times (Fig. 81); ventral surface of lobes smooth and shining, fine setae confined to lateral margins except on thorax; sensilla 7/8 not on a long projection, except on abdominal segment 7; anterior spiracles absent; dorsal vestiture on segments 1-7 consisting of domeshaped papillae lacking setae; ventral surface of anal segment smooth and shining, lacking papillae and setae; mesothoracic prolegs lacking crochets; rims of suckers coated in fine setae; lappet pair 1 not on a fleshy projection, reduced to sensillum and associated setae; posterior two pairs of lappets incorporated into the marginal band, as shown by the presence of apical sensilla in two of the three pairs of lobes on the anal segment, middle pair separating them lacking sensilla; posterior breathing tube orange; elongate such 
that transverse ridge at apex of tube (Fig. 101); cylindrical in cross-section and parallel sided; lightly punctate above the transverse ridge; spiracular plates close together and oval in outline shape; spiracular plates inclined, and openings consisting of three pairs of dorsal, circular depressions (Fig. 105); pupal spiracles either yellow or black, with openings clustered on the widened apical third (Fig. 109).

Diagnosis - adult: Male head with a group of eye facets slightly larger than elsewhere on the eyes; wings without well-defined brown maculae; abdominal tergites more black than yellow.

Taxonomic notes: This subgroup of two species is readily distinguished by the marginal band, which is complete round the margin of the entire body and includes the posterior two pairs of lappets. A complete marginal band is shared by the carlosii subgroup, but lappets are not included in that subgroup. Furthermore, the mesothorax and metathorax have two pairs of lobes (one each in the carlosii subgroup), and the first abdominal segment has three pairs of lobes (two in the carlosii subgroup). Additional characters include the marginal setae of the lobes, which branch into between three and five setae apically (two setae in the carlosii subgroup), the ventral surface of the anal segment is smooth and shining, and lacks either setae or papillae (setae present in other tank subgroups), and anterior spiracles are absent. Species of the elizabethae subgroup are known from epiphytic bromeliads in tropical forests in Costa Rica, Mexico, and Trinidad.

\section{COPESTYLUM BARBARA SP. NOV.} HANCOCK \& MARCOS-GARCÍA

Diagnosis - male holotype: Face yellow with strong, black, medial vitta and gena from eye margin to mouth shiny black, mostly black haired (Fig. 9); mesonotum black with yellow hairs anteriorly and black posteriorly; yellow lateral vittae present, but narrow and confined to extreme margin and not as broad as postalar callus; scutellum dark yellow and black haired; pleura lightly dusted, yellow in upper part, with black katepisternum, meron, anterior part of anepisternum and anepimeron; wing membrane hyaline with brown costal margin; cell R1 scarcely broadened apically, not petiolate; legs - black haired, coxae and trochanters fuscous; front and mid femorae black at base, hind femorae black almost to apex; front and mid tibiae yellow at base, black apically and hind tibiae black; tarsi fuscous; abdomen tergite 1 white, tergite 2 with a white anterior band and narrow (third of the length of tergite) black band, tergites 3 and 4 black, each with a pair of yellow sidespots in basal half; tergites black haired except for hairs on white band of tergites 1 and 2 ; sternite 1 white with mostly white hairs; sternite 3 and 4 black with a narrow, white, apical band and black haired; genitalia - surstylus triangular-shaped; hypandrium with lateral projections; aedeagus without serrated apical margin (Figs 41, 42, 43); female - similar to holotype male except scutellum brighter yellow, with band of yellow hairs at base; frons dark orange and shiny, lacking dust; width of vertex about $14.2 \%$ width of head. Length: body, $9.50-10.83 \mathrm{~mm}$; wing, $9.16-10.00 \mathrm{~mm}(N=3)$.

Diagnosis - larva and puparium: Suckers present on abdominal segments 1-6; marginal band complete, including both thorax and abdomen; first abdominal segment with three pairs of lobes; anal segment with lappets 2 and 3 incorporated into the marginal band; ventral surface of lobes smooth and shining; anterior spiracles absent; vestiture of anal segment of papillae with a crenate rim; posterior breathing tube orange above transverse ridge, about as long as body width, punctures light and inconspicuous above transverse ridge; pupal spiracles orange.

Material examined - holotype: Male with puparium, Costa Rica, Cartago, Paraíso, Orosi, Estación Quebrada, 6 October 1999, ex water tank of bromeliad, M. Alfaro (INBIO 0003056052) (INBio).

Material examined - paratypes: Two males and one female with puparia, same data as the holotype (INBIO 0003056050, INBIO 0003056053) (INBio).

Material examined - additional material: One larva, Costa Rica, Guanacaste, San Geraldo, August 2000, ex water tank of bromeliad, EGH \& GER (INBio).

Etymology: The name 'barbara' is descriptive of the name of one of my daughters (EGH).

Taxonomic notes: The entirely black gena, mesonotum with narrow yellow vittae, triangular surstylus, and hypandrium with lateral projections distinguish C. barbara from Copestylum elizabethae, the only other species in this subgroup. The colour pattern of the abdominal tergites are also distinctive among tank group species, and are only shared with $C$. xalapensis, but this species lack a medial vitta on the face. Subgroup Elizabethae early stages are distinguished from other tank subgroups by the complete marginal band and lappets incorporated into it. The early stages of C. barbara are readily distinguished from C. elizabethae by the vestiture of the anal segment consisting of papillae with a crenate rim (Fig. 88) and orange pupal spiracles.

Biology: Adults were reared from larvae in water tanks of bromeliads (Bromeliaceae), and are known only from Costa Rica. 

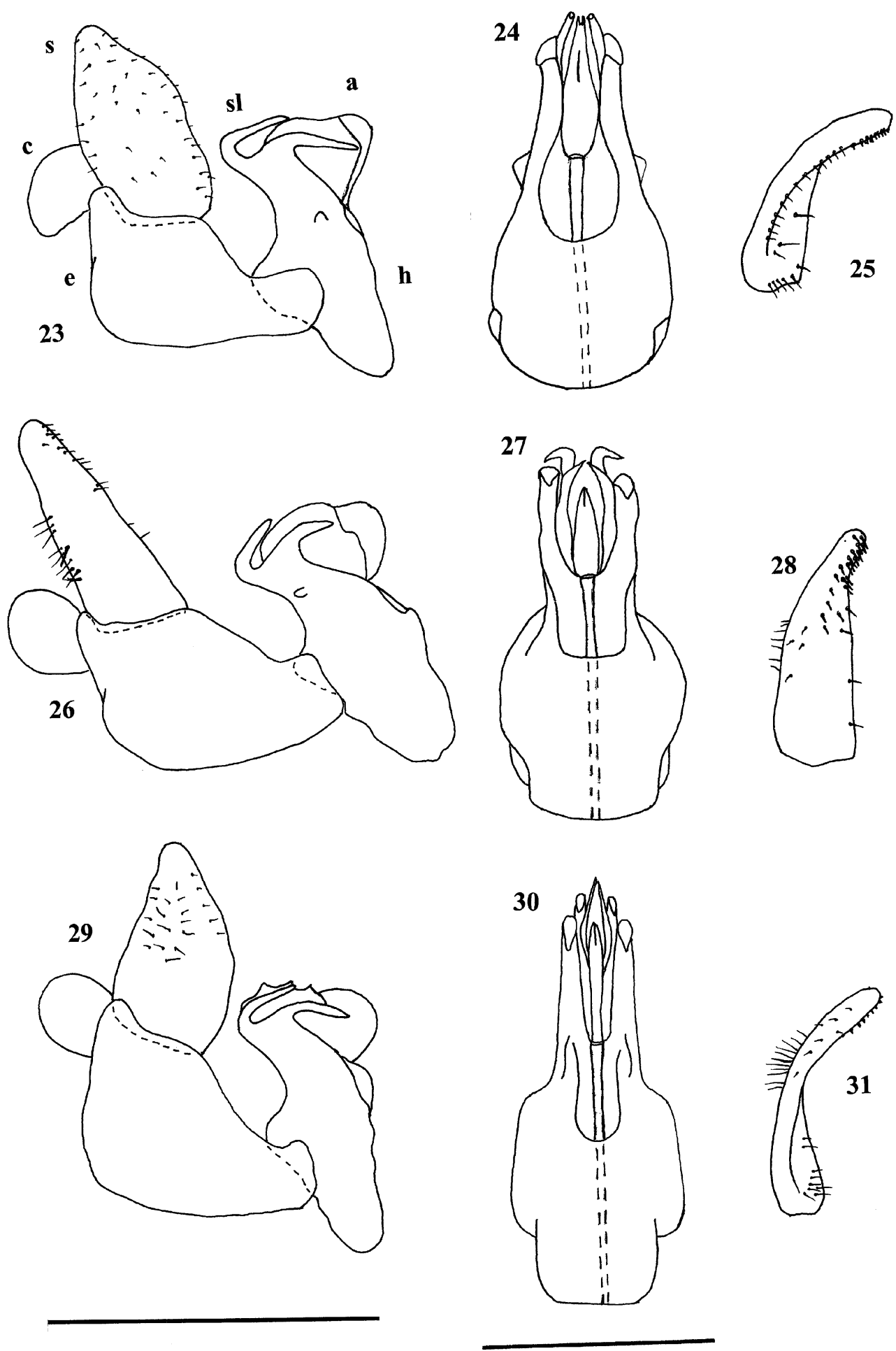

Figures 23-31. Adult Copestylum, male genitalia; right and left figures scale line $=0.50 \mathrm{~mm}$, for middle column figures, left-hand scale line $=0.85 \mathrm{~mm}$. Abbreviations: a, aedeagus; c, cercus; e, epandrium; h, hypandrium; s, surstylus; sl, superior lobes. 23-25. Copestylum galantei sp. nov., male holotype: 23. genitalia and associated structures, lateral view; 24, hypandrium, ventral view; 25. surstylus, ventral view. 26-28. Copestylum gelenita sp. nov., male holotype: 26 . genitalia and associated structures, lateral view; 27, hypandrium, ventral view; 28. surstylus, ventral view. 29-31. Copestylum oscillans sp. nov., male holotype: 29. genitalia and associated structures, lateral view; 30 . hypandrium, ventral view; 31. surstylus, ventral view. 


\section{COPESTYLUM ELIZABETHAE SP. NOV.} HANCOCK \& ROTHERAY

Diagnosis - male holotype: Face yellow with strong, black, medial vitta, and gena from eye margin to mouth dark, not shiny black; face with black hairs, mostly on medial vitta, and yellow elsewhere (Fig. 10); mesonotum black with yellow hairs anteriorly and black posteriorly; broad, yellow, lateral vittae present, about as wide as postalar callus; scutellum yellow and black haired; pleura lightly dusted, yellow except for black katepisternum, meron, anterior part of the anepisternum and anepimeron; wing membrane hyaline with brown costal margin; cell R1 scarcely broadened apically, not petiolate; legs black, marked at base of femorae, otherwise yellow/fuscous and black haired; abdomen - tergite 1 white, tergite 2 with a white anterior band and narrow ( 0.3 length of tergite) black band, tergites 3 and 4 black, each with a pair of yellow side-spots in basal half; tergites black haired except for hairs on white band of tergites 1 and 2; sternite 1 white with mostly white hairs; sternite 3 and 4 black with a narrow, white, apical band and black haired; genitalia - surstylus more elongate than triangular in outline shape; hypandrium lacking lateral projections; aedeagus without serrated apical margin (Figs 44, 45, 46); female - similar to holotype male except posterior anepisternum completely yellow including hairs; frons dark orange and shiny, lacking dust, and black marked beyond ocellar triangle; width of vertex about $12.5 \%$ width of head. Length: body, 7.50-9.50 mm; wing, 7.90-9.50 $\mathrm{mm}(N=3)$.

Diagnosis - larva and puparium: Suckers present on abdominal segments 1-6; marginal band complete, including both thorax and abdomen; first abdominal segment with three pairs of lobes (Fig. 77); anal segment with lappets 2 and 3 incorporated into the marginal band; ventral surface of lobes smooth and shining; anterior spiracles absent; vestiture of anal segment of dome-shaped papillae; posterior breathing tube black above transverse ridge, punctures heavy and obvious above transverse ridge (Fig. 101), three pairs of circular spiracular openings (Fig. 105); pupal spiracles orange at base, black above, openings clustered at apex (Fig. 109).

Material examined - holotype: Male with puparium, Mexico, Veracruz State, Xalapa, Crta. Coatepec, 4 July 1999, ex water tank of bromeliad, GER, EGH \& MAM (HM).

Material examined - paratypes: Five males and two females with puparia as follows: two males with the same data as holotype; one male, Northern Range, Hollis Dam, 6 July 1996, ex water tanks of bromeliad, EGH (HM); one male and one female, Trinidad, Northern Range, Hollis Dam, 9 July 1998, ex water tanks of bromeliads, EGH \& GER (NMS); one female, Trinidad, Mount Harris, Plum Military Road, 24 July 1998, ex water tanks of bromeliads, EGH \& GER (NMS); one male, Trinidad, Northern Range, Cumaca, 28 July 1998, ex water tanks of bromeliads, EGH (HM).

Material examined - additional material: Three larvae, Trinidad, Northern Range, Hollis Dam, 9 July 1998, ex water tanks of bromeliads, EGH \& GER; one larva, Trinidad, Northern Range, Cumaca, 28 July 1998, ex water tanks of bromeliads, EGH; three larvae, Trinidad, Mount Harris, Plum Military Road, 24 July 1998, ex water tanks of bromeliads, EGH \& GER (NMS).

Etymology: The name 'elizabethae' is descriptive of the name of my wife (EGH).

Taxonomic notes: The mesonotum with broad yellow vittae, elongate surstylus, and hypandrium without lateral projections distinguish C.elizabethae from C. barbara, the only other species in this subgroup. The colour pattern of the abdominal tergites are also distinctive among tank group species and are only shared with C.xalapensis, but this species lack a medial vitta on the face. Elizabethae subgroup early stages are distinguished from other tank subgroups by the complete marginal band with lappets incorporated into it. The early stages of C.elizabethae are readily distinguished from $C$. barbara by the vestiture of the anal segment consisting of domed, not crenate, papillae and the mostly black pupal spiracles.

Biology: Adults were reared from larvae in water tanks of epiphytic bromeliads (Bromeliaceae), and are known from Mexico and Trinidad.

Other species from live bromeliads

\section{COPESTYLUM LOUISAE SP. NOV. HANCOCK \& ROTHERAY}

Diagnosis - male holotype: Face uniform yellow, mostly black haired, upper part of face dusted, sides of face coated in whitish pruinosity leaving a cleared vitta from base of antennae to mouth (view from front), genae also pruniose (oblique view) (Fig. 16); eyes with yellow hairs reaching lower margin; mesonotum metallic greenish-blue with short yellow and long black hairs (side view), when viewed from behind, these hairs form a complex reflective pattern of yellow and dark blotches and vittae; posterior margin of mesonotum with a row of six black bristles; anepisternum with two black bristles, otherwise coated in yellow and black hairs and lightly dusted; scutellum 

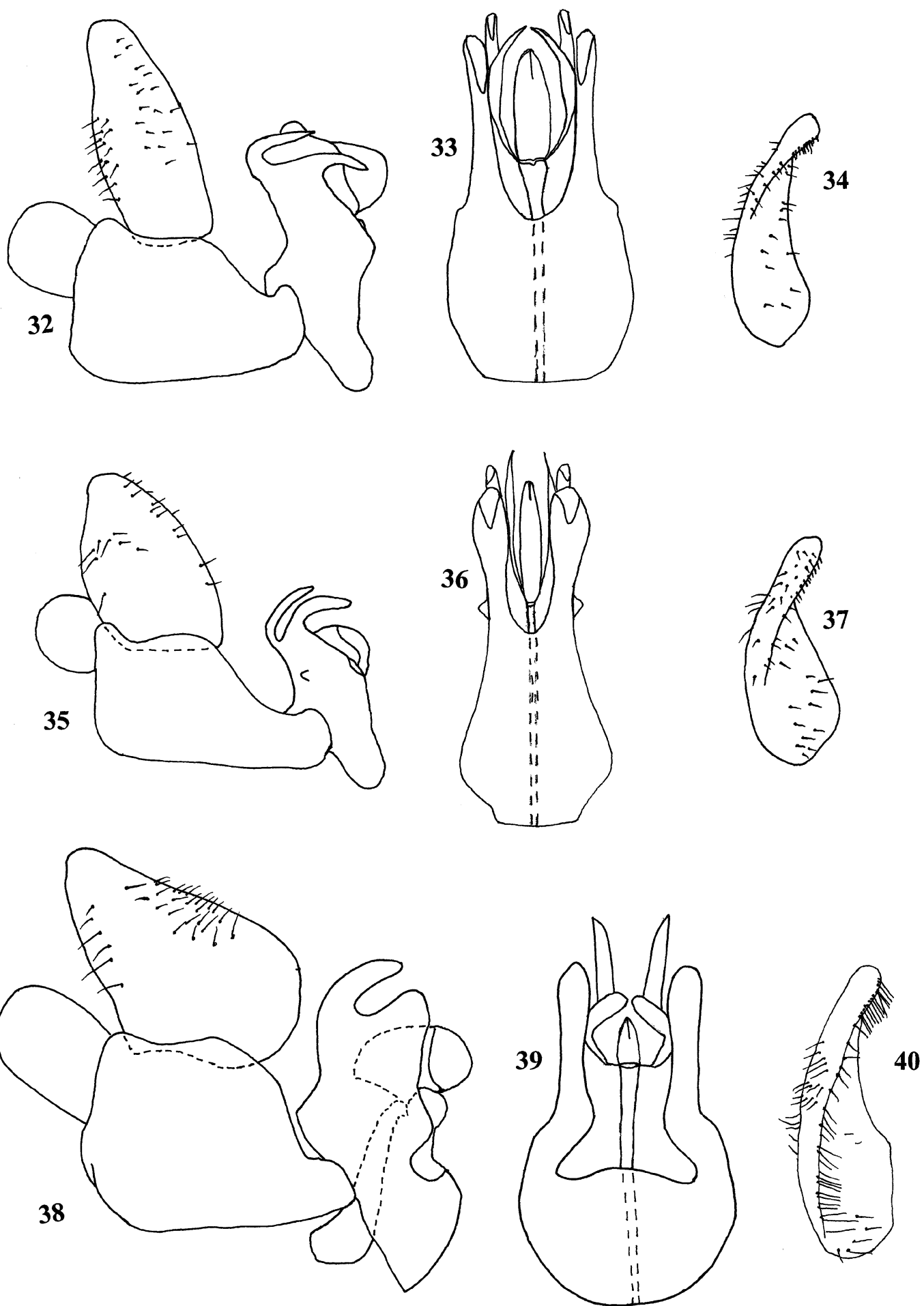

Figures 32-40. Adult Copestylum, male genitalia; right and left-hand figures scale line $=0.50 \mathrm{~mm}$, for middle column figures, left-hand scale line $=0.85 \mathrm{~mm}$. 32-34. Copestylum tacanense sp. nov., male holotype: 32 . genitalia and associated structures, lateral view; 33. epandrium, ventral view; 34. surstylus, ventral view. 35-37. Copestylum tapanti sp. nov., male holotype: 35 . genitalia and associated structures, lateral view; 36. hypandrium, ventral view; 37 . surstylus, ventral view. 38-40. Copestylum volcanorum sp. nov., male holotype: 38. genitalia and associated structures, lateral view; 39. hypandrium, ventral view; 40. surstylus, ventral view. 
yellow with mixed length black hairs and without preapical depression; wings without brown maculae and coated with extensive microtrichia; cell R1 open; abdomen dark brown with white hairs in first and second tergites, and black haired posteriorly; sternites dark yellow; genitalia - surstylus rectangular-shaped with tapered apex; epandrium with projection at point of articulation with hypandrium; hypandrium with windows and superior lobes, and aedeagus spatulate in lateral view, and apically expanded in ventral view (Figs 59, 60, 61); postanal plate bearing well-defined pair of crescentic sclerotized regions; female - abdominal hairs reclined backwards (upright in male); frons dark yellowish with lateral furrows coated with white pruinosity; width of vertex about $12 \%$ of width of head. Length: body, $8.50-9.00 \mathrm{~mm}$; wing, $8.80-10.00 \mathrm{~mm}$ $(N=5)$.

Diagnosis - larva and puparium (Fig. 86): Subcylindrical in cross-section; basal projection bearing antennomaxillary organs smooth; dorsal lip with tuft of setae; lateral lips with spicules basally and long, fine setae apically, not meeting apically; feeding channel (furrow between lateral lips) deep and conspicuous because of large size of lateral lips; thorax broad, wider than abdomen; anterior fold with a band of between seven and nine rows of brown spicules, spicules shortening posteriorly and not reaching sensilla on prothorax; anterior spiracles short, about as long as wide, with six openings across the apex; vestiture of fine, long setae (Fig. 91) coating dorsum and lateral margins of the body, and forming microspicules on the ventral surface; vestiture of prothorax short with long setae intermingled at posterior margin; margins of mesothorax and metathorax without spicules; segmental sensilla on long projections, longer then vestiture, with beween one and eight long, thick, often dark coloured, apical setae and pale, shorter setae at base of projection, apical setae almost as long as transverse folds across the dorsum; mesothoracic prolegs spherical in shape and well developed, with five rows of black-tipped crochets, eight primary crochets central, not so clustered at inner margin of proleg; prolegs on abdominal segments 1-6 spherical, well developed with five curved rows of black-tipped crochets (Fig. 86); sensilla 5-8 of abdominal segments $5-7$, and sensilla 9 of anal segment, on conspicuously elongate, more so than on segments $1-4$, parallel sided, fleshy projections; projections with inconspicuous, fine setae; anal segment extended up to more than 1.5 times as long as the sixth abdominal segment; lappet 1 on dorso-lateral margin of anal segment and much shorter than lappet 2, less then half as long; lappets 2 and 3 on dorso-ventral margin; lappets parallel sided with fine setae; posterior breathing tube long (Fig. 102), about twice width of prothorax, parallel sided, yellow and dark orange to black above indistinct transverse ridge; numerous short spiracular openings arranged round the cuticular scars (Fig. 106); pupal spiracles short, about as long as wide apart, yellow, nodulate basally with openings clustered about widened apex (Fig. 110); head skeleton ventral cornu less than ten times as long as dorsal cornu; dorsal cornu more than half as wide as ventral cornu; dorsal bridge present; sclerotized tentorial bars narrow apically beyond ventral bridge; mandibles and mandibular apodeme as narrow as tentorial bars or narrower.

Material examined - holotype: Male with puparium, British West Indies, Trinidad, Northern Range, Cumaca, 28 July 1998, ex water tank of bromeliad (Bromeliaceae), EGH (NMS).

Material examined - paratypes: One male and four females, as follows: one male and three females with puparia, same data as holotype (NMS); one female with puparium, British West Indies, Trinidad, Northern Range, Simla, 7 July 1996, ex water tank of Gravisia sp. (Bromeliaceae), EGH (HM).

Material examined - additional material: One larva, British West Indies, Trinidad, Northern Range, Lopinot, 6 July 1998, ex water tank of bromeliad, EGH \& GER (NMS).

Etymology: The name 'louisae' is descriptive of the name of one of my daughters (EGH).

Taxonomic notes: On adult characters, C. louisae is most similar to Copestylum cordiae (Townsend, 1897) among a large group of species including Copestylum macquarti (Curran, 1926), Copestylum procteri (Curran, 1939), Copestylum rafaelaneum (Townsend, 1897), Copestylum verdigaster (Hull, 1943), and Copestylum viridigaster (Hull, 1943). All these species share a general appearance, which includes: pointed to squarish, dusted, pruniose, either yellow or black faces, hairy eyes, iridescent and reflective thoracic pile, and a more or less elongate abdomen with large, either yellow or white, paired markings on tergite 2 , and sometimes on tergite 3. C. louisae differs from C. cordiae in having clearer wings, which are yellow infusicated in C. cordiae, and a more yellow abdomen. The early stages of $C$. louisae are distinct among those considered here in having spherically shaped prolegs on abdominal segments 1-6, with black crochets arranged in five curved rows. Spherical not transverse prolegs on segments 1-6 distinguish this species from puyarum, which it otherwise resembles.

Biology: Reared from water tanks of Gravisia sp. and other bromeliads (Bromeliaceae). It is only known from Trinidad. 

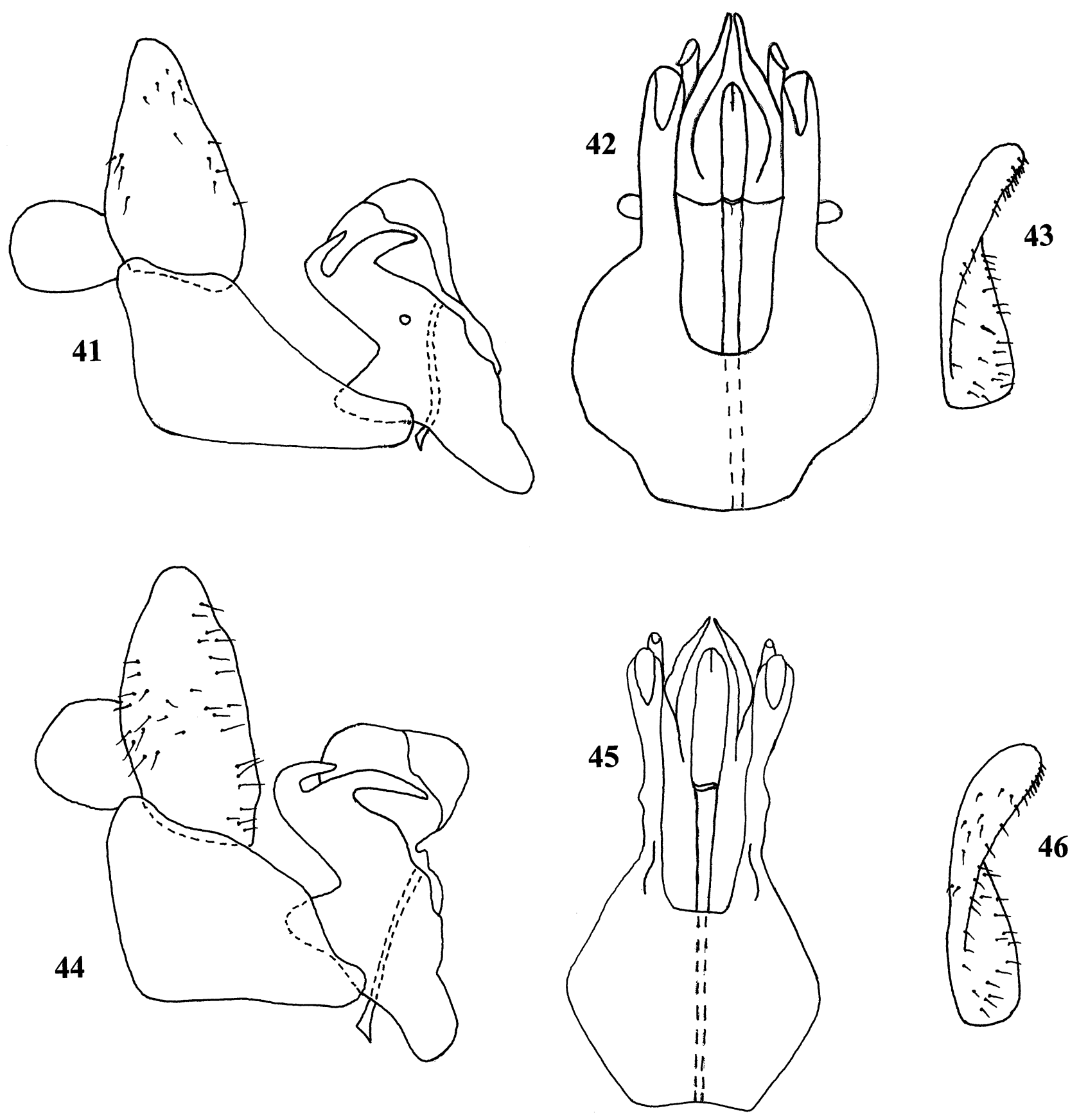

Figures 41-46. Adult Copestylum, male genitalia; right- and left-hand figures scale line $=0.50 \mathrm{~mm}$, for middle column figures, left-hand scale line $=0.85 \mathrm{~mm}$. 41-43. Copestylum barbara sp. nov., male holotype: 41 . genitalia and associated structures, lateral view; 42. hypandrium, ventral view; 43. surstylus, ventral view. 44-46. Copestylum elizabethae sp. nov., male holotype: 44 . genitalia and associated structures, lateral view; 45 . hypandrium, ventral view; 46 . surstylus, ventral view. 

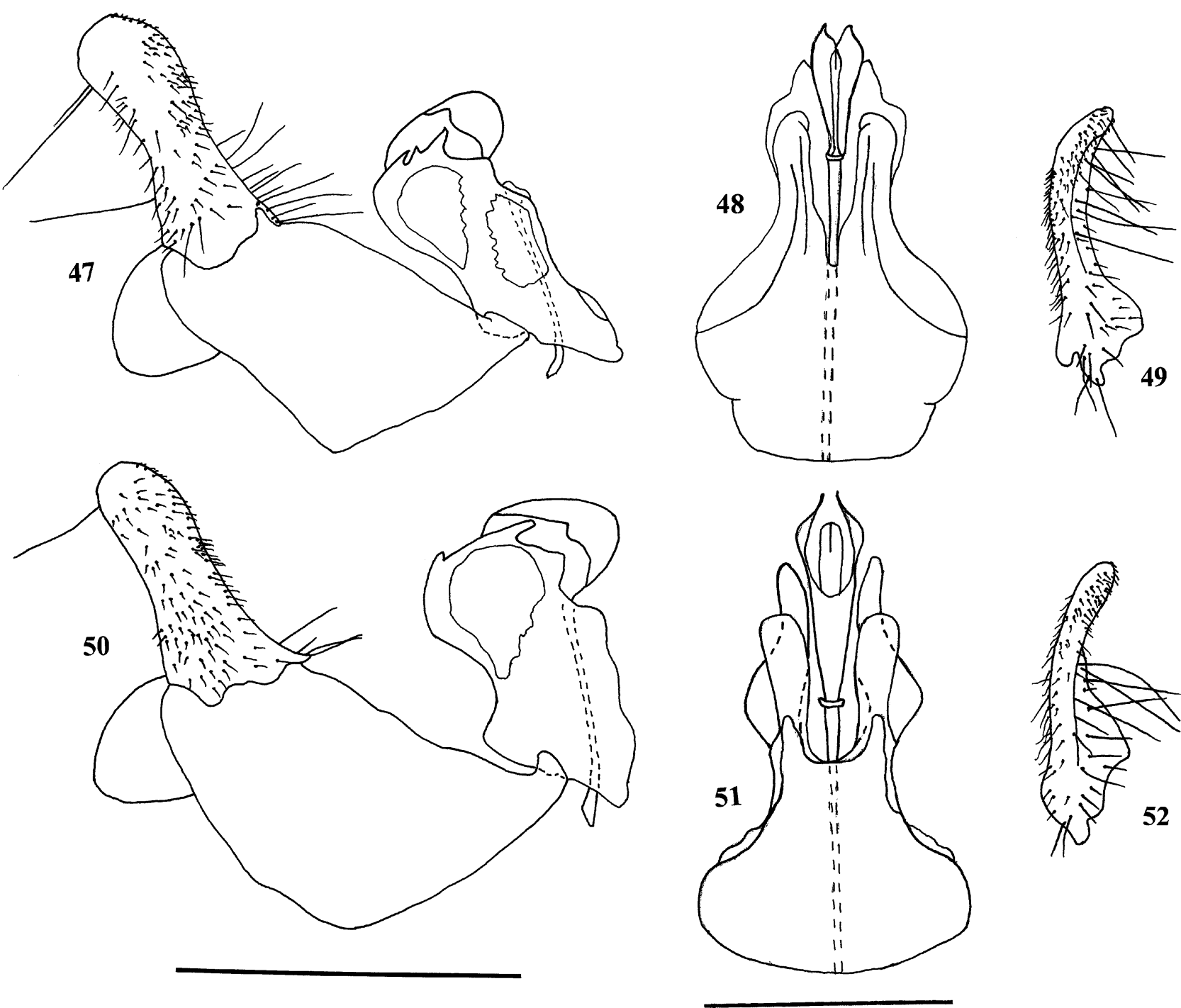

Figures 47-52. Adult Copestylum, male genitalia; right- and left-hand figures scale line $=0.50 \mathrm{~mm}$, for middle column figures, left-hand scale line $=0.85 \mathrm{~mm}$. 47-49. Copestylum boqueronense sp. nov., male holotype: 47. genitalia and associated structures, lateral view; 48. hypandrium, ventral view; 49. surstylus, ventral view. 50- 52. Copestylum triunfense sp. nov., male holotype; 50. genitalia and associated structures, lateral view; 51 . hypandrium, ventral view; 52 . surstylus, ventral view.

\section{COPESTYLUM OTONGAENSIS SP. NOV.} ROTHERAY \& HANCOCK

Diagnosis - male holotype: Face scarcely extended, with gena almost at right angles to the occiput, upper half of the face black and white dusted, lower part yellowish with medial vitta from mouthedge to tubercle, and gena black (Fig. 17); eye hairs black at top of head and orange elsewhere; antenna dark; very long labella; mesonotum mainly black (only the postpronotum and postalar callus are yellowish), with complex pattern of groups and stripes of long, black, reclined hairs, and shorter grey hairs; scutellum black and black haired; wings extensively microtrichose and costal margin darkened, R1 open; legs entirely black and densely black haired; abdomen matt black with grey hairs on tergites 1 and 2 , and extreme margins of tergites 3 and 4, otherwise hairs black on other tergites; sternites with shorter grey hairs and much longer yellowish hairs; genitalia - surstyli square-shaped, about as broad basally as tall with tapered apex; hypandrium broad in ventral view; superior lobes delicate with spinose ventral edge, aedeagus elongate and tube-like (Figs 62, $63,64)$; female - similar to holotype male except eye hairs all orange; hairs on frons black posteriorly reclined; width of vertex about $16.5 \%$ width of head. 
Length: body, 9.50-10.80 mm; wing, 9.50-10.50 mm $(N=7)$.

Diagnosis - larva and puparium: Larva dorso-ventrally flattened (Fig. 82); projections bearing antennomaxillary processes elongate, and joined medially by a lightly sclerotized plate; dorsal lip flat, smooth, and not projecting over the mouth; lateral lips coated in fine setae and touching medially; anterior margin of prothorax highly modified, and deeply bissected to form a pair of long, fleshy, tapering processes bearing sensilla, and coated apically, dorsally, and on the inner margin in setae (Fig. 83); these processes overlying the mouth and the anterior fold; anterior fold coated with transluscent microspicules; lateral margin of mesothorax with two pairs of anteriorly projecting lobes; larger, ventral lobe bearing sensilla 4 and 5 projecting forward each side of the prothorax with a short, out-curved, tapering, apical projection; the smaller dorsal lobe above coated in setae and overlying base of larger, ventral lobe and dorsolateral margin of the prothorax, the anterior spiracles are present but hidden within the space so formed; vestiture - dorsum of abdominal segments 1-6 with three equally wide, transverse bands of backwardly directed microspicules, posterior row of spicules larger than other rows in all three bands, and bands tapering and not reaching lateral margins; integument smooth and clear between these bands; bands absent on abdominal segment 7 and anal segment, but dorso-lateral margins of these segments with numerous groups of larger spicules; dorsum of mesothorax and metathorax smooth and clear of vestiture; lateral margins of metathorax and abdominal segments 1-7 from sensilla 3 on the dorsum almost to sensilla $7 / 8$ on the ventral surface coated with dark, blotch-like papillae, and with a narrow band of spicules and setae about sensilla 5 and 6; lateral margin of metathorax with one lobelike extension bearing sensilla 5 and 6 , these lobes, plus an additional smaller, anterior lobe without sensilla, continuing on abdominal segments $1-7$ so that the larva appears to have a marginal band; margin of anal segment with spicules; lappet 1 reduced to sensilla and setae; lappets 2 and 3 on margin of segment and apex with hook-like projections; mesothoracic prolegs small with up to 12 crochets; prolegs on abdominal segments 1-4 only, absent on segments 5 and 6, small and inconspicuous with up to five each of primary and secondary crochets; ventral surface of metathorax and abdominal segments 1-6 with almost continuous coating of rows of microspicules, except for intersegmental boundaries; ventral surface of abdominal segment 7 smooth, lacking spicules; ventral surface of anal segment with medial groups of larger spicules; posterior breathing tube dorso-ventrally flattened (Fig. 100), orange, corrugated at base, smooth and shiny above; numerous, short spiracular openings round the margin of the spiracular plates (Fig. 104); pupal spiracles yellow and elongate, being longer than the distance apart, slightly curved with spiracular openings to halfway point (Fig. 108); head skeleton (Fig. 94) - dorso-ventrally flattened; area where dorsal and ventral cornu joined elongate, longer than ventral cornu and sclerotized black; ventral cornu less than ten times as long as dorsal cornu; dorsal cornu narrow and sclerotized black, about half as wide as ventral cornu; dorsal bridge present; sclerotized tentorial bars narrow apically beyond ventral bridge; mandibles wider and mandibular apodeme as narrow as tentorial bars.

Material examined - holotype: Male with puparium, Ecuador, Pinchincha, Otonga Reserva, 21-26 August 2000, ex water tanks of Bromeliaceae, EGH \& GER (PUCE).

Material examined - paratypes: Three males and three females with puparia, same data as holotype (NMS).

Material examined - additional material: One larva, same data as holotype (NMS).

Etymology: The name 'otongaensis' is in reference to the type locality in Ecuador, Otonga, near Quito.

Taxonomic notes: This is a highly distinctive and remarkable species distinguished in the adult stage by the shape of the face, overall black colour of the thorax and abdomen, and the setulate superior lobes in the male genitalia, and in the larval stage, by the extreme dorso-ventral flattening, which includes the head skeleton, posterior breathing tube, and the bissected prothorax. In addition, C. otongaensis appears distinct among other species of Copestylum. It has a general similarity to Copestylum fumosum (Hull, 1943) described from Mount Roraima in north-east Brazil. Both species are black and have legs coated densely in setae. However C. fumosum has maculae on the wings, a longer face, and longer antennae that are yellow at the base.

Like the tank group, the larva of $C$. otongaensis has a marginal band, but the lobes are neither as developed nor separated from the body by integumental folds. Two additional samples of preserved larvae similar to C. otongaensis were studied. They were not reared to the adult stage. Three larvae were collected by parataxonomist D. Gutiérrez from live bromeliads in Costa Rica (JDG.057), and four larvae were collected from live bromeliads by J. Louton at Esperanza, Cuzco, Peru, in June 1993. Differences between these larvae suggest they belong to separate species. The 

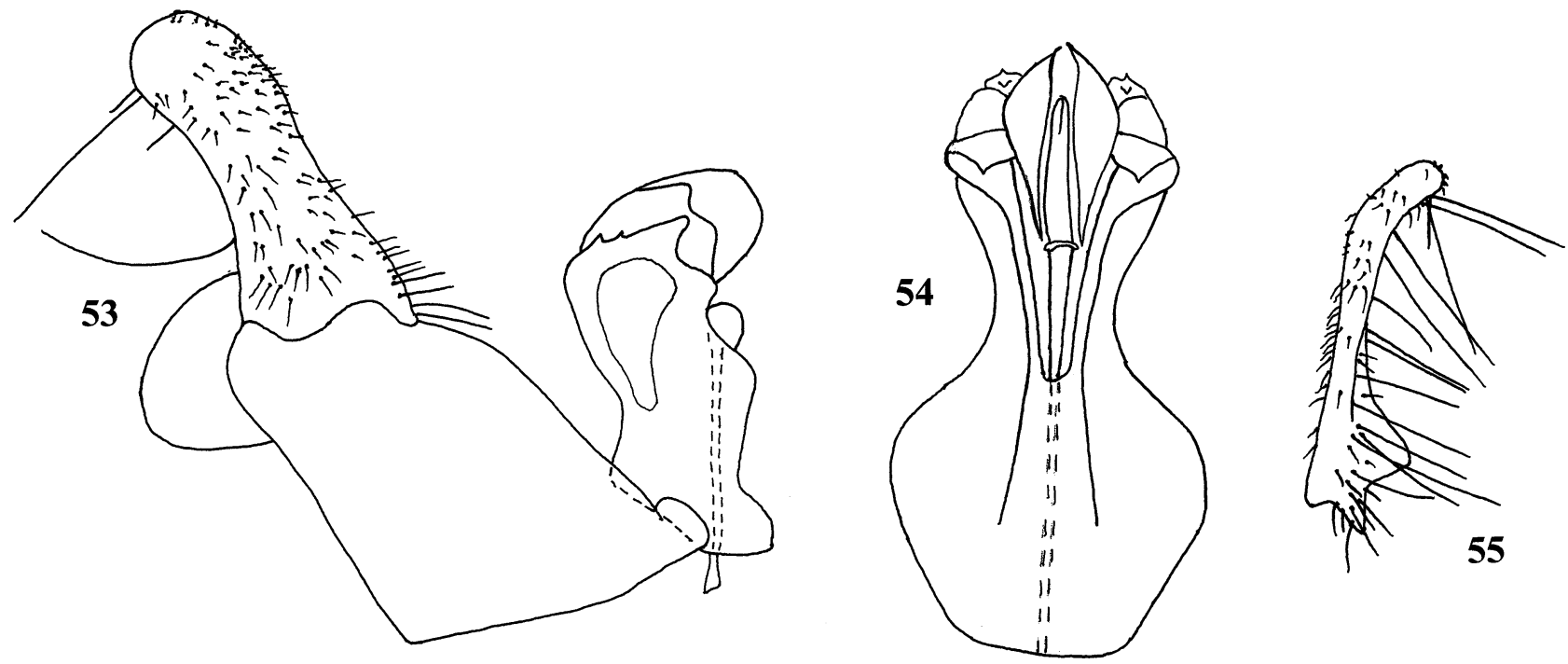

Figures 53-55. Adult Copestylum unamas sp. nov., male holotype, male genitalia; right-hand scale line = $0.50 \mathrm{~mm}$, for left and right column figures; left-hand scale line $=0.85 \mathrm{~mm}$, for middle figure. 53 . genitalia and associated structures, lateral view; 54. hypandrium, ventral view; 55. surstylus, ventral view.
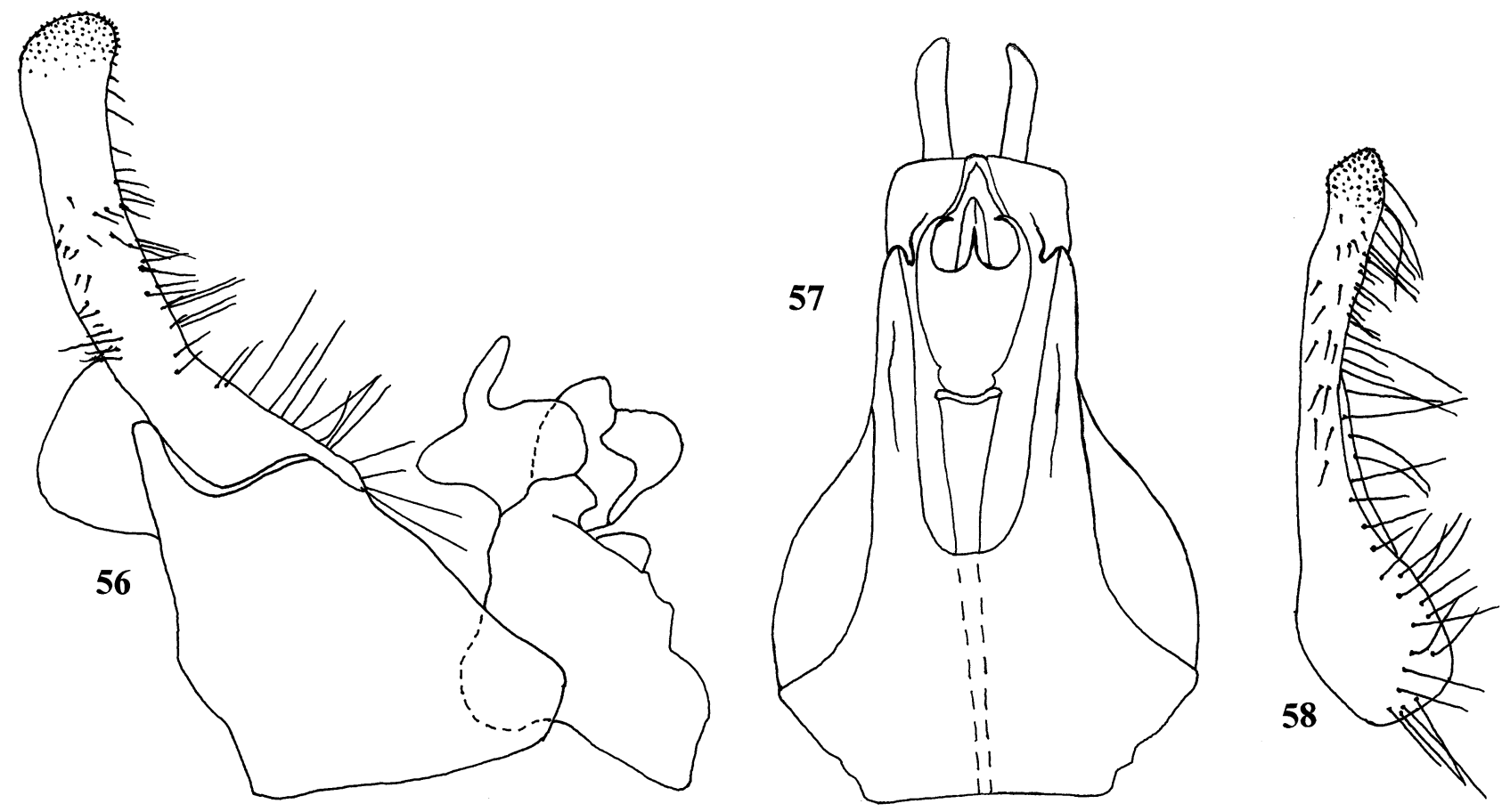

Figures 56-58. Adult Copestylum joei sp. nov., male holotype, male genitalia; right-hand scale line $=0.50 \mathrm{~mm}$, for left and right column figures; left-hand scale line $=0.85 \mathrm{~mm}$, for middle figure. 56-58. C. joei sp. nov., male holotype: 56 . genitalia and associated structures, lateral view; 57. hypandrium, ventral view; 58 . surstylus, ventral view. 
larvae from Peru are separated from the others by having spicules, not setae, coating the lobes of the marginal band. The larvae from Costa Rica are similar to $C$. otongaensis in having setae coating the lobes of the marginal band, but, in addition, the larva of C. otongaensis has blotches.

Biology: Adults were reared from larvae in water tanks of epiphytic bromeliads (Bromeliaceae), and are known only from Ecuador, but similar larvae of related but different species were studied from Costa Rica and Peru.

\section{Copestylum species reared from decaying bromeliads}

\section{Boqueronense group}

Diagnosis-adult: Face wide with tubercle barely projecting, so that, in side view, the face appears almost straight from below antennae to mouth, face elongate so that length of face from lower eye margin to edge of mouth half length or more of length of eye (view from side); face dusted below antennae; central vitta variable in length and brightness, but always present; genae with black markings; mesonotum with mixed length setae and prescutellar bristles; scutellar depression and apical ridge absent; wings with sharply defined brown maculae and extensive microtrichia; abdomen either with extensive yellow bands or black; genitalia - surstyli narrow and elongate with some very long setae, particularly on the inside surface, longer than width of the surstylus; epandrium rectangular-shaped, almost as long as basally broad, and projection at point of articulation with the hypandrium not developed; hypandrium with windows; superior lobes broad and flat apically with a distal hook and either one or two teeth on the apical margin; apex of aedeagus large and well developed, about as wide apically as width of hypandrium.

Diagnosis - larva and puparium: Basal projection bearing antennomaxillary organs nodulate; dorsal lip without tuft of setae; lateral lips with spicules basally, and long, fine setae apically, not meeting apically; feeding channel not deep because of small size of lateral lips; thorax broad, wider than abdomen (Fig. 84); anterior fold with a band of between seven and nine rows of pale, brown-tipped spicules, spicules shortening posteriorly and reaching anterior sensilla 3 of prothorax; anterior spiracles short, about as long as wide with either three or four openings across the apex; vestiture of short, upright setae coating dorsum and lateral margins of the body (Fig. 90), setae shorter between folds and forming microspicules on the ventral surface; vestiture of prothorax without longer setae at posterior margin; large spicules along the longitudinal folds of the prothorax; lateral margin of mesothorax with a pair of large, conspicuous brown hooks sharing the same sclerotized basal plate, margin of basal plate with tiny hooks; lateral margin of metathorax with one hook, as large as those on the mesothorax (Fig. 85); antero-ventral margin of metathorax with two groups of up to four large spicules; segmental sensilla on short projections, about as long as vestiture, with between one and five thick, pale coloured, apical setae; these setae much shorter than transverse folds across the dorsum; mesothoracic prolegs commashaped with two rows of brown crochets; either four or five primary crochets clustered at inner end of proleg; prolegs only on abdominal segments 1-5 and much less developed on segments 4 and 5; transverse in shape with three straight rows of brown crochets; sensilla 5-8 of abdominal segments 5-7, but not sensilla 9 of anal segment, on particularly elongate, more so than segments $1-4$, fleshy projections; projections tapering and coated in inconspicuous fine setae; abdominal segment 7 and anal segment tapering, and extended up to more than 1.5 times as long as sixth abdominal segment; lappet 1 on dorso-lateral margin of anal segment and barely projecting, lappet 2 , more than four times as long; lappets 2 and 3 on mid-lateral margin; lappets tapering and coated in inconspicuous fine setae; posterior breathing tube long, about 1.25 times width of prothorax, parallel sided, orange, shiny with light punctures above transverse ridge; three pairs of sinusoidal spiracular openings; pupal spiracles long, longer than distance apart, yellow, slightly curved, shiny, nodulate basally with openings close to base, below halfway point, not widened; head skeleton (Fig. 95) - ventral cornu less than ten times as long as dorsal cornu; dorsal cornu more than half as wide as ventral cornu; dorsal bridge present; sclerotized tentorial bars narrow apically beyond ventral bridge; mandibles and mandibular apodeme either as narrow as tentorial bars or narrower.

Taxonomic notes: This group is named after the first species reared. On adult characters the boqueronense group is similar to such species as Copestylum brunnigaster (Hull, 1943), Copestylum melleum (Jaennicke, 1867), and Copestylum pubescens (Loew, 1861) in being large with dusted faces, thoracic pile of mixed size, prescutellar bristles present and usually with extensively, yellow-marked abdomens. The boqueronense group differ from these species by their wide, flattened faces. The larvae have an elongate anal segment, lateral sensilla on abdominal segments 5-7 on long, fleshy tapering projections, and prolegs only on the first four or five abdominal segments, not on the first six, and are easily distinguished by the possession of large hooks on the lateral margins of the thorax.

Boqueronense species breed in decaying bromeliads and all four species we reared are from Mexico. However, we encountered similar hook-bearing larvae, but 

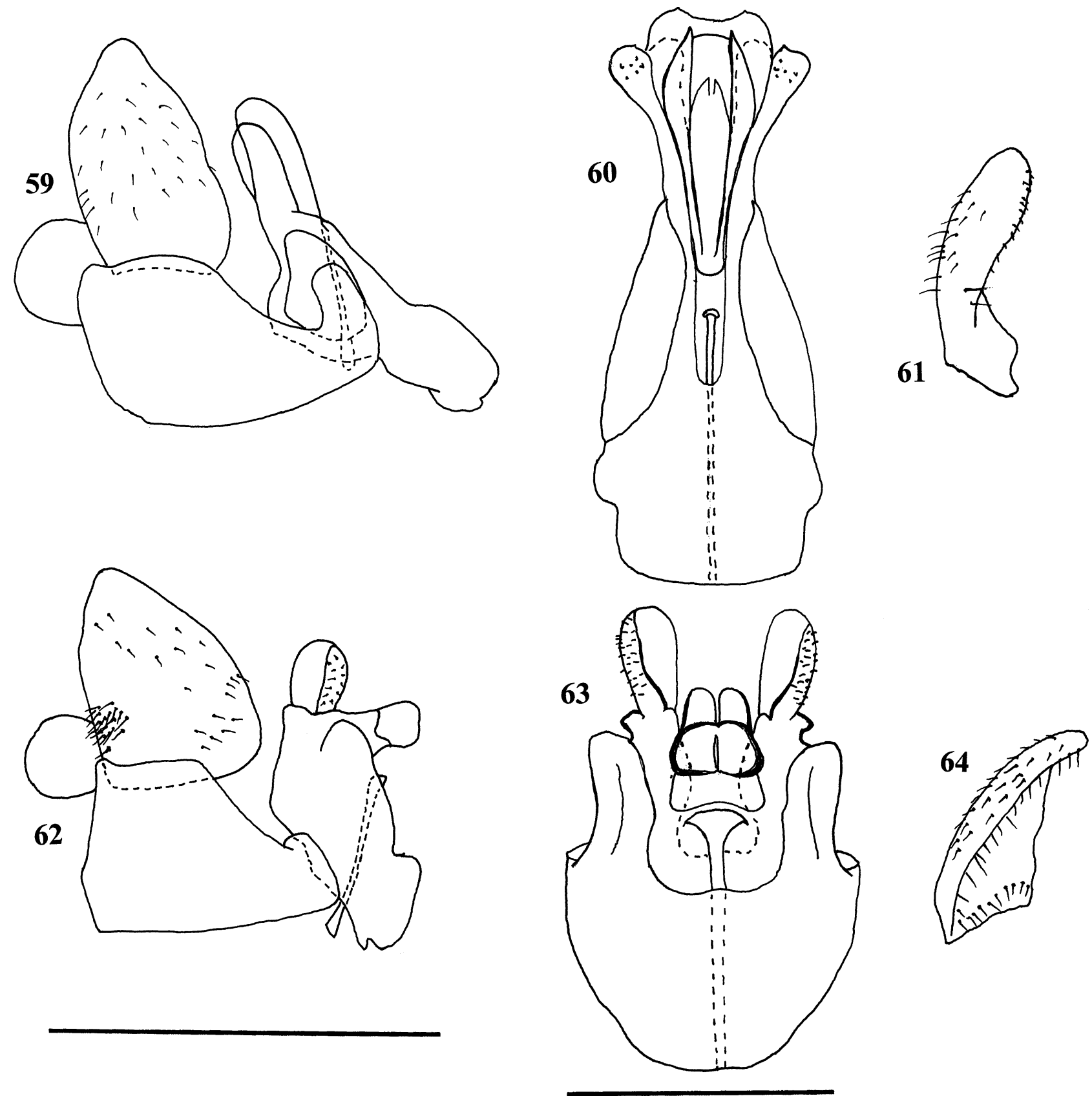

Figures 59-64. Adult Copestylum, male genitalia; right- and left-hand figures scale line $=0.50 \mathrm{~mm}$, for middle column figures, left-hand scale line $=0.85 \mathrm{~mm}$. Copestylum louisae sp. nov., male holotype: 59. genitalia and associated structures, lateral view; 60. hypandrium, ventral view; 61. surstylus, ventral view. 62-64. Copestylum otongaensis sp. nov., male holotype: 62. genitalia and associated structures, lateral view; 63 . hypandrium, ventral view; 64. surstylus, ventral view.

did not rear them, from decaying bromeliads in Bolivia, Ecuador, and Honduras.

\section{COPESTYLUM BOQUERONENSE SP. NOV. ROTHERAY \& MARCOS-GARCÍA}

Diagnosis-male holotype: Face with central vitta coated in black hairs and clearly reaching tubercle, only vague and indistinct from above to base of antennae; cheeks coated in dust and pruinosity; genae with black vittae and upper half coated in pruinosity (Fig. 11); eyes coated with black hairs; mesonotum dark with yellow lateral vittae and posterior margin with a triangular yellow spot; hairs of mixed length; yellow hairs anteriorly and black hairs posteriorly; 
four prescutellar bristles present; one black bristle on yellowish posterior anepisternum; pleurites dark; scutellum yellow with mixed length hairs; band of yellow hairs basally, otherwise black haired; legs black except for yellow marked tarsi, apex of femora, and anterior tibia; legs black haired except for yellow hairs on the ventral surface of the tarsi; abdomen yellow except tergite 4 fuscous; tergites 1 and 2 mostly yellow haired with posterior band of black hairs, and rest of abdomen black haired with hairs becoming gradually longer towards apex; sternite 1 black, sternites 2 and 3 yellow with yellow hairs; sternite 4 black covered with black hairs; genitalia - apical margin of superior lobes with tapering distal hook and two teeth behind, with deep gap between these teeth; epandrium with two pairs of windows (Figs 47, 48, 49); female - frons darker than face and black haired with three longitudinal furrows; width of vertex about $19 \%$ of width of head. Length: body, 11.30-12.00 mm; wing, $10.00 \mathrm{~mm}$ $(N=3)$.

Puparium: anterior fold with a band of pale, browntipped spicules, spicules shortening posteriorly and reaching anterior sensilla 3 of prothorax; anterior spiracles as long as wide with either three or four apical openings; vestiture of stout, upright setae on dorsum and lateral margins of the body, setae forming microspicules on the ventral surface; larger spicules on the longitudinal folds of the prothorax; lateral margin of mesothorax with a pair of large, conspicuous brown hooks sharing the same sclerotized basal plate, margin of basal plate with tiny hooks; lateral margin of metathorax with one hook, as large as those on the mesothorax; antero-ventral margin of metathorax with two groups of up to four large spicules; segmental sensilla on short projections, about as long as vestiture, with between one and five thick, pale coloured, apical setae; sensilla 5-8 of abdominal segments 5-7 on longer fleshy projections than these sensilla on segments 1-4; projections tapering and coated in inconspicuous fine setae; abdominal segment 7 and anal segment tapering, and extended to about 1.5 times as long as abdominal segment 6 ; posterior breathing tube punctate above the transverse ridge and wider than the width of the pupal spiracles; posterior breathing tube short, not as long as width of the puparium.

Material examined - holotype: Male with puparium, Mexico, Chiapas State, Boquerón, 19 April 2002, ex fallen decaying bromeliad (Bromeliaceae), GER \& MAM (NMS).

Material examined-paratypes: One male and two females with puparia, same data as holotype (CIBIO, one female NMS).

Etymology: The name of this species is descriptive of the name of the locality in Chiapas State, Mexico, where it was collected, Cerro Boquerón.
Taxonomic notes: Adult similar to other boqueronense group species. In the adult the main differences are in the face, with a vague central vitta, which is also present in C. mamorum. Other boqueronense group species have a clear and distinct black central vitta. C. boqueronense differs from C. mamorum in having black, not yellow, hairs on the face, mesonotum without vittae, and black-haired tergites 3 and 4 . The larva is very similar to other boqueronense group species. The main difference is in the posterior breathing tube that is punctate above the transverse ridge, and wider than the width of the pupal spiracles. The posterior breathing tube is also punctate in C. mamorum, but in that species it is narrower, only about as wide as the pupal spiracles. The posterior breathing tube is also short in boqueronense, being less than the width of the puparium. In C. mamorum it is longer than the width of the puparium.

Biology: Reared from larvae found in a fallen, decaying bromeliad (Bromeliaceae).

\section{COPESTYLUM MAMORUM SP. NOV. ROTHERAY \& MARCOS-GARCÍA}

Diagnosis - female holotype: Face with vague central vitta and coated in yellow hairs; cheeks coated in dust and pruinosity; genae with dark vittae and coated in pruinosity (Fig. 12); frons darker than face with black hairs medially; eyes coated in yellow hairs; mesonotum with black and yellow vittae, without a triangular yellow spot on the posterior margin; hairs of mixed length; yellow hairs anteriorly, and black and yellow hairs posteriorly; six prescutellar bristles present; one black bristle on yellowish posterior anepisternum; pleurites dark; scutellum yellow with mixed length hairs; band of yellow hairs basally, otherwise black haired; legs yellow except for base of femorae and midsection of hind tibiae; legs black haired except for yellow hairs on the ventral surface of the tarsi and posterior margin of mid-tibiae; abdomen yellow except for dark posterior margins of tergites 2 and 3; tergite 4 fuscous; tergite 1 yellow haired, tergites 2-4 yellow haired anteriorly and black haired posteriorly; hairs becoming gradually longer from tergite 2-4; sternites 1-3 yellow with yellow hairs; sternite 4 fuscous with black hairs; male unknown. Length: body, $12 \mathrm{~mm}$; wing, $10 \mathrm{~mm}(N=2)$.

Diagnosis - puparium: Anterior fold with a band of pale, brown-tipped spicules, spicules shortening posteriorly and reaching anterior sensilla 3 of prothorax; anterior spiracles as long as wide with either three or four apical openings; vestiture of stout, upright setae on dorsum and lateral margins of the body, setae forming microspicules on the ventral surface; larger spicules on the longitudinal folds of the prothorax; lateral 

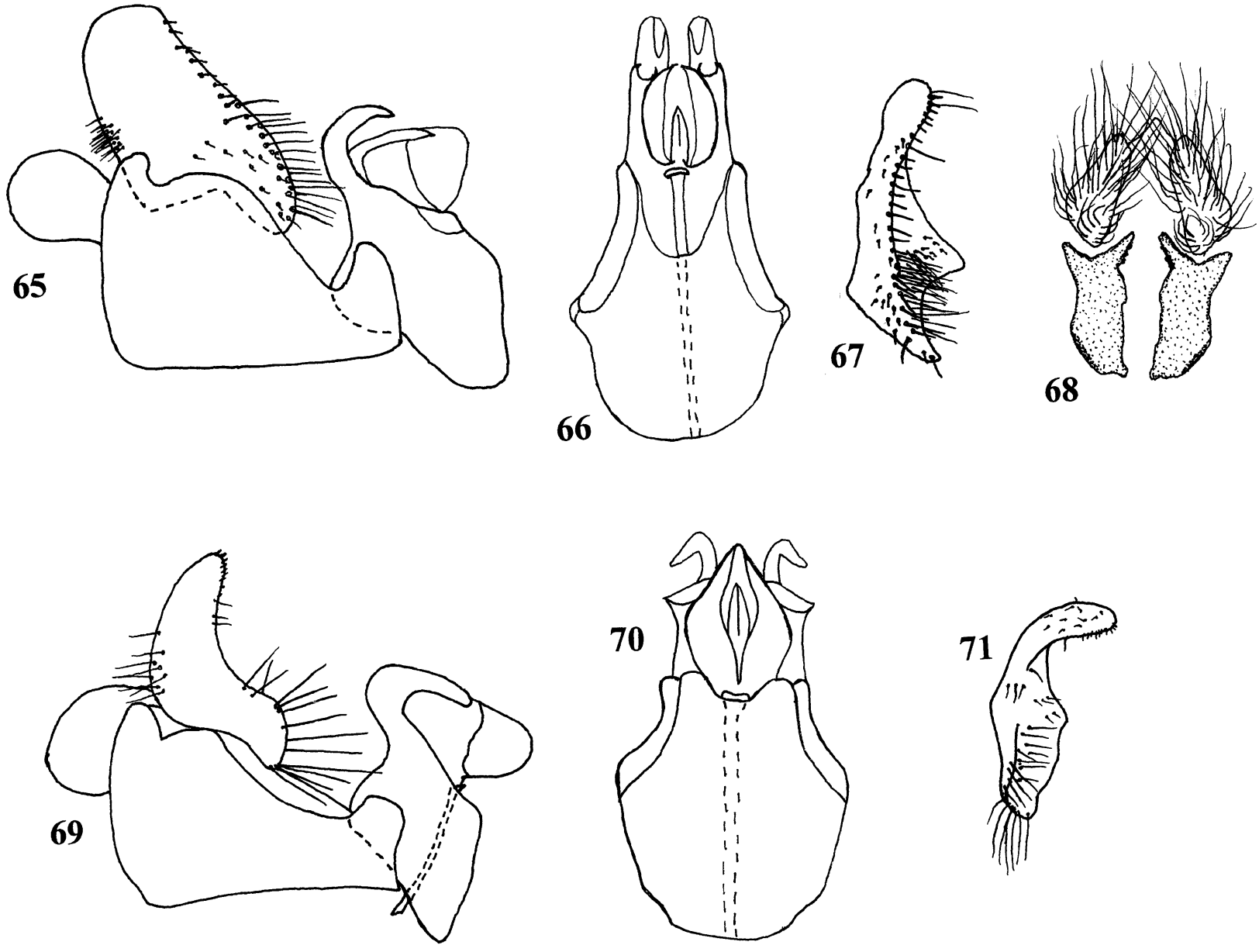

68
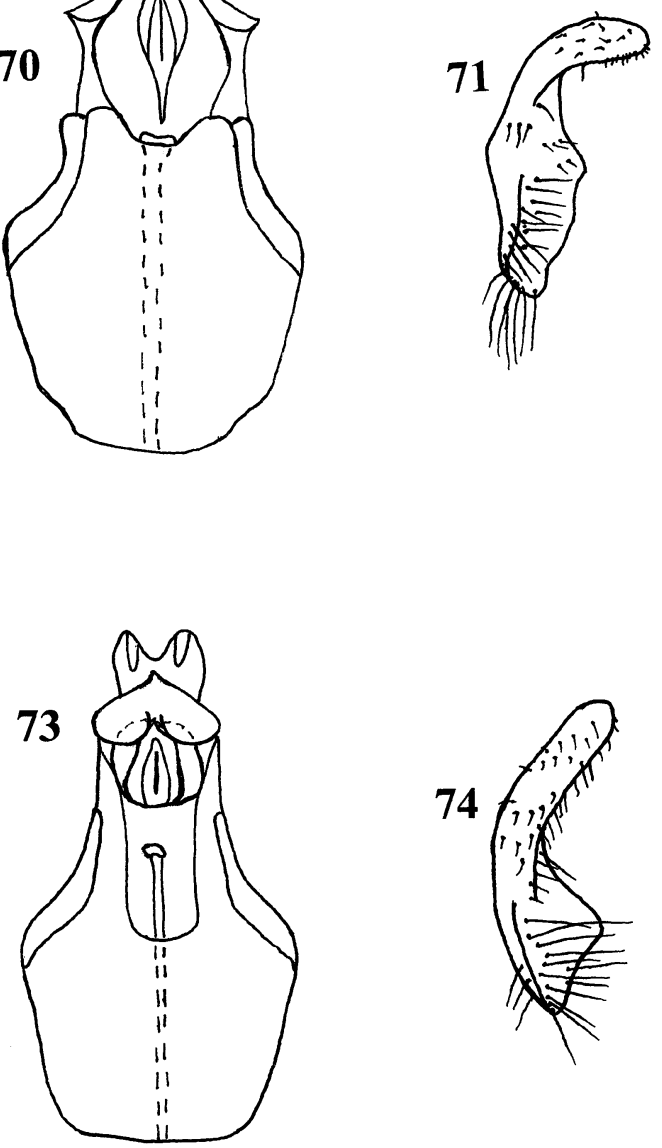

Figures 65-74. Adult Copestylum, male genitalia; right- and left-hand figures scale line $=0.50 \mathrm{~mm}$, for middle column figures, left-hand scale line $=0.85 \mathrm{~mm} .65-68$. Copestylum albertoi sp. nov., male holotype: 65 . genitalia and associated structures, lateral view; 66. hypandrium, ventral view; 67. surstylus, ventral view, 68. postanal plate, ventral view. 69-71. Copestylum conabioi sp. nov., male holotype: 69. genitalia and associated structures, lateral view; 70. hypandrium, ventral view; 71. surstylus, ventral view. 72-74. Copestylum tapia sp. nov., male holotype: 72. genitalia and associated structures, lateral view; 73. hypandrium, ventral view; 74. surstylus, ventral view. 
margin of mesothorax with a pair of large, conspicuous brown hooks sharing the same sclerotized basal plate, margin of basal plate with tiny hooks; lateral margin of metathorax with one hook, as large as those on the mesothorax; antero-ventral margin of metathorax with two groups of up to four large spicules; segmental sensilla on short projections, about as long as vestiture, with between one and five thick, pale coloured, apical setae; sensilla 5-8 of abdominal segments 5-7 on longer fleshy projections than these sensilla on segments 1-4; projections tapering and coated in inconspicuous fine setae; abdominal segment 7 and anal segment tapering, and extended to about 1.5 times as long as abdominal segment 6; posterior breathing tube punctate above the transverse ridge, as wide as the width of a pupal spiracle; posterior breathing tube elongate, more than the width of the puparium.

Material examined-holotype: Female with puparium, Mexico, Chiapas, Boquerón, 18 July 2003, ex fallen decaying bromeliad (Bromeliaceae), GER (NMS).

Material examined-paratype: Female with puparium, same data as holotype (NMS).

Etymology: The name of this species is descriptive of the name of the ethnic population living at the type locality, Boquerón, in Chiapas State, Mexico.

Taxonomic notes: Adult and larva similar to other boqueronense group species. In the adult the main differences are in the face with a vague central vitta, which is also present in C.boqueronense. Other boqueronense group species have a clear and distinct black vitta. C. mamorum differs from $C$. boqueronense in having yellow, not black, hairs on the face, vittae on the mesonotum, and tergites 3 and 4 with a band of yellow hairs anteriorly. The puparium can be distinguished by features of the posterior breathing tube that is punctate above the transverse ridge, and is only as wide as the width of a pupal spiracle. The posterior breathing tube is also punctate in C. boqueronense, but in that species it is wider than the pupal spiracles. The posterior breathing tube is also long in C. mamorum, being more than the width of the puparium. In C. boqueronense it is shorter than the width of the puparium.

Biology: Reared from larvae found in a fallen, decaying bromeliad (Bromeliaceae).

\section{COPESTYLUM TRIUNFENSE SP. NOV. HANCOCK}

Diagnosis - male holotype: Face yellow with black hairs; clear and distinct, black, central vitta reaching from mouth to base of antennae; cheeks shiny with inconspicuous dust and pruinosity (Fig. 13); frons yellow with black marked medially; genae with black vit- tae and upper half coated in pruinosity; eyes coated with black hairs; mesonotum and scutellum black without yellow vittae or marks; hairs of mixed length; yellow hairs anteriorly and black hairs posteriorly; six prescutellar bristles present; one black bristle on dark posterior anepisternum; pleurites dark; legs black with black hairs; abdomen black and black haired with hairs becoming gradually longer towards apex; genitalia - apical margin of superior lobes with blunttipped distal hook and one tooth; epandrium with one pair of windows (Figs 50, 51, 52); female - unknown. Length: body, $10 \mathrm{~mm}$; wing, $9 \mathrm{~mm}(N=1)$.

Diagnosis - larva and puparium (Fig. 84): anterior fold with a band of pale, brown-tipped spicules, spicules shortening posteriorly and reaching anterior sensilla 3 of prothorax (Fig. 85); anterior spiracles as long as wide with either three or four apical openings; vestiture of stout, upright setae on dorsum and lateral margins of the body, setae forming microspicules on the ventral surface; larger spicules on the longitudinal folds of the prothorax; lateral margin of mesothorax with a pair of large, conspicuous brown hooks sharing the same sclerotized basal plate (Fig. 85), margin of basal plate with tiny hooks; lateral margin of metathorax with one hook, as large as those on the mesothorax; antero-ventral margin of metathorax with two groups of up to four large spicules; segmental sensilla on short projections, about as long as vestiture, with beween one and five thick, pale coloured, apical setae; sensilla 5-8 of abdominal segments 5-7 on longer fleshy projections than these sensilla on segments 14; projections tapering and coated in inconspicuous fine setae; abdominal segment 7 and anal segment tapering and extended to about 1.5 times as long as abdominal segment 6; posterior breathing tube smooth and shiny at the apex with, at most, only vague indications of punctures; posterior breathing tube widening towards base and wider than a pupal spiracle.

Material examined - holotype: Male with puparium, Mexico, Chiapas State, El Triunfo Biosfere Reserve, 30 July 2003, ex fallen decaying bromeliad (Bromeliaceae), EGH (HM).

Material examined - additional material: Three larvae, same data as holotype but collected by EGH 29 July 2003 (NMS).

Etymology: The name 'triunfense' is descriptive of the type locality, El Triunfo Biosfere Reserve, in Chiapas State, Mexico.

Taxonomic notes: The completely black abdomen, mesonotum, and legs distinguish the adult of this species from other boqueronense group species. The male genitalia are also distinct, particularly in the one tooth on the apical margin of the hypandrium. Early 

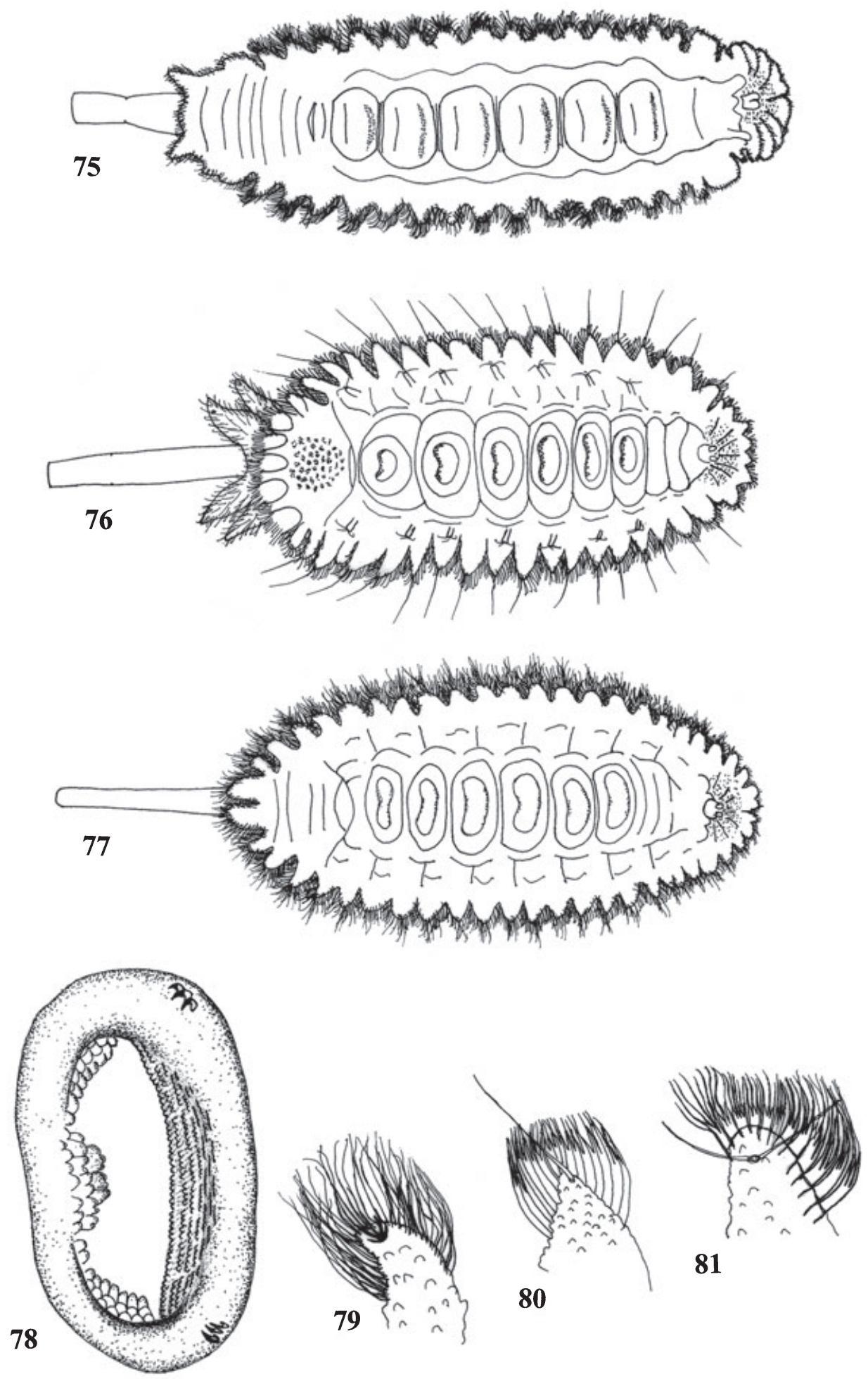

Figures 75-81. Third stage larvae of Copestylum. 75. Copestylum oscillans, whole larva, head to the right, ventral view, length $=11 \mathrm{~mm}$. 76. Copestylum carlosii, whole larva, head to the right, ventral view, length $=10 \mathrm{~mm}$. 77 . Copestylum elizabethae, whole larva, head to the right, ventral view, length $=11 \mathrm{~mm}$. 78. Copestylum carlosii, sucker from 4 th abdominal segment, anterior end to the right, ventral view, width $=1 \mathrm{~mm}$. 79. Copestylum oscillans, marginal lobe from 3rd abdominal segment, dorsal view, width $=0.35 \mathrm{~mm}$. 80. Copestylum carlosii, marginal lobe from 3rd abdominal segment, dorsal view, width $=0.35 \mathrm{~mm}$. 81. Copestylum elizabethae, marginal lobe from 3rd abdominal segment, dorsal view, width $=0.35 \mathrm{~mm}$. 
stages are very similar to other boqueronense group species. The main difference is in the posterior breathing tube, which is smooth and shiny at the apex with, at most, only vague indications of punctures. Only Copestylum unamas has a similar shiny apex to the posterior breathing tube. C. triunfense differs from $C$. unamas in that the posterior breathing tube widens basally and is wider than the pupal spiracles. In unamas the posterior breathing tube is parallel sided and about as wide as the pupal spiracles.

Biology: Reared from a larva found in a fallen, decaying bromeliad (Bromeliaceae).

\section{COPESTYLUM UNAMAS SP. NOV.} HANCOCK \& ROTHERAY

Diagnosis - male holotype: Face yellow with yellow and black hairs; clear and distinct, black, central vitta reaching from mouth to base of antennae; cheeks shiny with inconspicuous dust and pruinosity (Fig. 14); frons dark yellow and black haired; genae with black vittae and upper half coated in pruinosity; eyes coated with mostly black hairs, some yellow hairs on the posterolateral margins; mesonotum with yellow lateral vittae and triangular mark on posterior margin; hairs of mixed length; yellow hairs anteriorly and black hairs posteriorly; six prescutellar bristles present; scutellum yellow with hairs of mixed length, yellow hairs at base, black elsewhere; one black bristle on dark posterior anepisternum; pleurites dark; legs with femorae black except at apex; tibiae yellow at base, otherwise black; tarsi yellow; legs black haired, except yellow on ventral surface of tarsi; abdomen with tergite 1 black and tergites 2-4 yellow with black apical band; tergites 1 and 2 with yellow hairs anteriorly and black hairs on posterior margin; tergites 3 and 4 black haired, with hairs becoming gradually longer towards the apex; sternite 1 black and black haired; sternites 2 and 3 yellow and yellow haired, except black hairs on posterior margins; sternite 4 yellow and yellow haired only at base, otherwise black; genitalia - apical margin of superior lobes with blunt-tipped distal hook and two teeth not separated by a groove; epandrium with one pair of windows (Figs 53, 54, 55); female unknown. Length: body, $10 \mathrm{~mm}$; wing, $9 \mathrm{~mm}(N=1)$.

Diagnosis - larva and puparium: Anterior fold with a band of pale, brown-tipped spicules, spicules shortening posteriorly and reaching anterior sensilla 3 of prothorax; anterior spiracles as long as wide with either three or four apical openings; vestiture of stout, upright setae on dorsum and lateral margins of the body, setae forming microspicules on the ventral surface; larger spicules on the longitudinal folds of the prothorax; lateral margin of mesothorax with a pair of large, conspicuous brown hooks, sharing the same sclerotized basal plate, margin of basal plate with tiny hooks; lateral margin of metathorax with one hook, as large as those on the mesothorax; antero-ventral margin of metathorax with two groups of up to four large spicules; segmental sensilla on short projections, about as long as vestiture, with between one and five thick, pale coloured, apical setae; sensilla 5-8 of abdominal segments 5-7 on longer fleshy projections than these sensilla on segments 1-4; projections tapering and coated in inconspicuous fine setae; abdominal segment 7 and anal segment tapering, and extended to about 1.5 times as long as abdominal segment 6; posterior breathing tube smooth and shiny at the apex and parallel sided, not widening towards base, and about as wide as a pupal spiracle.

Material examined - holotype: Male with puparium, Mexico, Chiapas State, El Triunfo Biosfere Reserve, July 2003, ex fallen decaying bromeliad (Bromeliaceae), EGH (HM).

Etymology: The name of this species is taken from the Spanish words 'una mas', meaning more than one, because just when we had thought we had finished, we always seemed to discover yet another new species.

Taxonomic notes: The adult of C. unamas is similar to C. triunfense in having a clear and distinct central vitta between the mouth and the base of the antennae. It differs from that species in having a yellow abdomen and yellow marks on the mesonotum. The form of the male genitalia is also distinct in having two teeth on the apical margin of the superior lobes, not separated by a deep groove, and only one pair of windows in the hypandrium. The early stages are very similar to other boqueronense group species. The main difference is in the posterior breathing tube that is smooth and shiny at the apex with, at most, only vague indications of punctures. Only triunfense has a similar shiny apex to the posterior breathing tube. C. unamas differs from triunfense in that the posterior breathing tube is parallel sided, and does widen basally and is about as wide as the pupal spiracles. In triunfense the posterior breathing tube widens basally and is wider than the pupal spiracles.

Biology: Reared from a larva found in a fallen, decaying bromeliad (Bromeliaceae).

\section{Other species from decaying bromeliads}

\section{COPESTYLUM ALBERTOI SP. NOV. MARCOS-GARCÍA \& ROTHERAY}

Diagnosis - male holotype: Face shiny, dust confined to band under the antennae; face yellow with sharply defined cental and lateral black vittae (Fig. 19); frons yellow, dusted, fuscous centrally and black haired; 

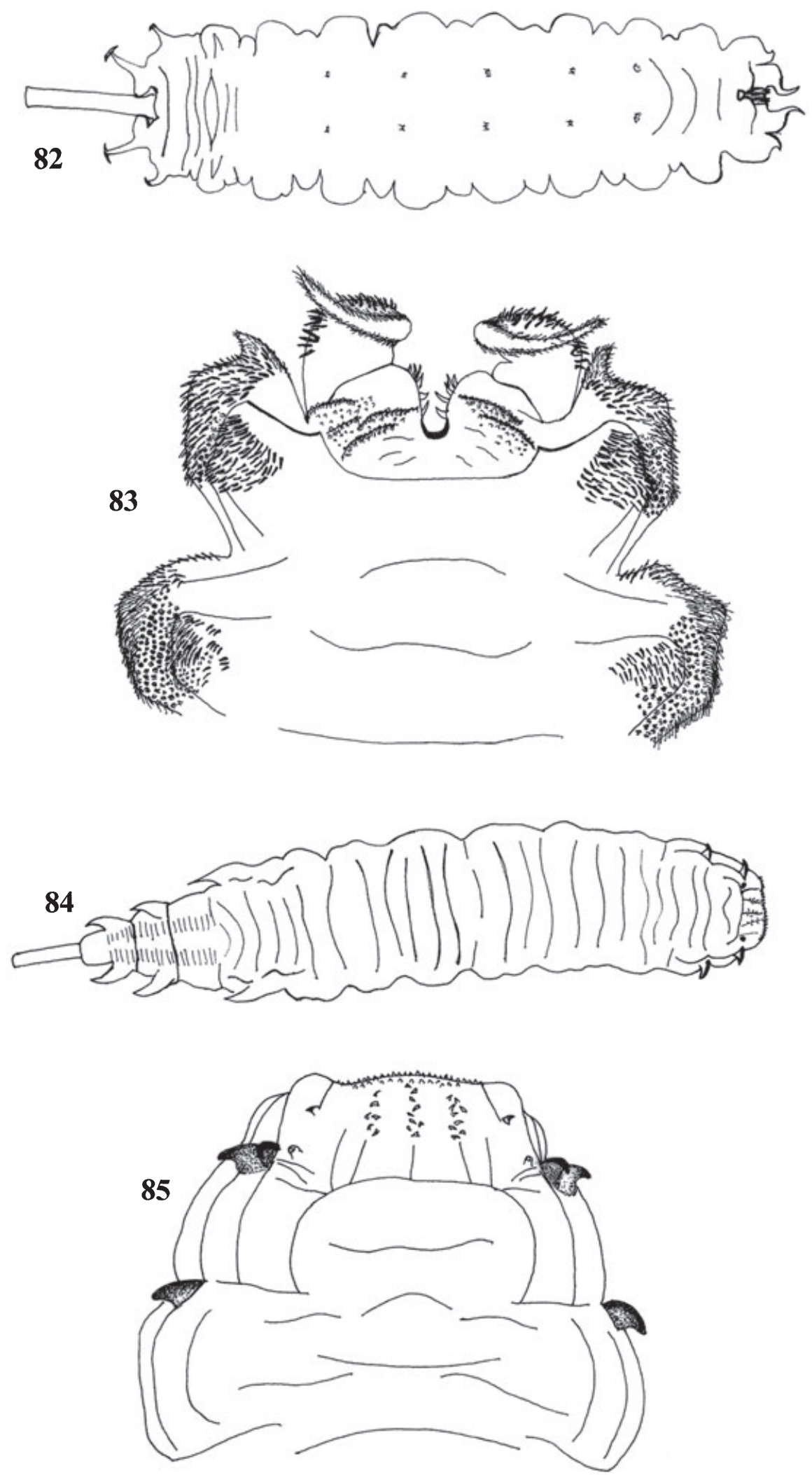

Figures 82-85. Third stage larvae of Copestylum. 82-83. Copestylum otongaensis: 82 . whole larva, head to the right, ventral view, length $=13 \mathrm{~mm}$; 83. thorax, dorsal view, width $=3.7 \mathrm{~mm}$. 84-85. Copestylum triunfense: 84 . whole larva, head to the right, dorsal view, length $=21 \mathrm{~mm} ; 85$. thorax, dorsal view width $=5 \mathrm{~mm}$. 
hairs absent from lower margin of the eyes; eye hairs yellow, except for band of black hairs on top of the the flattened, inclined head; mesonotum shiny metallic black with lateral yellow vittae; mesonotum with long hairs white basally and dark apically, and shorter white hairs; no prescutellar bristles; scutellum with yellow basal band, apical depression, and mixed length black hairs; upper half of the sides of the thorax yellow and black below; wings extensively microtrichose; R1 closed; legs entirely black with black hairs, except some yellow hairs on the posterior margin of the mid femorae; abdomen - tergite 1 whitish and white haired, tergite 2 with a pair of large white spots in basal half and a clear black band in the apical half, white haired over the spots, otherwise black haired; tergites 3 and 4 with small yellow spots on the apicolateral margins, base of these tergites with white hairs, otherwise tergites black and black haired; sternites 1 and 2 yellow and yellow haired; sternites 3 and 4 with a broad black band and narrow yellow bands at base and apex, yellow haired; genitalia - surstylus rectangular-shaped with broad rounded apex and basal projection coated in long setae; epandrium with projection at point of articulation with hypandrium; hypandrium without windows; superior lobes with one hook; postanal plate at base of cerci well defined by sclerotization (Figs 65, 66, 67, 68); female unknown. Length: body, $9 \mathrm{~mm}$; wing, $10 \mathrm{~mm}(N=1)$.

Diagnosis - larva and puparium: Projection bearing antennomaxillary organs nodulate, dorsal lip with a tuft of short setae; lateral lips with stout setae basally and fine setae apically, not meeting apically, feeding channel not deep; thorax not wider than abdomen; anterior fold with a band of 7-9 rows of brown spicules, becoming shorter anteriorly and not reaching sensilla 3 of prothorax; prothorax without spicules; anterior spiracles about as long as broad with three openings across the apex; vestiture of short, fine setae, slightly longer on lateral margins and shorter on ventral surface; lateral margins of mesothorax with three spicules and a paired group of spicules present on antero-ventral margin of metathorax; mesothoracic prolegs comma-shaped, coated in matted pubescense with short, medially arranged crochets; prolegs on abdominal segments 1-6, transverse with three rows of brown-tipped spicules, segmental sensilla mounted on fleshy projections with long apical setae, these projections longer on lateral margins of the abdomen, but not longer than half the length of lappets; lappet 1 about half as long as lappet 2; lappets 2 and 3 on lateral margin; posterior breathing tube orange, less than two times the width of a pupal spiracle, matt and coriaceous basally, shining and lightly punctured above transverse ridge; slightly tapered at extreme apex; three pairs of sinusoidal openings; pupal spira- cles orange, long, longer than distance apart, slightly curved, punctate basally, smooth and shining with openings spread apart, mostly further apart than their width across, not on raised bands and reaching below the halfway point, coated in very short, inconspicuous setae, not longer than width of an opening; head skeleton - ventral cornu less than ten times as long as dorsal cornu; dorsal cornu more than half as wide as ventral cornu; dorsal bridge present; sclerotized tentorial bars broader apically beyond ventral bridge; mandibles and mandibular apodeme either as wide as tentorial bars or wider (Fig. 98).

Material examined - holotype: Male with puparium, Mexico, Chiapas, Talquián, 07 June 2002, ex fallen, decaying bromeliad (Bromeliaceae), MAM, GER \& C. Pérez-Bañón (CIBIO).

Etymology: The name 'albertoi' is in reference to my son Alberto (MAM).

\section{COPESTYLUM CONABIOI SP. NOV. MARCOS-GARCÍA \& ROTHERAY}

Diagnosis - male holotype: Face yellow and yellow haired with well-developed central tubercle; black central vitta from mouth to base of antennae and black lateral vittae (Fig. 20); face shiny, only dusted below antennae, and pruinosity confined to small patches either side of the antennae and at base of genae; frons black with yellow hairs; eyes with yellow hairs ending before the lower margin; mesonotum shiny black with two broad yellow marginal vittae; mesonotum coated with long black and short yellow hairs, prescutellar bristles absent; scutellum shiny brown, yellow basally and coated in short and long black hairs; scutellum with a narrow, linear ridge round the entire dorso-apical margin; upper pleurites bright yellow, lower half of pleurites black; legs shiny black with black hairs; joints of femora-tibia yellowish; wings with some small maculae about the crossveins; $R 1$ closed; abdomen - tergite 1 white and white haired, tergite 2 white band in apical half, shiny black posteriorly, tergites 3 and 4 shiny black with a cresent-shaped yellow band from anterior corners to posterior half of each tergite; abdominal hairs short and inconspicuous, pale over most of tergites 1 and 2, and dark elsewhere except yellow over cresent-shaped markings; sternite 1 white; sternites 2 and 3 white with black posterior band; sternite 4 black except for narrow, anterior, yellow band; genitalia - surstylus with basal projection coated in long setae; epandrium with projection at point of articulation with hypandrium; hypandrium without windows; superior lobes simple with one hook (Figs 69, 70, 71); female - similar to male; frons entirely black with pale hairs; width of 

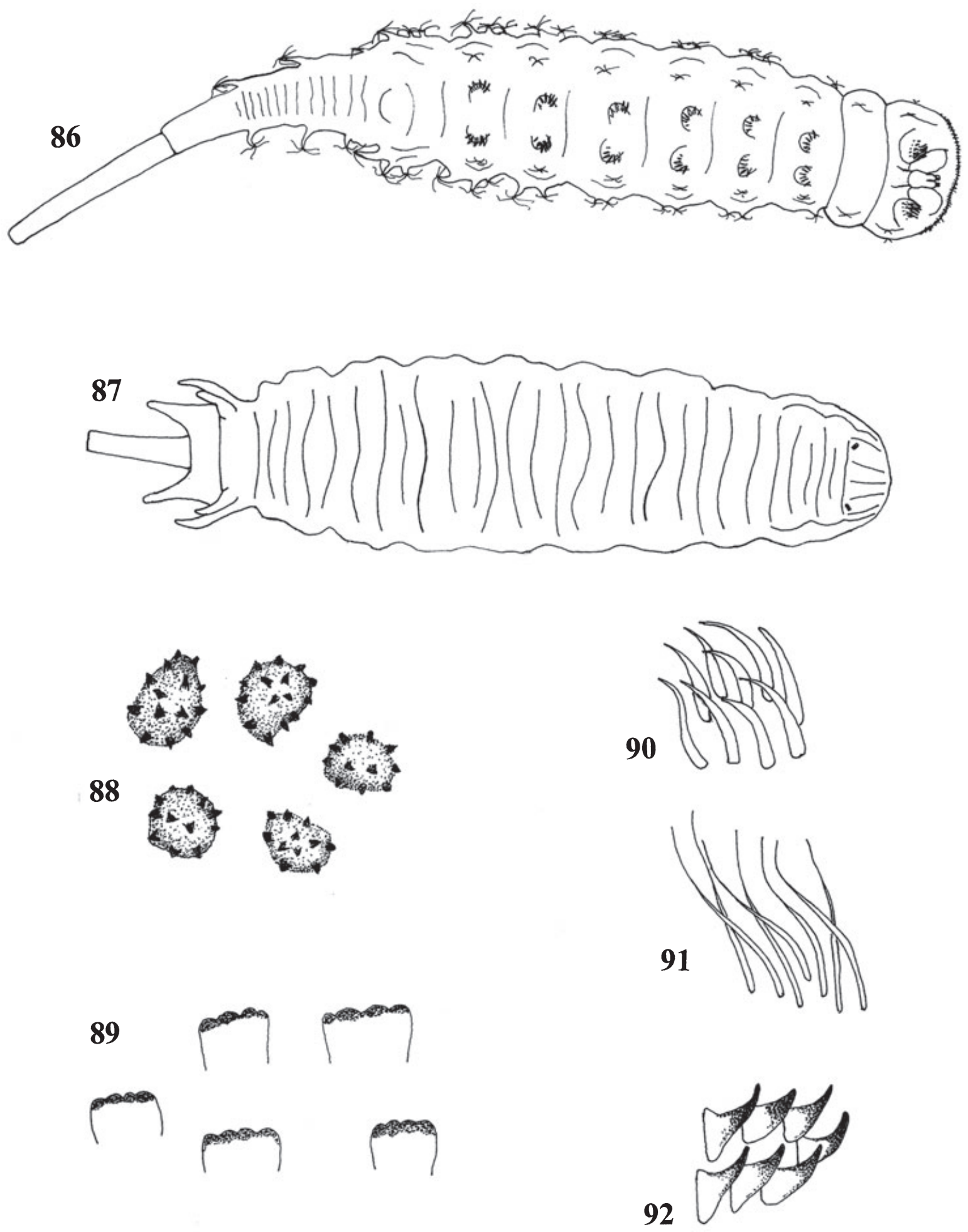

Figures 86-92. Third stage larvae of Copestylum. 86. Copestylum lousiae, whole larva, head to the right, ventral view, length $=14 \mathrm{~mm} .87$. Copestylum tapia, whole larva, head to the right, dorsal view, length $=11 \mathrm{~mm} .88$. Copestylum barbara, crenate papillae from the dorsal surface of the anal segment. 89. Copestylum xalapensis, dentate spicules from the anterior fold of the prothorax. 90. Copestylum mamorum, vestiture of stout setae from the dorsal surface of the second abdominal segment. 91. Copestylum louisae, vestiture of long, fine setae from the dorsal surface of the second abdominal segment. 92. Copestylum puyarum, tapering spicules from the anterior fold of the prothorax. 
vertex about $9 \%$ of width of head. Length: body, 8.50-9.30 mm; wing, 9.00-9.30 mm $(N=5)$.

Diagnosis - puparium: Dorsal lips and antennomaxillary organs not describable as a result of being hidden within the dried puparium; lateral lips with stout setae basally and fine setae apically, not meeting apically, feeding channel not deep; thorax not wider than abdomen; anterior fold with a band of between seven and nine rows of brown spicules, becoming shorter anteriorly and not reaching sensilla 3 of prothorax; prothorax without spicules; anterior spiracles about as long as broad with three openings across the apex; vestiture of long, conspicuous setae arranged in transverse rows across the dorsum, shorter and stouter on ventral surface; lateral margin of mesothorax with two groups of five and either two or three spicules, respectively; antero-ventral margin of metathorax without; mesothoraic prolegs comma-shaped with two rows of brown crochets; primary crochets arranged medially; prolegs on abdominal segments 1-6 not developed; segmental sensilla mounted on fleshy projections with long apical setae, these projections longer on lateral margins of the abdomen, but not longer than half the length of lappets; lappet 1 about as long as lappet 2; lappets 2 and 3 on lateral margin of the anal segment; posterior breathing tube orange, less than two times the width of a pupal spiracle, matt and coriaceous basally, shining and heavily punctured above transverse ridge; not tapered at apex; three pairs of sinusoidal openings; pupal spiracles yellow, long, longer than distance apart, slightly curved, punctate basally, smooth and shining with openings spread apart, mostly further apart than their width across, not on raised bands and reaching below halfway point, coated in fine inconspicuous setae that are short, not much longer than width of an opening; head skeleton - ventral cornu less than ten times as long as dorsal cornu; dorsal cornu more than half as wide as ventral cornu; dorsal bridge present; sclerotized tentorial bars narrow apically beyond ventral bridge; mandibles and mandibular apodeme either as narrow as tentorial bars or narrower (Fig. 97).

Material examined - holotype: Male with puparium, Mexico, Chiapas, Boquerón, 19 April 2002, ex fallen decaying bromeliad, GER, MAM \& C. Pérez-Bañón (NMS).

Material examined - paratypes: One male and three females, two with puparia (NMS); seven males and 14 females with puparia, same data as holotype (CIBIO); one male with puparium, Mexico, Chiapas, Talquián, 16 April 2002, ex fallen decaying bromeliad, GER, MAM \& C. Pérez-Bañón (SI); one male with puparium, Mexico, Chiapas, Motozal, 11 April 2002, ex fallen decaying bromeliad, GER, MAM \& C. PérezBañón (NMS).

Etymology: The name conabioi is in reference to the Comisión Nacional para el Conocimiento y Uso de la Biodiversidad, which, in Mexico, helped fund our fieldwork.

Taxonomic notes: The adult of C. conabioi is most similar in overall appearance to C.tapia and C. albertoi among the species considered here. It may be distinguished from these species by the ridge at the apex of the scutellum. Among other Copestylum species C. conabioi is most similar to Copestylum gertschi (Curran, 1939) in general appearance. Both species have a central vitta extending from the antennae to the mouth, lower half of the eyes without hairs, thoracic pile without bristles, and a ridge round the apex of the scutelleum. However, the darker colour of the abdomen and features of the male genitalia separate $C$. conabioi from this species. The early stages of C. conabioi are easily separated from other bromeliad Copestylum by the lack prolegs with crochets.

Biology: Reared from larvae found in fallen, decaying bromeliads in cloud forest in Mexico.

\section{COPESTYLUM JOEI SP. NOV. ROTHERAY \& HANCOCK}

Diagnosis - male holotype: Face black, elongate, and narrowing below tubercle, with both yellow and black hairs (Fig. 15); cheeks and space between base of antennae and tubercle coated in whitish dust and scattered pruinosity; basoflagellomere excavated dorsally; arista with very long plumes dorsally, and very short plumes ventrally; frons black and black haired; eyes coated in black hairs; mesonotum, pleurites, legs, and abdomen black; scutellum dark yellow; mesonotum, pleurites, and abdomen densely coated in black hairs; scutellum coated with black hairs of mixed length; three anepisternal bristles; wings with microtrichia only along costal margin and at apex of cell R2+3; R1 closed; black marks at apex of cell Sc, and where the spurious vein crosses the crossvein $r-m$; genitalia - surstyli elongate with bulbous apex; epandrium narrow with finger-like projection articulating with base of surstyli, and no projection at point of articulation with the hypandrium; superior lobes hammer-shaped with a medial finger-like, dorsal projection; upper lateral margins of epandrium with setae (Figs 56, 57, 58); female - unknown. Length: body, $14 \mathrm{~mm}$; wing, $12 \mathrm{~mm}(N=1)$.

Diagnosis - puparium: Unable to describe dorsal lip and base of antennomaxillary organs, which are obscured within the dried prothorax of the puparium; lateral lips with spicules basally, and long, fine setae apically, not meeting apically; feeding channel not deep because of small size of lateral lips; thorax as 


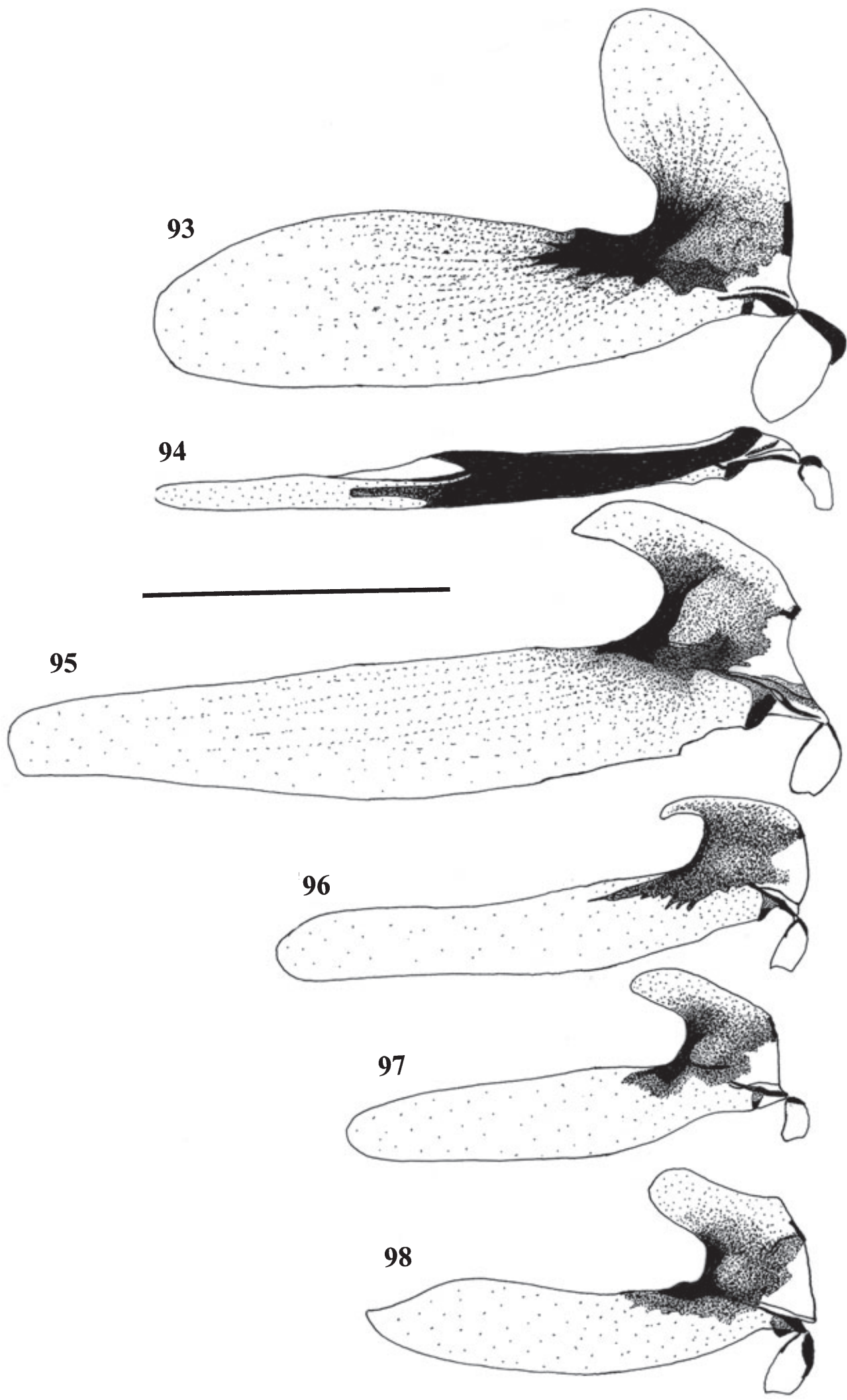

Figures 93-98. Third stage larvae of Copestylum, head skeletons, lateral view, anterior end to the right, scale line $=1 \mathrm{~mm}$. 93. Copestylum joei; 94. Copestylum otongaensis; 95. Copestylum mamorum; 96. Copestylum galantei; 97. Copestylum conabioi; 98. Copestylum albertoi. 
wide as abdomen; anterior fold with a band of between seven and nine rows of brown spicules, spicules larger medially and just reaching sensilla 3 of prothorax; anterior spiracles short, about as long as wide, with either two or three openings across the apex; vestiture of short, stout setae coating dorsum and lateral margins of the body; setae shorter on ventral surface; vestiture of prothorax all the same length; lateral margin of mesothorax with two groups of nine and five spicules, respectively, and bands of spicules on the antero-ventral margin of the metathorax; segmental sensilla on short projections, wider than long with inconspicuous apical setae; mesothoracic prolegs comma-shaped with three rows of brown-black crochets; primary crochets spread across the proleg, not clustered to inner side; transverse prolegs on segments $1-6$ with three rows of crochets; sensilla $5-8$ of abdominal segments 5-7 not on long projections; abdominal segment 7 and anal segment extended four or more times the length of segment 6 , and not particularly tapered at apex, and about half as broad as base of segment 7; lappet 1 on dorso-lateral margin of anal segment, and about the same length as lappet 2; lappets 1 and 2 aligned one above the other on a shared projection of the anal segment; lappet 3 on the mid-lateral margin; posterior breathing tube short, about as long as prothorax is wide, orange, matt at base, shiny above transverse ridge, lightly punctured; three pairs of sinusoidal openings; pupal spiracles short, only about half as long as distance apart; straight, nodulate below shiny apex with openings clustered at apex; head skeleton - ventral cornu less than ten times as long as dorsal cornu; dorsal cornu more than half as wide as ventral cornu and projecting almost at right angles to ventral cornu; dorsal bridge present; sclerotized tentorial bars broad apically beyond ventral bridge; mandibles and mandibular apodeme either as wide as tentorial bars or wider (Fig. 93).

Material examined - holotype: Male with puparium, Costa Rica, Cartago P.N. Cerro de la Muerte, February 1999, ex wet decay between basal leaves and base of dead flowering spike of Puya dasylirioides Stanley, 1927 (Bromeliaceae), GER (INB0003056077) (INBio).

Etymology: The name 'joei' is descriptive of my son (GER).

Taxonomic notes: This species is easily recognized from other bromeliad species by its almost completely black appearance. C. otongaensis is also black, but among other characters that species has a very different facial profile (Figs 15, 17). Among Copestylum species in general C. joei is most similar to Copestylum anna (Williston, 1887), but differs from that species in having black, not orange, eye hairs and antennae, a broader less tapering face, and a lack of pruniose patches on the gena. The early stages of $C$. joei share with $C$. louisae and Copestylum puyarum an extended posterior end, but the extension is much broader in C. joei. It has transverse prolegs like C. puyarum, but in $C$. joei they are equally developed on all first six abdominal segments. C. louisae has spherical prolegs. The vestiture of the thorax is much shorter in $C$. joei than in C. puyarum, and none of the segmental sensilla are on long projections. The close approximation of lappets 1 and 2, which lie one above the other and share a common base, also separates $C$. joei from other bromeliad Copestylum.

Biology: A larva was collected in wet decaying leaves at the base of a dead flower spike of a puya plant (Bromeliaceae) in Costa Rica. Larvae of C. puyarum were also present.

\section{COPESTYLUM PUYARUM SP. NOV. ROTHERAY \& HANCOCK}

Diagnosis - female holotype: Face yellow and yellow haired, with vague and indistinct central vitta only reaching as far as central tubercle from the mouth; sides of face heavily dusted and pruniose; genae with narrow, black vittae (Fig. 18); eyes coated in yellow hairs; frons orange behind ocelli and black beyond; frons black haired to base of antennae; central strip of yellow dust obscuring black ground colour; width of vertex about $10 \%$ of width of head; mesonotum dark with yellow lateral vittae and yellow triangular mark on posterior margin; mixed length hairs on mesonotum; yellow hairs anteriorly, black posteriorly; one black bristle on dark posterior anepisternum; pleurites dark and mostly dusted with black and yellow hairs; scutellum yellow with mixed length hairs; yellow hairs basally, otherwise black; scutellum without apical depression, but coracious oval-shaped mark present; legs yellow except base of femorae black, and mid and hind tibiae fuscous; legs black haired except for underside of tarsi; wings extensively microtrichose with maculae over the crossveins; cell R1 open; abdomen tergites 1-4 yellow except for black posterior margin of tergite 4 ; tergites 1 and 2 mostly yellow haired except for posterior margin; tergites 3 and 4 with crescentshaped anterior bands of yellow hairs reaching to about half the length of each tergite, otherwise black haired; sternites yellow with yellow hairs, except on posterior margins of sternites 3 and 4; male unknown. Length: body, $12 \mathrm{~mm}$; wing, $10 \mathrm{~mm}(N=1)$.

Diagnosis - larva and puparium: Basal projection bearing antennomaxillary organs nodulate; dorsal lip with tuft of setae; lateral lips with spicules basally, and long, fine setae apically, not meeting apically; feeding channel not deep because of small size of lateral lips; 

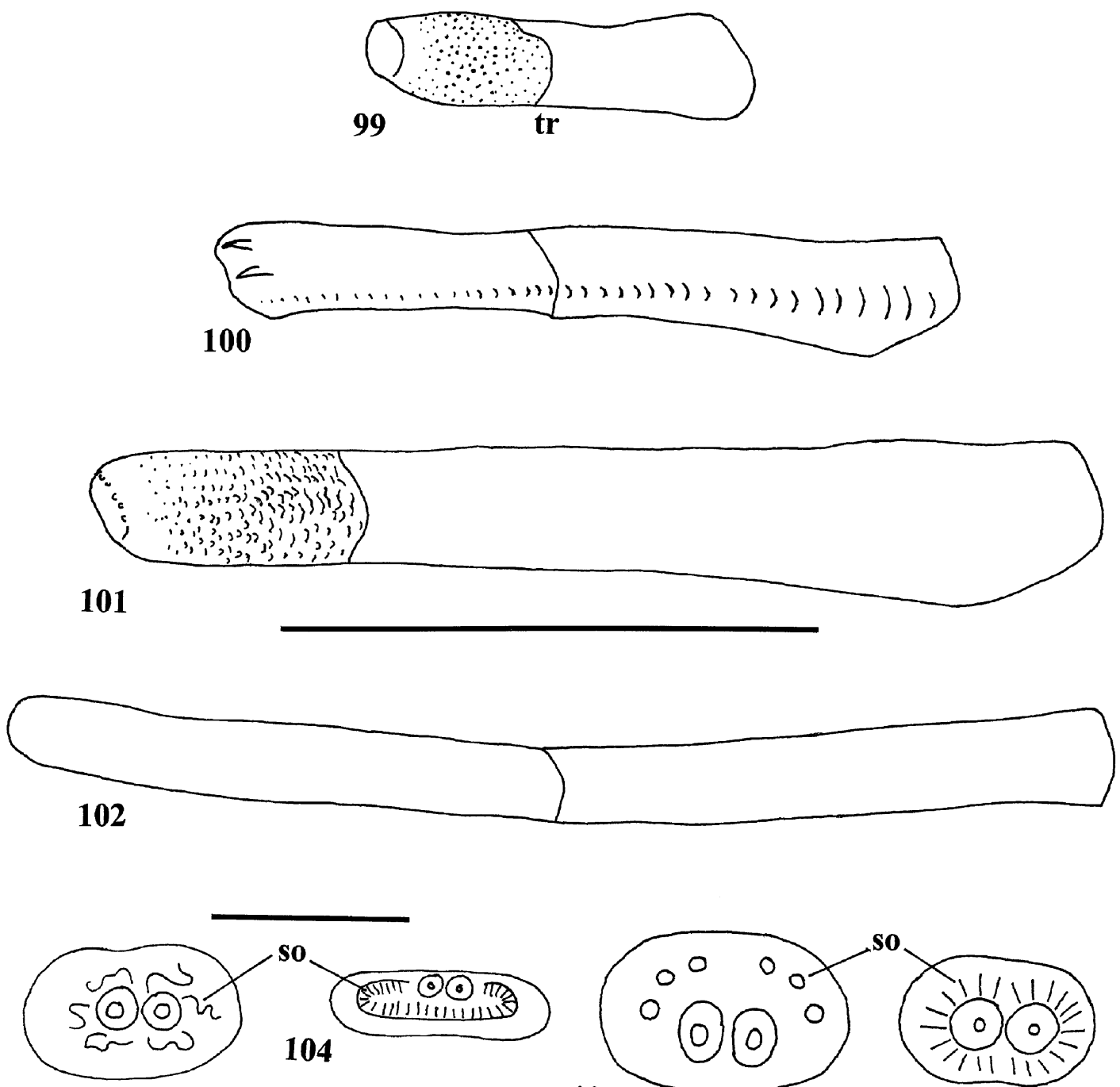

103

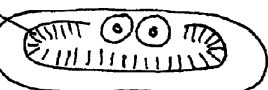

104

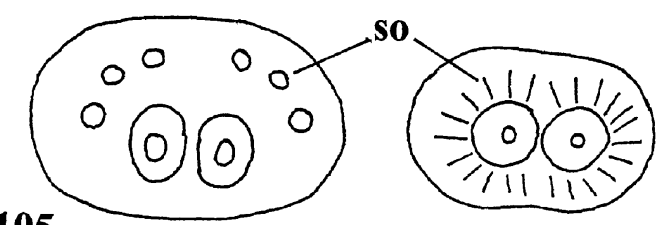

105

\section{6}
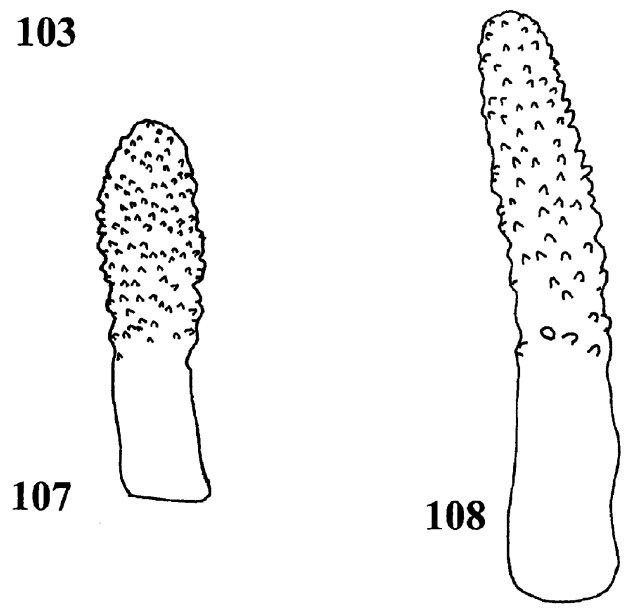

Figures 99-110. Early stages of Copestylum, respiratory structures. 99-102. Posterior breathing tubes of third stage larva, dorso-lateral view, apex to the left; tr, transverse ridge; scale line $=2 \mathrm{~mm}$. 99. Copestylum emeralda; 100 . Copestylum otongaensis; 101. Copestylum elizabethae; 102. Copestylum louisae. 103-106. Spiracular plates of posterior breathing tubes of third stage larva, dorsal view; so, spiracular openings; scale line $=0.6 \mathrm{~mm}$. 103. C. emeralda; 104. . C. otongaensis; 105 . C. elizabethae; 106. C. louisae. 107-110. Pupal spiracles from puparia, posterior view; scale line = $1 \mathrm{~mm}$. 107. C. emeralda; 108. C. otongaensis; 109. C. elizabethae; 110. C. louisae. 
thorax broad, wider than abdomen; anterior fold with a band of between seven and nine rows of brown spicules, spicules shortening posteriorly and reaching anterior sensilla 3 of prothorax; anterior spiracles short, about as long as wide, with either four or five openings across the apex; vestiture of long, stout, upright setae coating dorsum and lateral margins of the body (Fig. 92), longer and stouter on the anal segment, setae shorter between folds and forming microspicules on the ventral surface; vestiture of prothorax without longer setae at posterior margin; lateral margin of mesothorax and metathorax with groups of 12-15 and 6-9 spicules, respectively, and bands of spicules on the antero-ventral margins; segmental sensilla on short projections, about as long as vestiture, with between one and five thick, pale coloured, apical setae; these setae much shorter than transverse folds across the dorsum; mesothoracic prolegs comma-shaped with four rows of brown crochets; either four or five primary crochets clustered at inner end of proleg; prolegs only on abdominal segments 1-5, and much less developed on segments 4 and 5; transverse in shape, not well developed with three straight rows of brown crochets; sensilla 5-8 of abdominal segments 5-7, but not sensilla 9 of anal segment, on particularly elongate, more so than segments 1-4, fleshy projections; projections tapering and coated in conspicuous stout setae; anal segment extended up to more than 1.5 times as long as sixth abdominal segment; lappet 1 on dorso-lateral margin of anal segment, and a little shorter than lappet 2, more than half as long; lappets 2 and 3 on mid-lateral margin; lappets tapering and coated in conspicuous stout setae; posterior breathing tube long, about 1.5 times body width, parallel sided, orange, above transverse ridge smooth and shiny, without punctures; three pairs of sinusoidal spiracular openings; pupal spiracles long, longer than distance apart, pale yellow, slightly curved, nodulate basally shiny above with openings on not particularly widened apical half; head skeleton - ventral cornu about seven times shorter than dorsal cornu; dorsal cornu less than half as wide as ventral cornu; dorsal bridge present; sclerotized tentorial bars narrow apically beyond ventral bridge; mandibles and mandibular apodeme either as narrow as tentorial bars or narrower.

Material examined - holotype: Female with puparium, Costa Rica, Cartago P.N. Cerro de la Muerte, February 1999, ex wet decay between basal leaves and base of dead flowering spike of P. dasylirioides (Bromeliaceae), EGH \& GER (INBio).

Material examined - paratypes: two females with puparia, same data as holotype (INBio).

Material examined - additional material: Five larvae, same data as holotype, as follows: two larvae collected by APC, 0013.8 \& 0013.1; one larva, MLV 24.1 (INBio); two larvae GER (NMS).

Etymology: The name 'puyarum' is descriptive of the colloquial name of the host plant.

Taxonomic notes: C. puyarum is similar to the boqueronense group in size and general appearance. However C. puyarum does not have a flattened face and the tubercle is well produced. In comparison with other Copestylum species, C. puyarum is most similar to $C$. brunnigaster in being a large species with a narrow dusted face, thoracic pile of mixed size, prescutellar bristles, and with an extensively yellow abdomen. C. puyarum differs from C. brunnigaster in having a shorter face with black vittae, a broader band of apical black setae on tergite 2 , about a quarter the length of the tergite, and well developed prescutellar bristles. The larva and puparium of C. puyarum is most similar to C.louisae among those considered here. They both share a thorax broader than the abdomen, an elongate anal segment, and sensilla 5-8 of abdominal segments 5-7 on elongate fleshy projections. The ridge-shaped as opposed to spherical prolegs, and lappets covered in stout as opposed to fine setae, distinguish C. puyarum from C. louisae.

A larva similar to puyarum was found, but not reared, in the decaying bases of puya plants at the base of Mount Cotapaxi, near Quito, Ecuador in August 2000. This larva can be distinguished from puyarum by the vestiture, which is only about half as long.

Biology: Larvae were collected in wet decaying leaves at the base of dead flower spikes of puya plants (Bromeliaceae). Sometimes the level of decay was extensive and pools of water were present. Nonetheless, decay was generally deep down and often underground, and was located only with considerable effort.

\section{Copestylum TAPIA SP. NOV. ROTHERAY \& HANCOCK}

Diagnosis - male holotype: Face shiny, dust confined to band under the antennae; face yellow with sharply defined cental and lateral black vittae (Fig. 21); frons black and black haired with white dust on lateral margins; hairs absent from lower margin of the eyes; eye hairs yellow, except for band of black hairs on top of the the flattened, inclined head; mesonotum and scutellum shiny metallic black; mesonotum with long, black, and short, white hairs; no prescutellar bristles; scutellum with apical depression and mixed length black hairs; upper half of the sides of the thorax yellow, and black below; wings black microtrichose, except near the base so that the wings appear infused black with a hyaline blotch near the base; R1 closed; legs entirely black 
with black hairs, except some yellow hairs on the posterior margin of the hind femorae; abdomen tergite 1 whitish and with white and black hairs, tergite 2 with a pair of large white spots with a narrow black band at the apex, white haired over the spots, otherwise black haired; basal half of tergites 3 and 4 with whitish spots coated in white hairs, otherwise tergites black and black haired; sternites black and black haired, except for central yellow and yellow haired spots on sternites 2 and 3; genitalia surstylus with basal projection coated in long setae; epandrium with projection at point of articulation with hypandrium; hypandrium with a pair of windows; superior lobes simple with one hook (Figs 72, $73,74)$; female - frons bright black with short white hairs; width of vertex about $14.25 \%$ width of head; sixth abdominal segment with six long, white, apical hairs. Length: body, $9.50-10.00 \mathrm{~mm}$; wing 9$11 \mathrm{~mm}(N=22)$.

Diagnosis - larva and puparium (Fig. 87): Projection bearing antennomaxillary organs nodulate, dorsal lip with a tuft of short setae; lateral lips with stout setae basally, and fine setae apically, not meeting apically, feeding channel not deep; thorax not wider than abdomen; anterior fold with a band of between seven and nine rows of brown spicules, becoming shorter anteriorly and not reaching sensilla 3 of prothorax; prothorax without spicules; anterior spiracles about as long as broad with three openings across the apex; vestiture of long, fine setae matted together; this type of vestiture also coating the lateral margins, and also on the ventral surface where it is not as long; lateral margins of mesothorax with up to six spicules and a paired group of spicules present on antero-ventral margin of metathorax; mesothoracic prolegs commashaped, coated in matted pubescense with short, medially arranged crochets; prolegs on abdominal segments 1-6, transverse with three rows of browntipped spicules, segmental sensilla mounted on fleshy projections with long apical setae, these projections longer on lateral margins of the abdomen, but not longer than half the length of lappets; lappet 1 about half as long as lappet 2; lappets 2 and 3 on lateral margin; posterior breathing tube orange, less than two times the width of a pupal spiracle, matt and coriaceous basally, shining and lightly punctured above transverse ridge; not tapered at apex; three pairs of sinusoidal openings; pupal spiracles orange, long, longer than distance apart, slightly curved, punctate basally, smooth, and shining with openings spread apart, mostly further apart than their width across, not on raised bands and reaching below halfway point, coated in long, conspicuous setae, several times longer than width of an opening; head skeleton - ventral cornu under five times as short as dorsal cornu; dorsal cornu about half as wide as ventral cornu; dorsal bridge present; sclerotized tentorial bars width unchanged beyond ventral bridge; mandibles and mandibular apodeme as wide as tentorial bars.

Material examined - holotype: Male with puparium, Ecuador, Pinchincha, Otonga Reserva, 2-14 July 2002, ex fallen decaying bromeliad (Bromeliaceae), EGH \& GER (NMS).

Material examined - paratypes: Two males caught by handnet flying in subcanopy, same site as holotype, 21-26 August 2000, EGH \& GER (HM); nine males and ten females with puparia, same data as holotype (one male and one female each to CIBIO, HM, PUCE, with the rest to NMS).

Material examined-additional material: Two larvae, same data as holotype (NMS).

Etymology: The name 'tapia' is in reference to Don Cesar Tapia, in recognition for his help and assistance during fieldwork at Otonga, Ecuador.

Taxonomic notes: The adult of C. tapia is most similar to C. albertoi among bromeliad Copestylum. Both are relatively dark species with a depression at the apex of the scutellum, black legs, upper half of the sides of the thorax bright yellow, and tergite 2 with large white spots. This colour pattern is also found in C. barbara, C. elizabethae and Copestylum xalapaensis, but these three species do not have a scutellar depression. The same colour pattern is also found in C. conabioi, but the apex of the scutellum of that species has a ridge not a depression. C. tapia is most easily separated from C.albertoi by the mesonotum, which lacks lateral yellow vittae. Among other Copestylum, C. tapia most closely resembles Copestylum cupricolor (Hull, 1948), Copestylum lucilia (Hull, 1950), and Copestylum pertinax (Hull, 1950) in having sharply defined black vittae on the face, mesonotum without bristles, a scutellar depression, and tergites 3 and 4 with patches of white hairs. C. tapia differs from these species in lacking a yellow band at the apex to the mesonotum, and the peculiar long, white hairs at the apex of the sixth abdominal segment. Early stages of C.tapia are distinguished from other bromeliad Copestylum early stages by their subcyclindrical shape in cross-section, long, matted vestiture not in obvious, transverse rows, pupal spiracles with a coating of setae much longer than the width of a respiratory opening, and the posterior breathing tube not two times as wide as the pupal spiracles.

Biology: Reared from larvae found in fallen, decaying bromeliads in cloud forest in Ecuador. 


\section{COPESTYLUM YOWOI SP. NOV. ROTHERAY \& HANCOCK}

Diagnosis - female holotype: Face shiny metallic blue-black, except for vague yellow central vitta to central tubercle, and pale yellow lateral vittae (Fig. 22); face pale haired; face rounded and sunk below eye margins between base of antennae and tubercle; band of dust across face under base of antennae; eyes coated in thick, white hairs; frons shiny metallic blue-black with hairs at base of antennae, along the eye margins, and behind the ocelli proclined, otherwise hairs reclined; mesonotum shiny metallic blue-black with lines of altenating yellow and black hairs; most yellow hairs reclined, black hairs either reclined or orientated laterally; posterior margin of mesonotum with a band of longer yellow hairs; pleurites shiny metallic blue-black and coated in yellow hairs; one black bristle on dark posterior anepisternum; scutellum shiny and dark yellow with blue-black reflections, apical depression present and coated in yellow hairs of mixed lengths; legs shiny fuscous with yellow tarsi, and coated in black hairs except for basal half of femorae and tarsi; wings clear without maculae and extensively microtrichose; abdomen metallic green and coated in yellow hairs, except for some black hairs on the lateral margins of tergites 3 and 4 ; male unknown. Length: body, 8-9 mm, wings, 7-8 mm $(N=2)$.

Diagnosis - puparium: Dorsal lips and antennomaxillary organs not describable because they were hidden within the dried puparium; lateral lips with stout setae basally and fine setae apically, not meeting apically, feeding channel not deep; thorax not wider than abdomen; anterior fold with a band of between seven and nine rows of brown spicules, becoming shorter anteriorly and not reaching sensilla 3 of prothorax; anterior spiracles present with three apical openings; dorso-posterior margin of prothorax and mesotheorax with spicules; lateral margin of mesothorax with two groups of seven and three spicules, respectively; antero-ventral margin of metathorax with two rows of either five or six spicules; mesothorax comma-shaped with three rows of brown crochets; primary crochets arranged medially; transverse prolegs on abdominal segments 1-5 with three rows of brown crochets; crochets longer than vestiture, at least on segments $1-3$; vestiture of dorsal surface of abdominal segments 1-6 of long, fine setae becoming shorter and stouter on the ventral surface; segmental sensilla not mounted on fleshy projections, not with long apical setae; lappet 1 not longer than lappet 2; lappets 2 and 3 on lateral margin of the anal segment; posterior breathing tube orange, shorter than body width; shining and a few light punctures above transverse ridge; parallel sided; three pairs of sinusoidal openings; pupal spiracles orange, long, longer than distance apart, nodulate basally, with openings clustered at apex on conspicuous raised bands; head skeleton - ventral cornu less than five times as short as dorsal cornu; dorsal cornu about half as wide as ventral cornu; dorsal bridge present; sclerotized tentorial bars width unchanged beyond ventral bridge; mandibles and mandibular apodeme as wide as tentorial bars.

Material examined - holotype: One female with puparium, Costa Rica, Guanacaste, Bosque Nacional Diriá, cerca de Rio Enmedio, 6 November 2000, ex decaying flowers of Bromelia hemispherica (Lamarck, 1811) (Bromeliaceae), YCN (INBio).

Material examined - paratype: One female with puparium, same data as holotype (INBio).

Etymology: This species is named after the Costa Rican parataxonomist, Yow Cárdenas, who collected and reared it for the first time.

Taxonomic notes: The adult of C. yowo is similar to Copestylum emeralda (Hull, 1934) among species reared from bromeliads. However, C. yowoi is easily separated from C. emeralda by the thick eye hairs of C. yowoi. Among other Copestylum species, C. yowoi is most similar to Copestylum viride (Williston, 1880), which also has thick eye hairs, metallic body colouration, and wings extensively microtrichose. C. yowoi is most easily separated from $C$. viride by the blueblack colouration of the head and thorax, which in C. viride are metallic green. The early stages are also similar to $C$. emeralda, but are easily separated by the posterior breathing tube, which is about as wide as deep in C. yowoi and parallel sided, but in C. emeralda it is about twice as wide as deep and tapers above the transverse ridge. Also, the openings on the pupal spiracles are on the apical half, but in $C$. yowoi they are clustered at the apex.

Biology: Reared from larvae found in decaying flowers of B. hemispherica (Bromeliaceae).

\section{COPESTYLUM EMERALDA (HULL, 1934)}

Diagnosis - puparium: Dorsal lips and antennomaxillary organs not describable because they are hidden within the dried puparium; lateral lips with stout setae basally, and fine setae apically, not meeting apically, feeding channel not deep; thorax not wider than abdomen; anterior fold with a band of between seven and nine rows of brown spicules, becoming shorter anteriorly and not reaching sensilla 3 of prothorax; rest of prothorax including anterior spiracles undescribable because of absence of prothoracic plates from both specimens; vestiture of short, stout upright setae becoming shorter on ventral surface; lateral margin of 
mesothorax with two groups of seven and three spicules, respectively; antero-ventral margin of metathorax with two rows of either five or six spicules; mesothorax comma-shaped with three rows of brown crochets; primary crochets arranged medially; transverse prolegs on abdominal segments $1-5$ with at least two rows of brown crochets; crochets longer than vestiture, at least on segments 1-3; segmental sensilla not mounted on fleshy projections, not with long apical setae; lappet 1 either as long as or longer than lappet 2 ; lappets 2 and 3 on lateral margin of the anal segment; posterior breathing tube orange, very wide, more than two times as wide as a pupal spiracle, shining, and a few light punctures, tapering at apex (Fig. 99), three pairs of sinusoidal openings (Fig. 103); pupal spiracles orange, long, longer than distance apart, slightly curved, nodulate basally, with openings close together, as close as their width across, on conspicuous, raised bands; bands reaching halfway point (Fig. 107); head skeleton - ventral cornu about five times shorter than dorsal cornu; dorsal cornu half as wide as ventral cornu; dorsal bridge present; sclerotized tentorial bars width unchanged beyond ventral bridge; mandibles and mandibular apodeme as wide as tentorial bars.

Material examined: One male and one female with puparia, Costa Rica, Limón, Siguirres, Pacuarito 15 Feruary 2000, ex decaying outer leaves of a bromeliad (Bromeliaceae) on a branch of a cut tree, ER (INBio).

Taxonomic notes: The transverse prolegs only developed on abdominal segments 1-5 suggest this species is similar to C. puyarum, but the thorax is not as wide as the abdomen and there are no long fleshy projections bearing sensilla on any of the segments. It is also similar to C. yowoi, but has a wider than deep, tapering posterior breathing tube. In C. yowoi the breathing tube is as wide as deep and is parallel sided. The early stages of C. emeralda are also easily distinguished from all other bromeliad Copestylum early stages by the well-developed lappet 1 , which is either as long as or longer than lappet 2 , and the posterior breathing tube, which is broader than the pupal spiracles.

Biology: Reared from larvae found among the decaying outer leaves of a bromeliad (Bromeliaceae) on a branch of a cut tree in Costa Rica.

\begin{tabular}{|c|c|}
\hline & KEY TO SPECIES \\
\hline Adults & \\
\hline 1. & Eyes with scale-like hairs .......... \\
\hline - & Eyes without scale-like hairs... \\
\hline 2. & 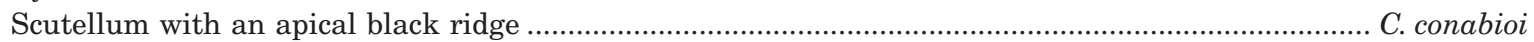 \\
\hline- & Scutellum without apical ridge ..................... \\
\hline 3. & Scutellum with pre-apical depression \\
\hline- & Scutellum without pre-apical depression \\
\hline 4. & $\begin{array}{l}\text { Species metallic green. Scutellum black pilose; discal cell entirely microtrichose; male - second and third terga } \\
\text { black haired apically }\end{array}$ \\
\hline- & Species not metallic \\
\hline 5. & 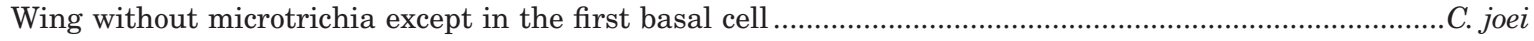 \\
\hline - & Wings with more extensive microtrichia \\
\hline 6. & $\begin{array}{l}\text { Third and fourth abdominal segments entirely black; first and second (except in posterior part) are white yel- } \\
\text { lowish; scutellum entirely black; antennae black }\end{array}$ \\
\hline- & $\begin{array}{l}\text { Third and fourth abdominal segments black with a pair of yellow spots; scutellum black with a yellow anterior } \\
\text { margin. Antennae yellow }\end{array}$ \\
\hline 7. & Wings with sharply defined brown maculae \\
\hline- & $\begin{array}{l}\text { Wings without well-defined brown maculae, either transparent or uniformly clouded on costal and apical wing } \\
\text { surface }\end{array}$ \\
\hline 8. & Face with perpendicular profile, straight above tubercle \\
\hline- & Face with concave profile above tubercle 13 \\
\hline 9. & 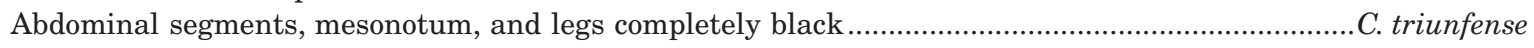 \\
\hline- & Abdominal segments mainly pale, only the posterior segment margins dark; legs partially pale .....................10 \\
\hline 10. & Scutum brownish, without distinct pale marks; tubercle pilosity pale ………………………….. mamorum \\
\hline- & Scutum dark with yellow lateral margins.......... \\
\hline 11. & 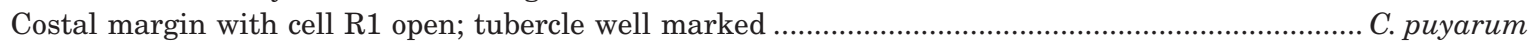 \\
\hline- & 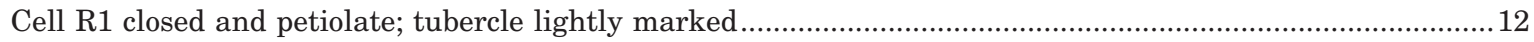 \\
\hline 12. & Epistome black from antenna base to mouth margin; scutum without yellowish spot in central posterior area \\
\hline- & Epistome black from tubercle to mouth margin; scutum with a rounded yellowish spot in central posterior area \\
\hline
\end{tabular}


13(8). Anepisternum with two long black bristles

- $\quad$ Anepisternum with only one long black bristle

14. Posterior margin of the scutum with setae; cell R1 closed in the costal margin; face uniform yellow

C. louisae

Posterior margin of the scutum without setae; cell R1 opened; face black in the upper part and yellow below

15. Scutum black with lateral yellow bands; scutellum brighter than scutum

C. otongaensis

- $\quad$ Scutum and scutellum uniform brown colour

C. volcanorum

16(7). Posterior margin of the scutum with setae C. carlosii

- Posterior margin of the scutum without setae 17

17. Abdominal tergites 2-4 yellow with black posterior margin; tergite 1 yellow

Abdominal tergites yellow with black posterior margin and a black longitudinal

C. gelenita

18.

Cell R1 clearly open; mesonotum yellowish with black spots

C. tacanense

18.

Cell R1 closed in the costal margin; mesonotum either brown or yellow

C. oscillans

19. Mesothoracic pleuron entirely black

- $\quad$ Scutum yellow; male, eye facets bigger in the upper part.....

21. Anepimeron yellowish brown; katepisternum black, yellow in the upper part; tubercle clearly nearer mouthedge

Anepimeron dark brown, katepisternum entirely black; tubercle at about equal distance from antennae and mouthedge.

\section{Larvae and puparia}

1. Locomotory organs on abdominal segments 1-6 consisting of suckers i.e. indentations with raised rims; lateral margins of abdomen with band comprising fleshy lobes bearing setae ..................................................... Locomotory organs either little developed or comprising prolegs and crochets, not suckers; lateral margins of abdomen without band comprising fleshy lobes and setae Marginal band complete, including both thorax and abdomen; anal segment with two or three pairs of lobes in the marginal band, and ventral surface without setae.

Marginal band incomplete, not including thorax; anal segment with one pair of lobes in the marginal band, and ventral surface coated in setae

3. Anal segment with two pairs of lappets (fleshy projections bearing sensilla) above and not part of the marginal band; vestiture of dorsal surface consisting of dark, flat papillae with apical setae; antero-lateral rim of suckers with between three and five crochets in addition to bands of microspicules on the inner rim, and sensilla 7/8 (next to each sucker) conspicuous, on a long projection; posterior breathing tube dark brown to black ............ 4 Anal segment with no lappets above the marginal band, vestiture consisting of bare dome-shaped papillae without apical setae; rim of suckers without crochets in addition to microspicules, and sensilla 7/8 inconspicuous, not on a long projection; posterior breathing tube orange

4. Posterior breathing tube longer, length of tube below transverse ridge more than twice the length of tube above ridge; pupal spiracles black with openings almost to base .......................................................... C. volcanorum Posterior breathing tube shorter, length of tube below transverse ridge about 1.5 times as long as length above ridge; pupal spiracles yellow-orange with openings clustered at apex.....

5. Vestiture of anal segment comprising dome-shaped papillae; pupal spiracles base orange, black above, posterior breathing tube black above transverse ridge, wider than width of mesothorax or pupal spiracles, heavily punctured above transverse ridge. C. elizabethae Vestiture of anal segment comprising crown-shaped papillae; pupal spiracles entirely orange; posterior breathing tube orange above transverse ridge, about as narrow as width of mesothorax or pupal spiracles, lightly punctured above ridge C. barbara

6(2). Posterior breathing tube yellow-orange with black tip..... 7

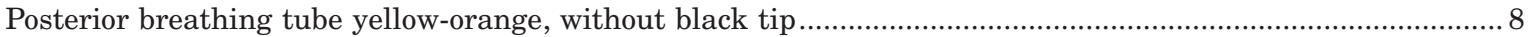

7. Vestiture comprising dome-shaped to cylindrical papillae C. gelenita Vestiture comprising fine setae species not reared, see under $C$. gelenita

8. Ventral surface of lobes of the marginal band on abdominal segments 1-6 coated with long, soft, fine setae; vestiture also of soft, fine setae usually lying flat C. galantei 
- Ventral surface of lobes of the marginal band on abdominal segments 1-6 coated in short, thick, stiff setae; vestiture fine, flat, or thick, upright setae....

9. Anal segment with ventral surface of third, apical pair of lappets setulate at base only .............................. 10

- $\quad$ Anal segment with apical pair of lappets setulate almost to apex............................................................... 11

10. Pupal spiracles narrow, about half as wide as posterior breathing tube and yellow at apex ............ C. tacanense

- $\quad$ Pupal spiracles wide, more than half as wide as posterior breathing tube and black-tipped............ . xalapensis

11. Posterior breathing tube with spiracular openings not parallel, middle pair orientated almost at right angles to the other two pairs; pupal spiracles yellow.....

C. tapanti

- $\quad$ Posterior breathing tube with spiracular openings more or less parallel; pupal spiracles dark brown to black

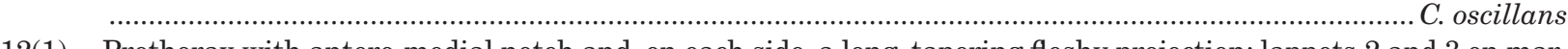

12(1). Prothorax with antero-medial notch and, on each side, a long, tapering fleshy projection; lappets 2 and 3 on margin of anal segment, stiff and upstanding with apical hook-like projections; posterior breathing tube and body dorso-ventrally flattened.....

C. otongaensis

Prothorax with continuous anterior margin, lacking deep medial notch and fleshy projections; lappets 2 and 3 trailing, not stiff and upright with apical hooks; posterior breathing tube, at most, two times wider than deep, but not flattened

13. Lateral margin of abdominal segments 5-7 with either two or three fleshy projections each; if projections present

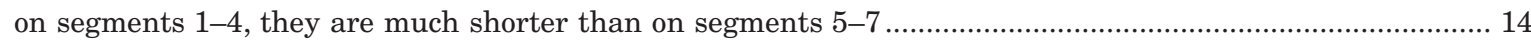

Lateral margin of abdominal segments 5-7 lacking fleshy projections longer than those on segments $1-4 \ldots .22$

14. Prolegs on abdominal segments 1-6; prolegs spherical in shape with curved rows of black crochets; apical setae of projections bearing dorsal segmental sensilla conspicuous, black at base and much longer than the projections bearing them.

C. louisae

Abdominal prolegs on segments 1-4, 5, or absent; if present, transverse in shape with straight rows of brown crochets; setae with segmental sensilla on dorsum of abdomen, inconspicuous, brown usually not much longer than basal projections

15. Lateral margins of thorax without large hooks, although spicules may be present ...................................... 16 Antero-lateral margin of mesothorax and metathorax with two large hooks and one large hook, respectively

- $\quad$ Ant

16. Prolegs and crochets not developed, if present, crochets not longer than surrounding vestiture; dorsal vestiture

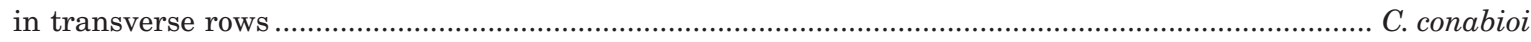
Prolegs and crochets developed on segments 1-6, crochets longer than surrounding setae, and dorsal vestiture not in clearly defined transverse rows

17

17. Posterior breathing tube longer than body width; dorsal vestiture of anal segment of long, stout, upstanding setae; pupal spiracles pale yellow . C. puyarum Posterior breathing tube shorter than body width; dorsal vestiture of anal segment of short, fine setae either lying flat or vestiture inconspicuous; pupal spiracles orange 18 Dorsal vestiture of long fine setae; pupal spiracles coated in long setae, longer than width of the openings......

C. tapia

Dorsal vestiture of short inconspicuous setae; pupal spiracles coated in short setae, either as short as or shorter than width of the openings C. albertoi

19(15). Apex of posterior breathing tube punctate 20 Apex of posterior breathing tube smooth, without punctures................................................................... 21

20. Apex of posterior breathing tube as wide as pupal spiracles, and posterior breathing tube about as long as body is wide...................................................................................................................................... C. boqueronense Apex of posterior breathing tube wider than pupal spiracles, and posterior breathing tube longer than width of body.....

21. Posterior breathing tube widening towards base and wider than the pupal spiracles. C. mamorum Posterior breathing tube parallel sided, not widening towards base, and about as wide as pupal spiracles .......

22(13). Prolegs with black crochets on abdominal segments 1-6; pupal spiracles short, shorter than distance apart

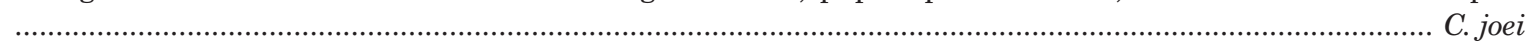

Prolegs with pale brown crochets on abdominal segments 1-4; pupal spiracles long, longer than distance apart

23. Posterior breathing tube about as wide as deep and not tapering at apex; pupal spiracles with openings clustered

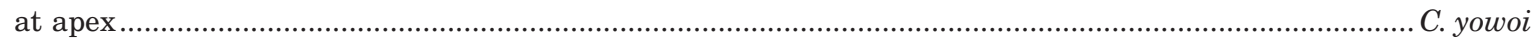
Posterior breathing tube about twice as wide as deep and tapered at apex; pupal spiracles with opening coating about half of length.... C. emeralda 


\section{DISCUSSION}

The 23 syrphid species reared from bromeliads in this study possess the key adult characters for inclusion in the volucelline genus, Copestylum i.e. they possess a recessive apical crossvein, plumose arista, bare anterior mesoanepisternum, and bare posterior mesoanepimeron (Thompson, 1972). Although similarities existed between some species, overall morphology appears to be highly variable in adult and particularly larval features, although no attempt was made to substantiate this observation quantitatively. With diverse genera like Copestylum it is not unusual to find affinities between species such that groups can be recognized. Even within the small subset of species reared from bromeliads we were able to recognize two groups and three subgroups. Without a phylogeny, however, supposed groups can neither be confirmed nor relationships, or trends between them, identified. For example, bromeliad Copestylum might have diversified from a single ancestor and therefore represent a monophyletic group. Alternatively, this may not have occurred and bromeliads have been colonized independently several times during the diversification of Copestylum.

Even without a phylogeny it seems likely that bromeliads were colonized independently, given the level of morphological disparity observed between species. Furthermore, from a study of over 200 Copestylum species we found 26 possible monophyletic groups based on a hierarchy of adult characters, including male genitalia (unpubl. data). All bromeliad species were part of one of these larger groups. Rearing data is incomplete for these larger groups, varying from 18 to $54 \%$ of species reared, but none are confined to bromeliads for breeding with the number of breeding sites varying from three to seven per group (unpubl. data). The likelihood that bromeliads were colonized from within these groups on separate, i.e. independent, occasions seems higher than alternative views, e.g. either bromeliad Copestylum form a group of their own or bromeliads were the breeding site of basal taxa across groups that include bromeliad-breeding species that subsequently diverged into other breeding sites.

The main changes in adult morphology across the bromeliad species reared here were: overall colour pattern with species varying from yellow to black, with a host of intermediate states involving combinations of yellow, orange, black, and metallic marks on the head, thorax, legs, and abdomen; the shape of the face, best appreciated in profile view (Figs 1-22); and the size, orientation, colour, and density of particulate dust, scale-like pruinosity, hairs, and bristles. In general, larger species had more diverse body hairs in terms of colour and size, and more extensive areas of dust and pruinosity. The main changes in larval morphology were: body shape in cross-section from subcyclindrical to dorso-ventral flattening; the size, distribution, and density of thoracic armature in the form of setae, spicules, and hooks; the size, shape, and number of prolegs and crochets; and the size and ornamentation of respiratory organs, in particular the posterior breathing tube and pupal spiracles.

In comparison with many Copestylum that live in open habitats such as deserts, bromeliad species differ in that their colour patterns do not seem to resemble noxious Hymenoptera. Instead, their colour patterns seem to be reflective and conform more to crypsis than to mimicry. In the dappled light of tropical forests the advantage of cryptic colour patterns over mimetic ones is obvious. Adults of bromeliad and other forest Copestylum species were often seen early in the morning flying beneath the canopy in shafts of sunlight. At other times, adults were encountered at rest on either the upper or lower sides of leaves of under storey plants.

Most bromeliad Copestylum have contrastingly coloured vittae on the face, sometimes on the sides of the abdomen, and often on tergite 2. These appear to be disruptive marks that draw the eye and are more conspicuous than the body outline (Edmunds, 1974). However, they may also play a role in mate recognition. Bromeliad Copestylum have a species-specific facial profile and colour pattern (Figs 1-22), and males, not females, often have enlarged eye facets at the top of the head, suggesting the importance of visual cues for intraspecific recognition. Two bromeliad species are almost entirely black, C. joei and C. otongaensis. In addition to any cyrptic function such colours have, they may also have a thermoregulatory role in facilitating heat gain in, for example, the early morning.

Copestylum species exploit bromeliads in two main ways. About half the 23 species were found in phytotelmata of live bromeliads, and half in dead, fallen bromeliads. In phytotelmata the larvae live submerged, between the overlapping leaves, although they presumably ascend to respire. In dead bromeliads larvae live either in or on, the decaying scape, leaves, or flowers. With one exception, no evidence was obtained of specificity for species of bromeliad. Of more importance were the conditions: usually size and volume of water in phytotelmata, and size and extent of wet decay in dead bromeliads. For example, C. tacanense was only found in small epiphytic and saxicolous bromeliads, whereas all other tank species seemed to prefer large plants. Only C. volcanorum had an apparent preference for a particular bromeliad species. It was found exclusively in the saxicolous bromeliad T. major, despite the close proximity of other species. C. joei and C. puyarum were also only reared from a single species of bromeliad, $P$. dasyliriodes, but it was the only species sampled at the locality where these two Copestylum were reared, so we are unable to say anything about the level of specificity. 
From bromeliad phytotelmata, we reared species of Copestylum with three general types of dorso-ventral flattening in the larval stages. The most frequent was the tank group with ten new species. The larval stage of the tank group is distinctive in having suckers, a marginal band round the edge of the abdomen in one subgroup, and round both the thorax and abdomen in two other subgroups, and flattened, dentate spicules, as opposed to the more usual, spine-like spicules coating the anterior fold (Figs 89, 92). Suckers are known only in the larval stages of one other syrphid genus, Ocyptamus Macquart, 1834 (Rotheray et al., 2000). Suckers in these two groups appear to be alike in operation. They consist of a flexible rim that is either raised or consists of a layer of fine setae surrounding a disc-shaped depression (Figs 75, 76, 77, 78). Muscles are attached to the base of the disc. When contracted, the base of the disc is pulled up into the body and pressure increases in either the air or the water-filled space below causing the rim to press against the substrate. When relaxed, the opposite occurs and the rim loosens from the substrate.

Like the tank group in relation to other Copestylum, only a few Ocyptamus species have suckers. They too live in bromeliad phytotelmata (Rotheray et al., 2000). However, Ocyptamus larvae are predators, not saprophages like Copestylum. The surface of bromeliad leaves is very smooth, particularly the submerged basal ends, and they are probably difficult to grip and hold. The development of suckers is a means of overcoming this problem. However, many vertebrate and invertebrate predators live in bromeliads (Kitching, 2000). Suckers, in combination with a marginal band, may be a defence against them. Suckers enable the larva to be firmly attached, and a rounded upper surface with a marginal band smoothly bordering the substrate may make the larva difficult to bite. A similar combination of marginal band and domeshaped upper surface characterizes another genus of syrphid larvae, Microdon Meigen, 1803. Microdon species are myrmecophilous, and larvae are predators of the early stages of ants (Duffield, 1981; Garnett et al., 1985; Barr, 1994). Observations show that when moving in ant nests, workers are unable to prevent Microdon larvae from predating the brood as long as the marginal band is pressed against the substrate, because ant mandibles are unable to grip the rounded upper surface (Donisthorpe, 1927). Tank group larvae may be protected in the same way.

Observations of tank larvae on glass surfaces show how they feed. Their food is presumably microorganisms, either adhering to or close to the surface of the leaf. When feeding, a tank larva scrapes the substrate with the anterior fold, which is coated in flattened dentate not tapering spicules (Fig. 89). This action loosens material, which passes either over or round the sides of the antennomaxillary organs to where it is guided into the mouth by the lobe-like, setulate lateral lips. At no time did we observe larvae feeding away from the leaf surface on material suspended in open water. The flattened spicules of the anterior fold are unique to the tank group.

The main differences in morphology between subgroups of tank larvae are in the structure of the marginal band. In the carlosii subgroup none of the lappets are incorporated into it, in the oscillans subgroup the third, posterior pair is included, and in the elizabethae subgroup the posterior and middle pair are included. The thorax is excluded from the band in the oscillans subgroup (Fig. 75). In the other subgroups the number of marginal lobes of the mesothorax, metathorax, and the first abdominal segment differ. Members of the carlosii subgroup have one pair for each thoracic segment, and two for the abdominal segment (Fig. 76). In elizabethae species the number of lobes is greater by one pair for each of these segments (Fig. 77). Furthermore, the setae of the marginal band differ between the subgroups. The lobes of the oscillans subgroup species are coated apically and laterally by long, fine setae that are not pressed together (Fig. 79), and the ventral surface of the lobes is coated either in long, fine, or short, stout setae. In the carlosii and elizabethae subgroups the apical and lateral setae of the lobes are broad, flattened, and pressed together basally, and divide apically into between two and five fine setae (Figs 80, 81). In the carlosii subgroup the ventral surface of the lobes have a coating of fine, matted setae, but in the elizabethae subgroup the surface is bare without setae. Also the posterior breathing tube in the carlosii and elizabethae subgroups is much longer than in the oscillans subgroup: with the transverse ridge about halfway down the tube in the latter subgroup, but at the apex in the former subgroups.

The significance of such differences is unclear. Except that both carlosii and elizabethae subgroups are more dorso-ventrally flattened than the oscillans subgroup. The differences in marginal band morphology between the groups may be associated with dorsoventral flattening. Dorso-ventral flattening is presumably an advantage in bromeliad phytotelmata because it enables access to confined spaces between the leaves. Here, not only is there food but also, perhaps, respite from predators. The extent to which carlosii and elizabethae subgroup larvae can go deeper into bromeliads than oscillans larvae has not been measured, but seems likely.

The larvae of C. otongaensis have taken dorso-ventral flattening to an extreme level. Not only is the body flattened, but the posterior breathing tube (Fig. 100) and the head skeleton are also flattened (Fig. 94). Furthermore the prothorax is highly modified with a 
medial notch and two long fleshy projections (Fig. 83). The significance of these unique and remarkable features is that the mouthparts can now be directed forwards and upwards, as opposed to just downwards as in tank group larvae. Furthermore, instead of dentate spicules on the anterior fold loosening food, as in tank group larvae, the larvae of $C$. otongaensis have a different mechanism for gathering food. The two halves of the antennomaxillary process are joined together by a narrow, trough-like sclerotized plate, and, at its base, the dorsal lip is flattened so that access to the mouth is direct from this sclerotized plate. Observations of larvae on glass reveal that the sclerotized plate moves back and forth, and loosens and gathers food that is then passed directly into the mouth. The prothorax is flexible and the mouth can be extended forwards to just beyond the medial notch. This permits feeding from both upper and lower leaf surfaces. This is not possible in tank larvae, which must turn over to reach the other side. These unique features suggest that the larvae of $C$. otongaensis can feed more effectively in even narrower spaces than those accessible to tank group larvae.

Two additional features occur in the larvae of C. otongaensis that appear to be related to feeding in narrow spaces. Anterior spiracles are absent in all tank larvae except the carlosii subgroup, but in the larva of C. otongaensis they are present and protected from being blocked or damaged by being concealed in a pocket created by an extension of the mesothorax and the lateral margin of the prothorax. Finally, the vestiture of the dorsal and ventral surfaces is similar in the larva of C. otongaensis and consists of transverse rows of backwardly directed, microspicules that are more extensive on the anterior segments. In tank larvae the vestiture varies from species to species and is useful for identification. It is not the same on both dorsal and ventral surfaces, and does not consist of microspicules. In the larva of $C$. otongaensis these microspicules probably help anchor the larvae between the leaves of a bromeliad, and prevent it from slipping backwards. In tank group larvae the suckers probably have this function.

The other species reared from bromeliad phytotelmata, C. louisae, also has a distinctive adult and larval morphology. The larva is the only one studied here with spherical prolegs bearing long, black crochets in more than three rows, but, unlike other live bromeliad Copestylum larvae, it is subcyclindrical in crosssection and is neither dorso-ventrally flattened nor with a marginal band. The thorax is large and broader than the abdomen, and the anal segment is extended. Other than bromeliads, breeding sites for the group within Copestylum to which C.louisae apparently belongs are all container habitats varying from tree holes to fallen cocoa pods. In the large thorax, extended anal segment, well-developed lateral lips, feeding channel, and locomotory organs, the larva is similar to those of other syrphid taxa living in container habitats, e.g. the long-tailed larvae of the Eristalinae (Syrphidae). Such larvae feed on food either in suspension or they extract it from sediment at the bottom of their containers (Rotheray \& Gilbert, 1999). Long-tailed eristaline larvae have large lateral lips and a feeding channel that facilitate the ingestion of suspended food. They also have large prolegs and crochets that enable the larvae to grip the bottom sediment without floating to the surface (Rotheray, 1993). We did not observe feeding in C. louisae, but the similarities between $C$. louisae and long-tailed eristaline larvae suggest it feeds in a similar manner. Not being flattened, the larva of $C$. louisae may be confined to higher parts of bromeliad phytotelmata than either tank group larvae or the larva of $C$. otongaensis. If it is exposed to predation in such a position, no greater means of defence was found than the ability to wriggle vigorously.

Decaying bromeliads do not impose the same spatial restraints as do live ones. A wet, decaying bromeliad is soft, and Copestylum larvae often burrow in the leaves or scape. Some decaying bromeliad Copestylum had the most generalized larvae of those considered here, i.e. few unique characters were found. The least specialized morphologically was $C$. conabio. In this species the locomotory organs are rudimentary and prolegs are not developed. The thorax bears no additional structures such as hooks or spicules other than those on the anterior fold. Other breeding sites for the Copestylum group to which C. conabio may belong are tree sap (three species), and decaying fruits and flowers (one species each). Breeding sites like these are characterized by viscous, oily material within which larvae are immersed. The mode of feeding is unlike C.louisae in that larvae imbibe this material directly by movements of the dorsal and lateral lips. This is similar to larvae of the genus Eumerus Meigen, 1822 (Syrphidae) (Rotheray \& Gilbert, 1999). C. conabio larvae may require the products of decomposition for food, as much as the microbes causing it, in a similar way as has been shown for certain Eumerus larvae feeding in decaying plant bulbs (Creager \& Sprujit, 1935).

C. emeralda, C.tapiai, and C. albertoi were also reared from decaying bromeliads, and C. yowoi was reared from decaying flowers. Their larvae are similar to $C$. conabio except that spicules are present on the lateral margins of the mesothorax and antero-ventral margin of the metathorax, and prolegs with crochets, at least on the anterior segments, are well developed. Additionally, C. yowoi had transverse rows of spicules along the posterior margins of the prothorax and 
mesothorax. They probably feed in a similar way to C. conabio.

Larvae of the boqueronense group are, however, different. They are larger, the anal segment is extended, fleshy projections line the lateral margins, particularly on the posterior abdominal segments, and the thorax is armed with large, conspicuous hooks and spicules (Fig. 85). There are two pairs of hooks on the lateral margins of the mesothorax, one pair on the lateral margin of the metathorax. Large spicules are present on the dorsum of the prothorax and on the antero-ventral margin of the metathorax. Boqueronense larvae share a feature characteristic of many Xylotini (Syrphidae), a thorax armed with hooks and spicules. In xylotines this armature seems to serve a dual function, to facilitate burrowing and to protect the surface of the thorax (Rotheray, 1993). It probably plays similar roles in boqueronense larvae, and probably enables access to a source of food denied species like C. conabio and C. tapiai, which lack such armature. It was noticeable in the field that boqueronense larvae were usually found burrowing in the partially decayed scape. Few C. conabio and C. tapiai larvae were ever found in the scape. More frequently, C. conabio and C. tapiai larvae were found either on the surface of leaves or in places where wet decay had accumulated. The scape represents a major source of food and the thoracic armature of boqueronense larvae may facilitate burrowing into it. Like Eumerus larvae, their burrowing probably exposes tissues to decomposition, and so these larvae may help create their own supplies of food.

The two Copestylum species we reared from puyas came from the same locality in Costa Rica. The larvae are very different from each other. However, C. puyarum is similar to the boqueronense group in adult and larval characters, except that the face of the adult is not as wide and the larva lacks thoracic hooks. The other species, $C$. joei, is unlike any other bromeliad Copestylum in its large size, lappets 1 and 2 on a shared basal lobe, and short pupal spiracles. The larva is most similar to species that have been reared from cacti, such as Copestylum apiciferum (Townsend, 1895), and the adult is most similar to C. anna. However, the broad and elongate anal segment separates the larva of $C$. joei. Other closely related species probably exist that share a broad apex to the extended anal segment. For example, we found such a larva in decaying puyas on the slopes of Mt. Cotopaxi in Ecuador, but did not rear it. It is easily distinguished from C. joei by the lack of dorsal vestiture, supporting the idea that it is a separate but related species. An elongate anal segment also occurs in C. puyarum, and such extensions enable larvae to respire while remaining submerged in water (Rotheray, 1993).

In both live and dead bromeliads differences exist in the resources used by the larvae of the various species and groups. In live bromeliads the axis of change could be depth in the bromeliad where feeding occurs, and this is related to modifications in body shape facilitating access. This is because below water, leaves are tightly packed and even closer together towards the scape at the centre of the plant. Larval body shape changes from subcylindrical in $C$. louisae to increasing levels of flattening across the subgroups of tank larvae, and achieving an extreme in C. otongaensis. Whether these larvae feed at characteristic depths in the bromeliad according to the degree they are dorsoventrally flattened has not been examined. In dead bromeliads the axis of change could also be accessing food in different places related to the degree to which the larval thorax is armoured. In larvae of species such as C. conabio and C.tapiai, the thorax is relatively unprotected by hooks and spicules, and larvae were usually found on leaf surfaces. However, armoured larvae of the boqueronense group often burrowed into the scape. The extent to which such feeding site differences are real and are either structured by competition or result from phylogenetic, or other causes, remains to be examined.

To investigate Copestylum we choose to look for breeding sites and rear larvae, as opposed to sampling adults using techniques such as hand netting or Malaise trapping. The chief disadvantage of looking for breeding sites is that it is frequently a search for the unknown, and fieldcraft, i.e. knowledge of what is needed to find and recognize breeding sites, has to be built up and developed over time. The main advantages of this approach are the extra data gained of breeding sites, early stage morphology, habits, and behaviour. Such data are critical in developing understanding of biodiversity beyond a species inventory. However, finding and rearing early stages is a valuable method of inventorying species (Rotheray, 1993). The high proportion of new species we discovered, 22 of 23 reared, demonstrates that reliance on adult sampling alone is not safe in insects such as these Diptera. Perhaps part of the reason why so many species remained undiscovered is that adults of bromeliad Copestylum are either hard to catch or are rare, and rearing is a better way to sample them. Such is the case for many European saproxylic syrphids (Rotheray \& MacGowan, 1990). Futhermore, this study is but a start. Many other new bromeliad Copestylum species undoubtedly exist over and above the ones we failed to rear.

\section{ACKNOWLEDGEMENTS}

The authors are very grateful to the following individuals, institutions, and organizations for assistance during this project: to FC Thompson for arranging a loan of specimens, for much helpful advice, and continuing interest and encouragement over many years; 
to the Leverhulme Trust for a research fellowship awarded to GER; to the Generalitat Valenciana for financial assistance to GER during visits to the Universidad de Alicante, Spain; to the Williston Fund for financial assistance to GER and EGH during visits to the Smithsonain Institution, USA; in Bolivia to the Darwin Initiative, 'Bolivian Important Biodiversity Areas Project' for financial support and to the project leader, Dr Ross MacLeod, for help in the field; in Costa Rica to the Instituto Nacional de Biodiversidad (INBio) for logistical and financial support over several years including the following Diptera parataxonomists for their enthusiasm and help in collecting and rearing material, M. Alfaro, D. Briceño, Y. Cárdenas, J. Gutiérrez, B. Hernández, A. Picado, E. Rojas, and M. Solis, specimens were collected under the INBioMINAE. Agreement for the Costa Rican National Biodiversity Inventory and also to Manuel Zumbado, at the time Diptera Curator at INBio, for his tireless support, enthusiasm, and help whenever it was needed, and also to Monty Wood and his wife, Grace, for their generosity and companionship in the field, and to Professor Dan Janzen for help in Guanacaste; in Ecuador to the Fundación Otonga for logistical support and especially to the Director of the Fundación, Professor Giovanni Onore, for his help in numerous ways, and also to Don César Tapia and his family for their help and enthusiasm in collecting material; in Mexico to the Instituto de Ecología de Xalapa [Research Programme Comisión Nacional para el Conocimiento y Uso de la Biodiversidad (CONABIO) project no. K038], to the Colegio de la Frontera Sur, Unidad Tapachula (CONABIO project no. Y037), and to Professor Gonzalo Halffter and Benigno Gómez for their support and help in the field; in Trinidad to the University of Glasgow Expedition Society and the students of the 1998 insect team, and also to Dr Roger Downie for help in various ways; in the USA, GER and EGH are grateful to the Smithsonian Institution and to the staff of the Diptera Floor for their assistance during study visits; GER and EGH are also grateful to Nigel Wyatt of the Natural History Museum, London, for help during visits to work on the Copestylum collection in his care.

\section{REFERENCES}

Barr B. 1994. Feeding behaviour and mouthpart structure of larvae of Microdon eggeri and Microdon mutablis (Diptera, Syrphidae). Dipterists Digest 2: 31-36.

Benzing DH. 1980. The Biology of the Bromeliads. Eureka, California: Mad River Press.

Bruch C. 1919. Observaciones biologicas sobre Temocera spinigera Weid. (Diptera, Syrphidae). Revista del Museo de la Plata 24: 175-181.
Bugbee RE, Reigel A. 1945. The Cactus Moth, Melitara dentata (Grote), and its effect on Opuntia macrorrhiza. Western Kansas. American Midland Nataturalist 33: 117-127.

Creager DB, Sprujit FJ. 1935. The relation of certain fungi to larval development of Eumerus tuberculatus Rondani (Syrphidae, Diptera). Annals Entomological Society of America 28: 425-437.

Donisthorpe H. 1927. The Guests of British Ants. London: Routledge and Son.

Duffield RM. 1981. Biology of Microdon fuscipennis, with interpretations of the reproductive strategies of Microdon species North of Mexico. Proceedings Entomological Society of Washington 83: 716-724.

Edmunds J. 1974. Defence in Animals: a Survey of AntiPredator Defences. London: Longmans.

Erwin TL. 1982. Agra, arboreal beetles of Neotropical forests: erythropus group systematics (Carabidae). Systematic Entomology 7: 39-71.

Frank JH. 1983. Bromeliad phytotelmata and their biota, especially mosquitoes. In: Frank JH, Lounibos LP, eds. Phytotelmata: Terrestrial Plants as Hosts for Aquatic Insect Communities. Medford, New Jersey: Plexus Press. 101-128.

Frank JH. 2002. A bibliography of the aquatic biota in bromeliad phytotelmata. http://BromeliadBiota.ifas.ufl.edu/ fitbib1.htm

Garnett WB, Akre RD, Sehlke E. 1985. Cocoon mimicry and predation by myremecophilous Diptera (Diptera: Syrphidae). Florida Entomologist 68: 615-621.

Greene CT. 1923. A new species of Volucella (Diptera). Proceedings Entomological Society of Washington 25: 165-168.

Hubbard HG, Schwarz EA. 1899. Insect fauna of the giant cactus of Arizona: Letters from the Southwest. Psyche Suppl. 1: $1-14$.

Johnston TH. 1921. Biological control of the prickly-pear pest. Queensland Agriculturalist 16: 65-68.

Kitching RL. 2000. Food Webs and Container Habitats: the Natural History and Ecology of Phytotelmata. Cambridge: Cambridge University Press.

Maier CT. 1982. Larval habitat and mate-seeking sites of flower flies (Diptera: Syrphidae: Eristalinae). Proceedings Entomological Society of Washington 84: 603-609.

Maldonado Capriles J, Berrios A. 1977. The immature stages of Copestylum vacuum (F.) (Diptera: Syrphidae). A new record for Puerto Rico. Journal of Agricultural University Puerto Rico 61: 395-399.

Mann J. 1969. Cactus-feeding insects and mites. Bulletin of the US National Museum 256: 1-158.

Marcos-García MA, Pérez-Bañón C. 2001. Immature Stages of Copestylum tamaulipanum and Copestylum lentum (Diptera: Syrphidae). European Journal of Entomology 98: $375-385$.

Marcos-García MA, Pérez-Bañón C. 2002. Life cycle, adult and immature stages of a new species of Copestylum (Diptera: Syrphidae) from México reared from Cactaceae. Annals Entomological Society of America 95: 432-440.

Myles TG. 1986. Oviposition and development of Volucella isabellina (Diptera: Syrphidae) on Saguaro cactus Cereus giganteus. Entomological News 97: 104-108. 
Picado C. 1913. Les broméliacées épiphytes considérées comme milieu biologique. Bulletin of the Scientifique de la France et de la Belgique 47: 215-360.

Rotheray GE. 1993. Colour Guide to Hoverfly larvae (Diptera, Syrphidae) in Britain and Europe. Dipterists Digest 9: 1-155.

Rotheray GE, Gilbert F. 1999. Phylogeny of Palaearctic Syrphidae (Diptera): evidence from larval stages. Zoological Journal of the Linnean Society 127: 1-112.

Rotheray GE, MacGowan I. 1990. Re-evaluation of the status of Callicera rufa Schummel (Diptera: Syrphidae) in the British Isles. Entomologist 109: 35-42.

Rotheray GE, Zumbado M, Hancock EG, Thompson FC. 2000. Remarkable aquatic predators in the genus Ocyptamus (Diptera, Syrphidae). Studia Dipterologica 7: 385-398.

Ryckman RE, Ames CT. 1953. Insects reared from cacti in Arizona. Pan-Pacific Entomologist 60: 326-331.

Sack P. 1921. Dr. L. Zurcher's Dipteren-Ausbeute aus Paraguay. Archiv Jür Furnaturgeschichte (Abt A) 87: 127-149.

Santana FJ. 1961. The biology of immature Diptera associated with bacterial decay in the giant sangaro cactus (Cereus giganteus Englemann). MS Thesis, University Arizona.

Seifert RP, Seifert FH. 1976a. A Heliconia insect community in a Venezuelan cloud forest. Ecology 60: 462-467.
Seifert RP, Seifert FH. 1976b. Natural history of insects living in inflorescences of two species of Heliconia. New York Entomological Society 84: 233-242.

Stahls G, Hippa H, Rotheray G, Muona J, Gilbert F. 2003. Phylogeny of Syrphidae (Diptera) inferred from combined analysis of molecular and morphological characters. Systematic Entomology. 28: 433-450.

Telford HS. 1973. The Syrphidae of Puerto Rico. Journal of Agricultural University Puerto Rico 57: 217-246.

Thompson FC. 1972. A contribution to a generic revision of the Neotropical Milesiinae (Diptera, Syrphidae). Archivos de Zoologia Sao Paulo 23: 73-215.

Thompson FC. 1981. The Flower Flies of the West Indies (Diptera: Syrphidae). Memoirs of the Entomological Society of Washington 9: 1-200.

Wallace JB, Lavallee AG. 1973. Immature stages of Milesiinae (Syrphidae) 1: Cheilosia pallipes and Volucella apicalis. Journal of Georgia Entomological Society 8: 187-194.

Williams FX. 1939. Biological studies in Hawaiian waterloving insects. III. Diptera or Flies. B. Asteidae, Syrphidae and Dolichopodidae. Proceedings Hawaiian Entomological Society 10: 281-315.

Zimmerman HG, Erb HE, McFadyen RE. 1979. Annotated list of some cactus-feeding insects of South America. Acta Zoologica Lilloana 33: 101-112.

\section{SUPPLEMENTARY MATERIAL}

The following material is available for this article:

Table S1. Copestylum reared from bromeliads (Bromeliaceae), character states for adults. Column headings: first two columns on the left-hand side refer to characters and their alternative states numbered sequentially; subsequent columns: numbers refer to species diagnosed in the text; $\mathrm{m}$, male; $\mathrm{f}$, female; symbols in the body of the table: 1 , character state present; 0 , character state absent; a, male character only; $\mathrm{n}$, sex not available for scoring; $\mathrm{x}$, specimen damaged, part missing.

Table S2. Copestylum reared from bromeliads (Bromeliaceae), character states for larvae and puparia. Column headings: first two columns on the left-hand side refer to characters and their alternative states numbered sequentially; subsequent columns: numbers refer to species diagnosed in the text; symbols in the body of the table: 1 , character state present; 0 , character state absent; $\mathrm{u}$, character unscorable; $\mathrm{x}$, character obscured, part missing.

This material is available as part of the online article from:

http://www.blackwell-synergy.com/doi/abs/10.1111/j.1096-3642.2007.00288.x

(This link will take you to the article abstract).

Please note: Blackwell Publishing are not responsible for the content or functionality of any supplementary materials supplied by the authors. Any queries (other than missing material) should be directed to the corresponding author for the article. 